\title{
Das Frühneuhochdeutsche Wörterbuch (FWB): Von der Entstehung bis zur Digitalisierung
}

\author{
1 Zur Gründung des Wörterbuches \\ 2 Zur Motivierung \\ 3 Die Planung: Überlegungen \\ und Entscheidungen \\ 4 Die Arbeitsverhältnisse und \\ die wissenschaftliche Resonanz \\ des Vorhabens \\ 5 Die innere Geschichte \\ und ihre Ergebnisse \\ 6 Veranschaulichung \\ an einem Beispiel
}

\author{
7 Zur zweiten Phase der Arbeit: \\ Äußeres \\ 8 Zur heutigen Praxis \\ 9 Die wissenschaftliche Ebene \\ historischer Lexikographie \\ 10 Zur Online-Stellung \\ des Wörterbuches \\ 11 Literatur
}

Die Titelformulierung des hier vorgelegten Beitrags deutet eine Darstellungslinie des Unternehmens Frühneuhochdeutsches Wörterbuch (FWB) an, die von ersten lexikographischen Intentionen und Überlegungen seines Gründers in der Vorphase über den Arbeitsbeginn bis in die Gegenwart reicht und sich der Planung nach bis in die zweite Hälfte der zwanziger Jahre unseres Jahrhunderts fortsetzen wird. Es geht also um die Jahrzehnte zwischen dem Gründungsjahr 1977 und dem vorgesehenen Abschluss des Werkes im Sommer 2027, mithin um ein halbes Jahrhundert. Diese Zeitspanne soll hier deshalb stets im Blick bleiben, weil viele lexikographietheoretische Festlegungen aus der Gründungszeit heute noch bestimmend sind und viele technische Selbstverständlichkeiten der Gegenwart Inkubationsvoraussetzungen hatten, die bereits in den siebziger Jahren erkennbar waren. Die folgenden Ausführungen haben demnach eine narrative Grundlage mit teils persönlichen Zügen. Diese letzteren werden allerdings so gefasst, dass sie als lexikographische Sinnbestimmungen sowie als arbeitspraktische, kulturpädagogische, kulturpolitische sowie als fundamentale sprachtheoretische Leitlinien verstanden und ins wissenschaftlich Relevante gehoben werden können. Immerhin geht es darum, die Anfänge, das theoretische Konzept, das Corpus, die Artikelstruktur, die lange Zeit private, seit 5 Jahren institutionelle Regie, das Fortschreiten, die Ergebnisse eines auf 13 Bände angelegten und bereits mit 10 Bänden realisierten lexikographischen Unternehmens zu einer Groß-

\footnotetext{
Prof. Dr. Oskar Reichmann, Wissenschaftlicher Leiter des Frühneuhochdeutschen Wörterbuchs,
} Geiststraße 10, 37073 Göttingen, e-Mail: oskar.reichmann@urz.uni-heidelberg.de 
corpussprache darzustellen, für das keine Vorlagewörterbücher existieren. ${ }^{1}$ Es geht um die völlige Neubegründung eines Projektes zu der Sprachstufe, die dem neuzeitlichen Deutschen unmittelbar vorausgeht und schon deshalb herausgehobene Beachtung verdienen sollte.

\section{Zur Gründung des Wörterbuches}

Als Gründungsdatum wurde soeben das Jahr 1977 angegeben (vgl. Anderson/Goebel/Reichmann 1977). In Wirklichkeit handelte es sich um eine längere Zeitphase, die biographisch durch meinen Wechsel von der Vrije Universiteit Amsterdam an die Universität Heidelberg bestimmt war und sich bei mir mit der kaum hinterfragten Zuversicht verband, nunmehr an einer forschungsorientierten Institution des eigenen Landes arbeiten zu können, und zwar auf Lebenszeit, in maximaler Selbständigkeit, mit individueller Verantwortlichkeit, mit einer hohen Planungssicherheit und mit der Erwartung institutioneller und irgendwann irgendwie auch erreichbarer finanzieller Unterstützung. In einer solchen Situation überlegt man sich, welche offensichtlichen Forschungslücken das Aufgabengebiet einer ordentlichen Professur, in meinem Fall für „Germanistische Sprachwissenschaft mit besonderer Berücksichtigung der Sprachgeschichte“, aufweise und wie sich diese Lücken, natürlich unter Berücksichtigung der eigenen Interessen und mit dem Blick auf mittelfristige Abschließbarkeit, füllen ließen. Anders ausgedrückt: Es ging mir um ein Vorhaben, das den weitgehend üblichen Wettlauf um die Anzahl kurzlebiger Einzelartikel zu möglichst vielen Teilbereichen eines Faches ausschloss und durch ein Projekt ersetzte, von dem ich eine Bedeutung für das Gesamtfach sowie für die Nachbarfächer erwartete, von dem ich mir ferner eine gewisse Nützlichkeit für alle kulturhistorischen Wissenschaften mit sprachlich verfasstem Gegenstand versprach und von dem ich meinte, dass sein Endprodukt auch noch einige Generationen später benutzbar sein sollte. Ich vertraute dabei mit guten Gründen auf die computertechnische Hilfe zweier mir aus meiner Amsterdamer Zeit befreundeter Kollegen, Robert R. Anderson und Ulrich Goebel. Obwohl diese Hilfe auch aufgrund meiner eigenen Vorstellungen ins Leere ging, ist Letzterer bis heute Mitherausgeber des FWB und zählt zu meinen verlässlichsten Beratern und Gesprächspartnern, seit über 20 Jahren auch von Anja Lobenstein-Reichmann, seit 2006 Mitherausgeberin des Werkes. - Im Nachhinein betrachtet stelle ich fest: Meine Vorstellungen entsprachen der Forschungsrealität an deutschen Universitäten höchstens teilweise; meine Begeisterung überwog meine Handlungsbefähigung

1 Eine ausführlichere Darlegung mit weiteren Angaben zu den meisten der in diesem Artikel angesprochenen Gegenstandsaspekte findet sich bei Reichmann 2012. Ich verzichte im Folgenden auf rein technische Verweise, beschränke mich also auf besonders betonte oder neue Aspekte. Auch das Literaturverzeichnis ist mit dem Blick auf die gerade angegebene Monographie möglichst kurz gehalten. 
und Handlungsmöglichkeiten bei weitem; insbesondere habe ich die Zeitdimension lexikographischer Tätigkeit sowie die fachinterne Gleichgültigkeit und Abschätzigkeit gegenüber jedweden lexikographischen Ansätzen stark unterschätzt, umgekehrt die Möglichkeiten finanzieller Unterstützung von Seiten der Universität überschätzt. Das Risiko individueller Arbeit, damit die Möglichkeit des Scheiterns jahrelanger Mühen, war mir zwar stets bewusst, erschien mir aber doch nicht so stark, dass ich die Motivation verloren hätte. Erreicht wurden nach meinem eigenen Urteil (zum mindesten bis jetzt) die (natürlich immer vorläufige) Schließung einer Forschungslücke, die linguistisch begründete Konzeption eines Werkes, deren Realisierung in einem Wörterbuch mit relativ hoher Homogenität und unbestrittener Individualität über alle inzwischen publizierten 10 Bände, eine anerkannte Bedeutung des Werkes für verwandte Unternehmen, sein zumindest vereinzelt erahnter Nutzen für die gesamte kulturgeschichtliche Forschung und nicht zuletzt der Nachweis der Realisierbarkeit textlinguistisch basierter, hermeneutisch interpretativ arbeitender, semantisch orientierter Lexikographie, damit auch der Beweis, dass individuelle geisteswissenschaftliche Forschung auch heute noch möglich ist. ${ }^{2}$ Immerhin wurde ein Findebuch zu etwa 400 Glossaren zu Ausgaben frnhd. Texte, ein weiteres $\mathrm{zu} 15$ zeitgenössischen Wörterbüchern des Frnhd. zusammengestellt, aber nicht publiziert. Die Erarbeitung eines Wörterbuches aus derartigen Zusammenstellungen erwies sich aber als nicht durchführbar.

\section{Zur Motivierung}

Das Vorgetragene setzt bereits im Titel voraus, dass eine meiner Lebensentscheidungen auf die Behebung der oft so genannten „großen lexikographischen Lücke“ des Deutschen fiel. Gemeint ist die Zeit von der Mitte des 14. bis zur Mitte des 17. Jahrhunderts (bezüglich des hochdeutschen Raumes): Die Wörterbücher des Mittelhochdeutschen (= Mhd.), also Benecke/Müller/Zarncke (1845-1866) und Lexer (1872-1878) bzw. das Deutsche Wörterbuch (= DWB) von Jacob Grimm und Wilhelm Grimm (1854-1971) streifen die frühneuhochdeutsche (= frnhd.) Zeit teils eher beiläufig (so die Wörterbücher zum Mhd.), teils aber auch sehr dicht und nach den Maßstäben der jeweiligen Bearbeitungszeit und -umstände qualitativ hochwertig (so das DWB in weiten Teilen und natürlich seine Neubearbeitung für die Strecke $a$ - bis $f$-; 1963-2018). Man könnte insofern der Meinung sein, dass das Frnhd. lexikographisch hinreichend erfasst sei und dass sich ein eigenes großes Wörterbuch für diese Epoche demnach erübrige, zumal der sprachgeschichtlich so relevante Rechtsbereich durch das Deutsche Rechtswörterbuch (= DRW; 1914 ff.), der Fremdwortschatz durch das Deutsche Fremdwörterbuch (= DFWB; seit 1913; Neubearbeitung mit Publikationen seit 1995), einige regionale Varianten des Deutschen z. B.

2 Mein eigener Beitrag zum FWB beläuft sich auf inzwischen über 6000 Seiten. 
durch das Schweizerische Idiotikon (= Schweiz. Id.; seit 1881; zugleich national motiviert), das Schwäbische Wörterbuch (= Schwäb. Wb; 1904-1924) und verwandte Unternehmen teils unübertreffbar abgedeckt seien. Einige Gegenargumente sprachen dennoch für meinen Plan: Zum einen ist die Sprachstufe ,Frühneuhochdeutsch' trotz des gerade Gesagten schwächer, nach je spezifischen (z. B. regionalen, subnationalen) Interessen sowie generell uneinheitlicher bearbeitet als die vorausgehende und die folgende Stufe. Zum anderen stehen die vorhandenen lexikographischen Werke (natürlich mit Ausnahmen) trotz möglicher entgegen gerichteter (und teils nachvollziehbarer) Argumente bis auf den heutigen Tag auf der Theorie- und Beschreibungsbasis letztlich des 19. Jahrhunderts. Man denke nur an die bereits barocke und aufklärerische (in Wirklichkeit bereits antike) Copiavorstellung mit der ihr inhärenten Betonung der Zeichengestalt und damit Ausdrucksbezogenheit, umgekehrt mit einer verbreiteten Semantikabstinenz, und mit dem ihr ebenfalls inhärenten Isolationismus (also der Einzelwortbezogenheit); oder man realisiere sich die darstellungsfunktionale Ausrichtung, die weitgehend herrschende Dreigliedrigkeit der Artikel (Stichwort - Bedeutungserläuterung - Belege), teilweise auch die nicht hinreichend bewusst gemachte Ideologielastigkeit schon infolge der Literatur- und Hochschichtorientierung der Corpora. Das bedeutete umgekehrt unter Anderem: Es war mindestens eine veränderte lexikographische (natürlich ihrerseits ideologisch motivierte) Theorie festzulegen, ein breiteres, theoretisch neu fundiertes Beschreibungsprogramm zu entwickeln und ein neueren Ansprüchen entsprechendes Corpus zusammenzustellen, jeweils mit dem Zweck, die gerade geäußerten Bedenken zu reduzieren. - Im Einzelnen heißt das:

Das Gewicht einer möglichst großen Copia, damit die Verehrung der großen Lemmazahl, der ausdrucksseitig lautgesetzlichen Herleitung jedes Stichwortes, teils auch dessen sprachgeographischer Varianz, ferner der morphologischen Einordnung jedes einzelnen Zeichens, war hinsichtlich seines Verhältnisses zur Semantik zu befragen. Provokativ formuliert: Wem nützen und welchen Wert haben Informationen des Typs, dass babst auch bapst geschrieben wird, dass bach als Maskulinum und als Femininum begegnet oder dass viele Verben außer mit Akkusativobjekt auch (noch) mit Genitivobjekt gebraucht werden?

Daraus folgt: Das Verhältnis der Ausdrücke, deren Bedeutung sich seit geschichtlicher $^{3}$ (z. B. mhd., frnhd.) Zeit nicht oder kaum verändert hat, zu denjenigen Ausdrücken, die - wie etwa der Wortschatz des mhd. Tugendsystems oder der glaube-, gnade-Wortschatz der Reformationszeit - zeittypisch je anders semantisiert werden, war neu zu justieren, und zwar makrostrukturell unter dem Aspekt der Stichwortauswahl, mikrostrukturell unter dem Aspekt der Ausführlichkeit der Behandlung. Warum sollte man einen Ausdruck z. B. zum Frnhd. voll umfänglich so beschreiben, so stark abstrahieren, das er kaum noch etwas besagt, und so bele-

3 Das Adjektiv geschichtlich wird hier und im Folgenden als >in vergangener Zeit stattgehabt< verstanden; historisch heißt so viel wie geschichtsbezogen, charakterisiert also die Tätigkeit des Historikers, seinen Bezug auf das Geschichtliche. 
gen, dass er mit nur einigen technischen Änderungen in ein Wörterbuch der Gegenwartssprache übernommen werden könnte?

Der herrschende Isolationismus war aufzubrechen. Er besteht darin, dass jedes einzelne Stichwort ohne systematischen Bezug zu jedem anderen Stichwort abgehandelt und das Wörterbuch damit zu einer Auflistung nach Telefonbuchart für reine Nachschlagezwecke degradiert wird. ${ }^{4}$ Die mehrdimensionale Vernetzung des Wortschatzes kam höchstens zufällig zum Ausdruck, und selbst dann nur nach dem Alphabetprinzip, d. h. mit Unterbrechungen durch Einschübe lediglich schreibähnlicher, ansonsten völlig anderer Ausdrücke. Dies alles ist als Schwäche der Lexikographie hinreichend bekannt.

Die Darstellungsfunktion lexikalischer Einheiten ist nur eine von mehreren Funktionen des Lexikons. Ihre Gewichtung war demnach in eine irgendwie begründete Relation zu der kognitiv-inhaltsbildenden, der kommunikativ-appellbezogenen Funktion und der Symptomfunktion ${ }^{5}$ des Wortschatzes zu bringen. Dieser Punkt wird sich im Folgenden unter verschiedenen Aspekten immer wieder als besonders relevant erweisen.

Das einem historischen Wörterbuch zugrundeliegende Corpus sollte alle pro Zeit begegnenden und insbesondere die zeittypischen Textsorten in ausgewogener (was immer dies heißt) Verteilung enthalten sowie das spätere Interesse an ihnen spiegeln. So wird sich die Zusammenstellung eines Corpus zum Frnhd. wesentlich von einem Corpus zum Mhd. zu unterscheiden haben. Aus vielen, sowohl überlieferungsgeschichtlichen, darunter quantitativen, wie aus kulturpädagogischen Gründen wird man einmal (so für das Mhd.) der hohen Rolle höfischer (epischer und lyrischer) Texte gerecht werden, ein anderes Mal (so für das Frnhd.) die Textsortenexplosion des späteren Mittelalters mit Gewichtungen auf z. B. sozial bindenden, legitimierenden, erbauenden (usw.) Texten ${ }^{6} \mathrm{zu}$ dokumentieren haben. Auf jeden Fall werden Auswahlentscheidungen getroffen werden müssen. Der diesbezügliche Entscheidungsraum kann nur Verzweiflung hervorrufen und zur Kritik geradezu einladen. Aus diesen Gründen in die Quantität zu fliehen, führt zum Ersticken jeder weiteren Arbeit. Dies sei hinsichtlich des angesprochenen quantitativen Aspektes etwas breiter ausgeführt.

Es dürfte unbestritten sein, dass die lexikographische Bearbeitbarkeit eines Corpus innerhalb einer überschaubaren Zeit (sagen wir mal: spätestens innerhalb zweier Generationen) gesichert sein muss. Ferner sei hier vorausgesetzt, dass Spra-

\footnotetext{
4 Formulierungen dieser Art sind (hier und an anderen Stellen) bewusst überzeichnet; sie dienen in erster Linie der Deutlichkeit der Argumentation.

5 Hinter dieser Nennung von Funktionen steht Bühler 1934, freilich in speziell hinsichtlich der kognitiven Funktion adaptierter Form.

6 Ich spiele damit auf das Frühneuhochdeutsche Lesebuch an; es enthält eine Textsortengliederung nach unterstellten Autorenintentionen; vgl. Reichmann/Wegera 1988. Gemeint ist aber auch, dass das FWB nicht als ein auf literarische Textsorte gedachtes Werk, damit als ein Wörterbuch für Germanisten, speziell für Literaturhistoriker, gedacht ist, sondern als Grundlagenwerk, das sich auf die gesamte Textüberlieferung bezieht und die gesamte Traditionsforschung ansprechen will.
} 
che zum Zwecke von Semantik da ist. Dies mag sprachtheoretisch diskutabel, sprachpragmatisch und vor allem wissenschaftspragmatisch wird es aber akzeptabel sein: Geschichtlich-sprachpragmatisch gesehen ist entscheidend, wie man sich etwa in der Reformationszeit seine (soziomorphen) Gegenstände ertextet und sie vermittelt hat, wer/welche Gruppen dabei gestaltend waren (kognitiv gesehen), wer/welche Gruppen eher rezipierend und wer/welche Gruppen eher weitergebend tätig waren (jeweils kommunikativ gesehen). Für die wissenschaftliche Ebene gilt Analoges: Auch der Lexikograph ist objektsprachlich Tätiger (vgl. Abschnitt 9). Als solcher wird er die mittelalterliche ,minne‘ oder die reformatorische Semantik um glaube und werk herum nicht interesselos beschreiben und seine Erkenntnisse gleichsam kognitiv gereinigt an irgendeinen bildungssoziologisch unspezifizierten Rezipienten mitteilen; er wird in seine Erläuterungen vielmehr werbende Züge einflechten, Staunen hervorrufen, zusammengefasst: bewirken wollen, dass ein immer soziokulturell bestimmter Rezipient, selbst wenn dieser sich als bloß erkennen wollender Wissenschaftler geriert, in sich geht, sich befragt, wie sich das Aufgenommene auf seine persönliche und seine soziale Welt bezieht und was mögliche Stolpersteine an Haltungs- und Handlungsfolgen mit sich bringen könnten. - Wie immer man geschichtliche Semantik als Gegenstand historischer Forschung und Gegenstand je gegenwärtiger Rezeption im Detail auch sehen und betreiben mag: Sie ist bereits aufgrund dieser Komplexität auf jeden Fall zeitaufwendiger als jede ausdrucksseitig orientierte Lexikographie. Daraus folgt: Das beste Corpus ist dasjenige, das mit einem möglichst geringen Umfang und infolge gezielter Berücksichtigung der verschiedenen Textsorten ein Maximum an Ausbeute verspricht. Corpora, die die herkömmlichen Belegzahlen (für die größeren Wörterbücher etwa im Bereich einer einstelligen Millionenhöhe) auf zwei- bis dreistellige Werte oder gar auf Milliarden erhöhen, sind für Zwecke einer ernst zu nehmenden historischen Semantik die sicherste Möglichkeit, ein Werk bereits vor der ersten Lieferung scheitern zu lassen, es sei denn, man beschränke sich auf dasjenige, was der Computer kann.

Die mit all dem angedeuteten Entscheidungsnotwendigkeiten waren für mich als einen sich (zumindest damals) eher als konservativ betrachtenden Sprachhistoriker nicht durch einen radikalen Abbruch vorhandener lexikographischer Traditionen als durch vorsichtige Dosierungen, ein möglichst kontrolliertes Drehen an den Stellschrauben des Hergebrachten gekennzeichnet. Natürlich hat der Copiagedanke trotz seiner Quantititis (gleichsam seines Geburtsfehlers), trotz des Gewichtes von Lautgeschichte und Lautgeographie und trotz der oft überhöhten Rolle der Etymologie eine wie auch immer zu umreißende Berechtigung. Entsprechendes gilt für die Dominanz der Darstellungsfunktion, für die Corpuscruces (gerade hinsichtlich ihrer Hochschichtlastigkeit), aspektuell sogar für den Isolationismus und generell für alle weiteren, soeben bereits genannten Monita. Dem damit ausgedrückten Respekt für das Hergebrachte stand allerdings die Überzeugung entgegen, auch gewisse Veränderungen vornehmen zu müssen. Diese ergaben sich einmal aus den schleichenden Paradigmenüberlagerungen und -wechseln der Sprachtheorie, nämlich von der (oft 
national orientierten) kulturgeschichtlichen und -pädagogischen Orientierung des 19. und der ersten beiden Drittel des 20. Jahrhunderts zum Strukturalismus, dann zur Sprachsoziologie und schließlich zur Sprachpragmatik. Mitte der siebziger Jahre begann dann auch noch der Siegeszug der neuen Informationstechnologien mit all ihren Auswirkungen auf das technisch Mögliche, damit auch auf die Erkenntnisanliegen, auf die bis dahin relativ konstante Praxis der Erarbeitung von Wörterbüchern, auf die Rezeption ihrer Inhalte und schließlich auf den wie auch immer bestimmten und keinesfalls zu unterschätzenden Mehrwert an Erkenntnis.

\section{Die Planung: Überlegungen und Entscheidungen}

Angesichts der - wie vorgetragen - eingeschätzten Forschungssituation waren Entscheidungen zu treffen. Diese unterlagen folgenden Ideen, Abwägungen, teils auch Unsicherheiten. Ich halte mich hier an die Stufen des sog. lexikographischen Prozesses, der von der Leitidee zum Corpus, von da über das Darstellungskonzept und über die Artikelredaktion zur Publikation und zur Rezeption führt.

Die Leitidee sah aus Umfangs- und Machbarkeitsaspekten einen Dreibänder vor, gleichsam einen Lexer zum Frühneuhochdeutschen. Die Bearbeitungszeit wurde auf 15 Jahre bemessen. - Als Verlag kam nach einigen Sondierungen im Feld der Drittmittelgeber nur das Haus Walter de Gruyter in Betracht, obwohl man sich auch dort des natürlich vorhandenen Risikos, dass das Unternehmen scheitern könnte, voll bewusst war und obwohl keinerlei Aussicht auf Druckkostenzuschüsse bestanden (mögliche Drittmittelgeber gingen wie auch viele Kollegen davon aus, dass das Vorhaben ohnehin sehr bald den Weg alles Irdischen gehen würde). Vorgreifend auf die gesamte Zukunft sei gesagt: Die Bindung des FWB an de Gruyter blieb bis auf den heutigen Tag unbestritten; sie war und ist über alle Veränderungen des Konzeptes sowie des Umfangs ein Stabilitätsanker, über den man nur mit Dankbarkeit berichten kann. Auch für die elektronische Fassung, die seit der Übernahme des Werkes durch die Akademie der Wissenschaften in Göttingen (im Rahmen des sog. Unionsprogrammes; seit 2013) parallel zur weiterhin bestehenden Druckfassung in Arbeit ist, gibt es eine verlässliche und gut funktionierende Übereinkunft. - Die Probleme bzw. die Möglichkeiten, die sich mit dem Einsatz des Computers verbinden, waren bis in die achtziger Jahre kein ernsthaftes Gesprächsthema. Im Hintergrund deuteten sich aber schon damals Verwicklungen an, dass hier etwas unumgehbar sein könnte, sei es auch nur durch einfältig kritische Fragen der Art: Warum machen Sie das Wörterbuch nicht mit der Maschine? Ich selbst sah meine zentrale Aufgabe damals und sehe sie noch heute in der Produktion ${ }^{7}$

7 Hier wird also die wissenschaftliche Produktion von Wörterbüchern von der ebenso wissenschaftlichen Befassung mit der Rezeption, darunter der Benutzungsforschung, unterschieden (dazu: Wiegand 1998a). Es geht dabei um zwei Seiten einer Medaille: Produktion ist nicht sinnvoll 
lexikographischer Artikel mit besonderer Betonung linguistisch-hermeneutischer Erschließung von Wortbedeutungen aus Einzelbelegen von Quellentexten und in einer so übersichtlich gestalteten sprachlichen Fassung, dass der Wörterbuchrezipient sie gestaltend in seine kulturelle Tätigkeit einbinden kann. Das bedeutet logischerweise, dass ich die gesamte Welt der lexikographiebezüglichen Informationstechnologie lange Zeit ausgeblendet habe und schließlich an Fachleute delegierte. Dies Letztere wurde in zufriedenstellender und dankenswerter Weise erst an der Göttinger Akademie und in Absprache mit dem Verlag möglich.

Drei Bände sind angesichts der Tatsache, dass Wörterbücher dazu tendieren, im Verlaufe ihrer Erarbeitung immer umfänglicher zu werden, ein relativ knapp bemessener Umfang. Das mahnte mit dem Blick auf die sich zunehmend verringernde Hoffnung auf eine solide Finanzierung des Werkes nicht nur zur Vorsicht gegenüber allen Ausweitungsgelüsten, sondern wirkte sogar in Richtung auf einige Eingrenzungen. Gedacht ist hier insbesondere daran, dass das FWB zumindest hinsichtlich bestimmter Aspekte (vor allem der sog. Vollständigkeit, der Belegdichte, auch der Etymologie) keineswegs in Konkurrenz mit den oben genannten DWB, DRW, DFW, Schweiz. Id. usw. treten wollte. Das FWB war also seit seiner Planung nicht darauf angelegt, etwa mehr hochalemannische (= halem.) Fremdwörter in rechtsrelevanter Bedeutung und mit kitzelnder Etymologie aufzunehmen als (in diesem Fall) das Schweiz. Id. Gleiches gilt für offensichtlich fachspezifische Verwendungen, wo immer diese gegenüber den allgemeinsprachlichen auch anzusetzen sind.

Noch entscheidender war die bereits angesprochene Ausrichtung eines meinen theoretischen Vorstellungen entsprechenden und gleichzeitig bearbeitbaren Corpus, also seiner Zusammenstellung und seines Umfanges. Die Crux bestand in Folgendem: Ein Corpus für ein Wörterbuch, das auf darstellungstheoretischer Basis als Nachschlagewerk für Studierende und für bloße Nachschlagezwecke im Wissenschaftsbetrieb angelegt ist (wie letztlich Lexer), wird anders zu konzipieren sein als ein Corpus für ein Wörterbuch, das als neue Fragen ermöglichendes Arbeitsinstrument für fiktional- und handlungssemantisch infizierte Sprachhistoriker gedacht ist. Ein Dreibänder erlaubt einen kleineren Corpusumfang und eine Exzerption, die pro Beleg weniger differenziert und weniger interpretationsintensiv ist als ein Vielbänder mit hoch wissenschaftlichen Zielsetzungen. Diese Crux wurde in ihrer Komplexität unterschätzt und keineswegs gelöst. Sicher war nur, dass schon der bloße Gedanke an Vollständigkeit ${ }^{8}$ für eine Großcorpussprache wie das Frnhd. von vorneherein absurd ist; auch der immer mal wieder als Notwendigkeit vorgetragene ausschließliche Zugriff auf archivalisch (und meist ungedruckt) vorliegen-

und letztlich auch nicht möglich ohne fortwährende Antizipation eines Rezipienten (darunter eines Benutzers), und Rezeption ist nicht möglich ohne ein vorhandenes Werk.

8 Bereits die äußere Vollständigkeit ist aufgrund der Offenheit des lexikalischen Inventars ein Unsinnsbegriff, erst recht die innere Vollständigkeit. 
de statt auf wissenschaftlich edierte Texte scheitert bereits an jeder denkbaren Arbeitspraxis; die stets im Raum schwirrende Schaffung eines sog. repräsentativen Corpus erstickt schon in der Diskussion der Frage, was aus welchem Grund repräsentativ sei; die mögliche Idee, ein Kerncorpus Einheit für Einheit durchzuexzerpieren und dann mal weiterzusehen, kommt in die Nähe lexikographischen Selbstmordes; Ähnliches gilt für den wohlmeinenden Rat, bei offensichtlich schwacher Belegung eines Bedeutungsansatzes $>\mathrm{a}<{ }^{9}$ eines Stichwortes $w$ gezielt nach zusätzlichen Belegen zu suchen. Eine linguistische Teildisziplin namens Corpuslinguistik gab es noch nicht und würde, falls es sie in heutiger Form gegeben hätte, sicher zu mehr Fragen als praktikablen Antworten geführt haben. In einer solchen Situation setzt man auf die Praxisprobe. Sie bestand für mich darin, Texte (natürlich Corpuskandidaten) nach den in ihnen enthaltenen Ausgabenglossaren zu exzerpieren, dabei Zeiten zu messen und Fragen wie die nach dem äußeren und inneren Schnitt, nach dominanten Erkenntnisanliegen (im Kern semantischen), nach gezielten Annotationen des Belegs und Weiterem zu entscheiden, und zwar jeweils mit dem Blick auf Hochrechnungen arbeitszeitlicher Art und auf Ergebnisse, die das Offensichtliche übersteigen. Dieses Verfahren erschien mir in der Planungsphase und in der Zeit seiner ersten Erprobung grundsätzlich bedenklich, erwies sich im Verlaufe der Arbeit aber als realisierbar, quantitativ zufriedenstellend und auch wissenschaftlich durchaus ergiebig, insgesamt dann immer mehr als unumgänglich. Inzwischen halte ich es sogar für die einzig realisierbare Möglichkeit, die Bearbeitbarkeit eines Corpus zu sichern.

Genau gesprochen bestand das Verfahren darin, die für zahlreiche frnhd. Texte vorliegenden Ausgabenglossare zur Grundlage der Belegexzerption zu machen. Seine Berechtigung ergibt sich wie folgt: Alle historischen Disziplinen mit einem sprachlich verfassten Gegenstand haben viele ihrer Texteditionen mit Glossaren versehen. Diese dokumentieren trotz aller Brechungen in ihrer Gesamtheit einmal (nämlich gegenstandsbezüglich) die Semantik der Texte einer Geschichtszeit wie des Frnhd., und zwar in ihrer räumlichen, ihrer sozialen, zeitlichen, fachlichen Dimension; sie geben zum anderen (dies bezüglich der Textrezeption) die Traditionen des Interesses an Texten aller Räume, Sozialschichten, Zeiten, Textsorten, Fachgebiete einer Epoche zu erkennen, weisen also auf die volle Rezeptionsbreite, die diesen Texten im Laufe der vergangenen rund 200 Jahre zuteil wurde, und schöpfen das jeweils als offensichtlich beurteilte Besondere und deshalb Vermerkte ab. Damit sprechen sie den antizipierten Rezipienten des Wörterbuches an, jedenfalls in dem Maße, in dem dieser in der Traditionslinie der Texteditoren steht. Die in den Glossaren gelieferten semantischen Informationen beruhen auf der Kenntnis

9 Diese Art der Notation kennzeichnet hier und im Folgenden eine >Bedeutung<, einfache Häkchen stehen für einen ,Begriff‘ (und einiges Andere), Kursive für ein Zeichen und deren Ausdrucksseite (jedenfalls dann, wenn es um derartige Unterscheidungen geht und wenn sie überhaupt möglich sind). 
der gesamten Edition, gehen also weit über die Informationen hinaus, die ein enger Belegzusammenhang bei punktueller Exzerption ermöglicht. Mit eng meine ich das Schreckbild einer Exzerption, die ein Lexikograph anlässlich der Bearbeitung eines Stichwortes $w$ aus einer Liste von Tausenden von Stellenangaben notwendigerweise zufällig innerhalb einer Zeiteinheit von wenigen Minuten mit zwei oder zehn Zeilen vor und nach dem Stichwort ohne Kenntnis des Gesamttextes vollzieht. Unter arbeitstechnischem Gesichtspunkt ermöglicht die glossargeleitete Angabe von Belegstellen, bei zeitlich unaufwendiger linearer Ordnung des Materials ${ }^{10}$ einen den gesamten Quellentext umfassenden Leitfaden für die lineare Exzerption eines Textes, den man kennt, zu bilden. Trotz alledem bleiben schwere Bedenken. Sie betreffen vor allem die Idiotismenlastigkeit der Ausgabenglossare, damit die Minderberücksichtigung des allgemeinen Wortschatzes einer Epoche: Das ist aber oft genau der Wortschatz, der eine relativ geringe Differenzqualität zur nhd. Beschreibungssprache hat und von dem oben gesagt wurde, er könne möglicherweise etwas weniger differenziert behandelt werden.

Quantitativ ausgedrückt sei mitgeteilt: Das Corpus des FWB umfasst insgesamt rund 600 Quellentexte, darunter vielbändige Quellenreihen aus allen Einzeldisziplinen kulturgeschichtlicher Forschung. Die Schwächen, die sich aus dem Prinzip der Glossarbasierung der Exzerption ergeben, wurden dadurch zu beheben versucht, dass eine Reihe zusätzlicher Texte in jeweils spezifisch festgelegter Dichte selektiv linear durchexzerpiert und dass in erheblichem Maße von Verschiebebelegen ${ }^{11}$ Gebrauch gemacht wurde. - Potentiell jeder Beleg enthält Annotationen des Exzerpierenden, die auf die Informationstypen der Wörterbuchartikel abgestimmt sind. Wenn man also - wie das FWB - eine Informationsposition ,onomasiologische Vernetzung' oder ,Syntagmen' hat, sollte man bedeutungsverwandte Wörter zum Belegwort bzw. seine syntagmatische Einbindung annotieren; ist dies nicht das Fall, erübrigt es sich. Die Corpusexzerption (im FWB auf Belegkarteien) wird damit zur Basis der Artikelbearbeitung. Trotzdem ist jedes Corpus immer zu klein; ein hinreichend umfängliches und hinreichend qualifiziert annotiertes Corpus gibt es nicht, weil es nicht herstellbar ist. Wenn es herstellbar wäre, würde es nicht bearbeitbar sein. - Die Bände 1 und 3 des FWB dokumentieren das Corpus. Es beläuft sich auf (hochgerechnet) mindestens 300.000 Normalseiten, von denen schätzungsweise zwei Drittel auf Editionen mit angehängtem Glossar entfallen. Es sei allerdings betont, dass Zahlenangaben dieser Art wertlos sind, so lange nicht angegeben ist, wie dicht die Exzerption erfolgte, ob und wie die Belege geschnitten und wie sie annotiert wurden, aus welchen wie verschiedenen Textsorten sie stammen, welche

10 Zur Erläuterung: Die Ausgabenglossare sind alphabetisch geordnet; die Stellenangaben folgen also keiner Linie. Ihre Umstellung auf eine Linie (vom Anfang zum Endes Textes) schlägt arbeitszeitlich kaum zu Buche.

11 Das sind solche Belege, die an vorangehender Stelle des Wörterbuches bereits einmal zitiert wurden, natürlich unter dem pro Lemmazeichen spezifischen und deshalb pro Neuverwendung kritisch zu prüfenden Zweck. 
Type-Token-Relation sie aufweisen. Auch nur das Letztere genau zu ermitteln, ist bereits unter arbeitszeitlichen Aspekten nicht für alle Texte des Corpus zu verantworten. ${ }^{12}$ - Die sich hier natürlich stellende Frage, ob die dargestellten Probleme nicht mittels moderner Datenverarbeitung zeitsparend gelöst werden könnten, ist $\mathrm{zu}$ verneinen: Jede ernst $\mathrm{zu}$ nehmende Lexikographie muss jedem Beleg einen gezielt angebrachten äußeren sowie inneren Schnitt geben, und zwar mit Blick auf die gewollte (für das FWB: semantische) Information; der Exzerpierende sollte die Belegstellenbedeutung der in Frage stehenden Einheit formulieren (was in einem strengen Sinne die Kenntnis des Gesamttextes verlangt); er sollte die Syntax des Belegwortes angeben, seine Synonyme aus dem Umfeld des Belegwortes erschließen, auf Phraseme und Wortbildungen achten usw. ${ }^{13}$

Zur Leitidee gehörte auch die bereits mehrfach angesprochene Frage, welche semantische Funktion lexikalischer Einheiten das Beschreibungszentrum bilden solle. Die Darstellungsfunktion (oder, hier synonym gebraucht: die Bezeichnungs-, Benennungsfunktion) besteht darin, dass ein Wort etwas darstellt, bezeichnet, nennt. Dieses zu bezeichnende Etwas muss, wenn es denn dargestellt werden will, diskret, also zumindest irgendwie von anderen unterschieden vorhanden sein; es ist vorhanden in einer als vorsprachlich angenommenen, also sprach- und selbst kognitionsunabhängig gedachten Wirklichkeit oder in deren mentaler Repräsentation, in letzterem Fall am reinsten in Form von Begriffen. Begriffe sind demnach im wahrsten Sinne des Wortes onto-logische Gegebenheiten, also Identitäten, die nach aufgenommenen Wahrnehmungen mittels der Regeln allgemeinmenschlicher Logik erarbeitet, danach in einer Einzelsprache zeichenhaft-abbildlich gefasst und in der Parole kommunikativ umgesetzt werden. Sie verbinden sich mit einem hohen und berückend korrumpierenden Anspruch von Sachlichkeit, Logik, Richtigkeit anthropologisch gesicherter Art und damit transgeschichtlicher und transsozialer Geltung. Eine beliebige, hinsichtlich ihres Status im allgemeinen nicht reflektierte einfache Gegebenheit wie ,Baum‘ (versus ,Strauch') oder ,Ast‘ (versus ,Zweig‘) müsste sich insofern im Suaheli, im Japanischen und im Deutschen mit Ausdrücken fassen lassen, die inhaltlich in dem Maße deckungsgleich sind, wie sich Bäume und Äste in Afrika, in Japan und Mitteleuropa ähneln. Sprachunterschiede würden zumindest auf lexikalischer Ebene nur Unterschiede der Bezeichnung sein,

\footnotetext{
12 Von bestimmten Texttypen weiß man das aus Erfahrung: Erbauungstexte enthalten nach einer zweistelligen Seitenzahl in der Regel keine neues Wort und keine neue Bedeutung mehr, für literarische Texte gilt eher das Umgekehrte.

13 Die Ausführung des damit umrissenen Exzerptionsprogramms erfordert Einschränkungen, diese sind teils in Regeln formulierbar, teils beruhen sie auf Erfahrung, hier: auf der Kenntnis der Quellentexte sowie auf handwerklich-lexikographischen Fertigkeiten. Ich bitte dies als Seitenhieb auf Arbeitsverträge der Art zu verstehen, Inhaber einer Zeitstelle könnten die notwendige Erfahrung innerhalb einer Zeit von weniger als zwei Jahren erwerben. Anstellungen mit solcher Begrenzung sind Geldverschwendung; sie führen kaum zum Fortschritt der Produktion, nehmen nur die Arbeitszeit der Erfahrenen in Anspruch.
} 
Übersetzungen würden zum Austausch von Wörtern (und natürlich vielem Weiteren) mutieren. Selbst auf textlicher Ebene setzt sich diese Denkmöglichkeit trotz aller Brechungen fort. Die frühneuzeitlichen mehrsprachigen Wörterbücher sind ihr reinster Niederschlag.

Dieser (rationalistischen, in der Aufklärung natürlich kritisch und differenziert ausgearbeiteten) Denklinie von der Sache zum (sinnlichen) Wahrnehmungsinhalt, zum (logomorphen) Begriff, zum Wort (als seiner sprachlichen Entsprechung) und schließlich zur Äußerung ist eine Auffassung der lexikalischen Einheit diametral entgegengesetzt, die hier und im Folgenden als soziopragmatisch charakterisiert werden soll. Sie lautet in stark vereinfachter rhematischer Form genau umgekehrt: Es ist die einzelne Sprachäußerung einer einzelnen Person in einer je einmaligen Situation, die den Wortgebrauch von der Beziehung der Sprechenden her bestimmt. Die so bestimmte Äußerung gilt dabei als (verbalsymbolisches) Handeln; das Handeln ist nicht realitätsbezüglich abbildend motiviert und folglich nicht mit Richtigkeitsaspekten behaftet, sondern genuin intentional partnerbezogener Konvenienz; also konstituiert man seine Inhalte nach den je besonderen Zwecken, die man gerade verfolgt, und natürlich so, wie man das - wenn auch stets ein wenig anders - immer schon getan hat, darunter natürlich auch so, dass sie irgendwie richtig sind. Damit offenbart sich das Sprechen als Möglichkeitsraum einer seiner Seinsweise nach permanent vollzogenen und umfassenden Gestaltung der gesamten sozialen Lebenswelt. - Dieser Prozess hat mindestens zwei nur analytisch trennbare Seiten, einmal eine inhaltliche und zum andern eine handlungsbezogene:

Inhaltlich geht es um den mentalen Zuschnitt von Wahrnehmungsaspekten zu semantischen Identitäten. Wenn diese Zuschnitte im Sprechen erfolgen und das Sprechen immer als einzeln, einmalig, beziehungsfunktional gesteuert und je anders gedacht wird, leitet sich auch die Sprechweise (als kollektiv-soziale Größe) vom Einzelnen ab. Die so verlaufende Inhaltsbildung ist damit von ihrer Existenzweise her ein sozialer (interaktiver) Prozess, womit die entstehenden Identitäten sich als soziokognitive/soziomorphe (nicht logomorphe) Gegebenheiten erweisen. Gemeint sind sowohl großzügige Generalisierungen wie feinfühlige Differenzierungen, je wechselnde referenzielle Grenzziehungen in Spektren und ihre Aufladung durch Wertungen; sie reichen bis zu Gesellschaftsutopien, poetischen Fiktionen, wissenschaftlichen Theorien und allen sog. möglichen Welten als Ergebnis. Selbst die Unterscheidung von ,Baum' und ,Strauch“ und erst recht die von ,Verstand', ,Vernunft', ,Geist‘, ,Witz‘, ,Intellekt' erscheint folglich als poetischer Akt; Sprechen ist eben im Ursprung und im gesamten, dem einzelnen Sprechen inhärenten Prozess sowohl der Abstrahierung wie der Prototypisierung zur sprachlichen Einheit poetisch. Eine sachliche Begründung, die logischer als eine andere sei, dass also der ,Strauch' in genau zwei und nicht erst in vier Metern Höhe und schon bei zwei und nicht erst bei vier Stämmen zum ,Baum‘ werde, wird schwer auszumachen sein; die Realprobe versagt. Demzufolge sollte man den Inhalt der Zeichen Baum oder Strauch auch nicht Begriff, sondern lieber Bedeutung nennen und Begriff (falls 
der Ausdruck denn nötig werden sollte) auf wie auch immer seiende sprachunabhängig gedachte allgemeinlogische Identitäten beschränken. - Indem ich die soziokognitive Seite der sprachlichen Inhaltsbildung besonders herausstellte, präsupponierte ich den Menschen als soziokognitives, also als kopfgesteuertes Wesen und stellte ihn damit letztlich in (freilich sozial verwässerte) aufklärerische Zusammenhänge. Das immer partnerbezogene Sprechen, das üblicherweise pragmatisch verortet und - übertragen gesprochen - in die ,Hand' der Kommunizierenden verlegt wird, erscheint dabei als Leistung des ,Kopfes‘.

Der Handlungsbezug beruht auf einer fundamental anderen Vorgabe: Der Mensch sei ein Handlungswesen, nicht primär ein wie auch immer geartetes ens rationale (Vernunftwesen). Im Hintergrund lauert dann der Verdacht, dass sich zum mindesten die soziale Vernunft und letztlich sogar die Vernunft, wie sie in der Tradition der Aufklärung verstanden wird, als eine Ableitung der Handlungskonstituiertheit des Menschen erweisen könnte: Nicht der Kopfinhalt (welcher Art auch immer) würde dann die Handlung, sondern die Handlung den Inhalt des Kopfes bestimmen. Das ist ein sprachtheoretischer Sprengsatz, dessen Auswirkungen auch auf die Lexikographie nicht einmal ansatzweise erfasst sind.

In der Planungsphase eines Wörterbuches hat man sich mit Problemen der gerade vorgetragenen Art auseinanderzusetzen, nicht um sie zu lösen, sondern sich einfach $\mathrm{zu}$ fragen, in welcher Weise sie für die Lexikographie und speziell für die historische Bedeutungslexikographie von Belang sein könnten. Ohnehin wird man nicht darum herum kommen, sich schon im Vorfeld klar darüber zu werden, ob man den Wortschatz eher hinsichtlich seiner ausdrucksseitigen Kennzeichen (etwa der Schreibungen, der Formen der Syntax) oder eher hinsichtlich seiner Bedeutungsseite zum Gegenstand machen will. Entscheidet man sich (und das stand für mich nie in Frage) für Letzteres, dann wird man sich der je kategorialen Leistung der herrschenden Formen der Bedeutungsdefinition, -paraphrase, -beschreibung, -erläuterung (wie immer man auch sagen möge) mit dem Blick auf die Semantik und auf die genaue theoretische Sicht der Semantik zu vergewissern haben: In Betracht kommen dann vor allem die Synonymenangabe und die Phrase. Es ist dann jeweils das wissenschaftliche Ziel, das die (hier: semantische) Stoßrichtung jedes einzelnen Wörterbuchartikels und damit die standardisierten Beschreibungsmuster bestimmt. Die unkritische Übernahme bekannter Muster kann das wissenschaftliche Ziel aber auch unterlaufen. Dies soll am Beispiel der Synonymenangabe kurz erläutert und dann in den Gegensatz zur phrastischen Erläuterung gestellt werden.

Die Synonymenangabe funktioniert - obwohl ein urpragmatischer Handlungstyp - auf einer strikt rationalistischen Vorgabe: Man setzt voraus, eine zu beschreibende, z. B. frnhd. Bedeutung (im inhalts- wie im handlungssemantischen Sinne) eines geschichtlichen Wortes $w$ werde in der nhd. Beschreibungssprache statt mit diesem $w$ mittels $x$ gefasst, minne also etwa mit nhd. Liebe, barmherzigkeit gar gestaltgleich mit nhd. Barmherzigkeit. Dieses Muster hat in dieser fiktiv demonstrier- 
ten Form keinerlei Beschreibungswert; es fördert nur die kognitiv beruhigende, aber ahistorische, jede semantikhistorische Differenzierung hemmende, generell horizontverschmelzende Auffassung, dass etwa ahd., mengl. oder nnl. Ausdrücke ein inhalts- und handlungssemantisch Gleiches nur unter anderer oder sogar erkennbar gleicher/ähnlicher Zeichengestalt fassen. Wenn es trotzdem allgemein gebraucht wird, wird man Gründe dafür suchen müssen. Sie liegen wohl darin, dass es neben semantikhistorischen Differenzen auch über Jahrhunderte und selbst über ganze Geschichtsepochen hinweg existierende Konstanten, jedenfalls so viele Ähnlichkeiten gibt, dass man einen geschichtlichen Text so hinreichend und auf die Weise versteht, wie man es gerade für sinnvoll erachtet bzw. in seiner gerade gegebenen Handlungskonstellation zu brauchen meint. Damit garantiert die Synonymenangabe die Bedingung der Möglichkeit des Verstehens historischer Texte (selbstverständlich immer eines Irgendwieverstehens). Das meine ich positiv, denn ein anderes gibt es nicht. Schließlich spart sie auch noch Druckraum, dies schon deshalb, weil nur zwei Gegebenheiten im Spiel sind: das lexikographische Stichwort (pro Bedeutung) und das beschreibungssprachliche Synonym; die bezeichnete Sache bleibt ja konstant.

Demgegenüber ist die phrastische Erläuterung hoch komplex: Man kann jede Generalisierung, Differenzierung, Grenzziehung und jede noch so feine Nuancierung, Wertung, Konnotation usw. eines Lemmazeichens syntaktisch beliebig genau dosieren. Der Gestaltungsfreiheit des Lexikographen sind kaum Grenzen gesetzt. Dies ist so offensichtlich, dass es nicht weiter beschrieben werden muss.

All diese Überlegungen, Überzeugungen, Gewichtungen usw. sind in der Form, wie sie hier vorgetragen wurden, das Ergebnis meines heutigen Urteilsstandes. Dieser deckt sich weitgehend, aber nicht in seinen Einzelheiten und nicht in allen Wertungen mit meinem diesbezüglichen Einsichtsstand in den Gründungs- und Vorbereitungsjahren des Wörterbuches. - Relativ konstant geblieben sind:

- die semantikzentrierte Auffassung des Corpus: kleinstmöglich, damit überschaubar; kognitiv zumindest ansatzweise bekannt und für den Lexikographen pro Text beurteilbar; daraus folgend die Auswahl der einzelnen Texte aus allen Zeiten, Räumen, Textsorten

- die Corpusexzerption: dem Anspruch nach streng gefiltert zugunsten erkenntnisrelevanter bzw. zuungunsten erkenntnisirrelevanter Quantitäten und auf das oberste (semantische) Beschreibungsziel des Wörterbuches ausgerichtet

- die Sicht der verschiedenen Funktionen des Wortschatzes: Darstellung (sachbezogen), Bildung soziomorph-semantischer Identitäten (kognitionsbezogen), Handlungsaufladung (kommunikativ gesehen), Anzeichenfunktion (= Symptomfunktion)

- die Überwindung jeder Form des Isolationismus: Vermeidung von Schreibformenauflistungen und -behandlungen

- die grundsätzliche Semantikzentrierung aller Artikel: natürlich unter Beachtung aller Funktionen, strenge Adressierung jedweder Information an das Orientierungszentrum ,Semantik` 
- die Aufbrechung der eingefahrenen Artikelstruktur: zwar fakultative Erhaltung der Dreiergliederung des lexikographischen Artikels (also: Lemmazeichen, Bedeutungsangabe, Belege) aus Orientierungsgründen; aber Reduktion ihrer Dominanz bereits durch eine polysemistisch gesteuerte, im FWB nach Zahlen gegliederte Reihe von sog. Einzelbedeutungen (besser: Sememen, Bedeutungsansätzen) sowie durch die freie Syntax der phrastischen Erläuterung

- eine Informationsstruktur, die folgende Eigenschaften des lexikalischen Zeichens betriff: Gestalt des Lemmazeichens, seine Morphologie (diese beiden an das Lemma adressiert und eher beiläufig, nur der äußeren Orientierung nach), danach die Bedeutung des Lemmazeichens (gegliedert in einzelne Bedeutungsansätze), de facto also: der einzelne Bedeutungsansatz, seine Symptomwerte (nach Raum, Zeit, Textsorte), sein Vorkommen in Phrasemen, seine (partiellen) Synonyme (bedeutungsverwandten Ausdrücke), seine syntaktischen Vorkommen, die zugehörigen Wortbildungen, die Belegzitate und Angaben ausgewählter Belegstellen (dies alles an den einzelnen Bedeutungsansatz adressiert)

- die Möglichkeit sog. Kommentare des Lexikographen: potentiell zu jeder der genannten Informationspositionen; damit die Freiheit, je nach Anlass einer Besonderheit gerecht zu werden.

- In darstellerischer Veranschaulichung ergibt sich folgendes Bild der Artikelstruktur. Die Einrückung (nach rechts) gibt die jeweilige Adressierung an (einfache Einrückung = direkte Adressierung, doppelte/dreifache Einrückung = gestufte Adressierung):

Lemma

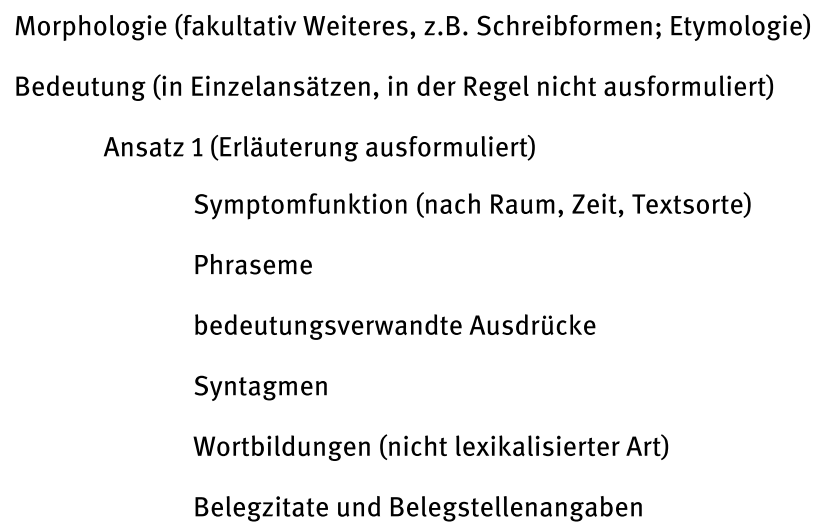

Abb. 1: Die Artikelstruktur des FWB. 
Die Füllung der Positionen kann schwanken. So dürfte es z.B. ohne weiteres einsichtig sein, dass ein Artikel zu einem nur einmal belegten Lemmazeichen anders ausfällt als ein Artikel, der auf mehreren Hunderten oder gar Tausenden von Belegen beruht. Systematisch entscheidender ist, dass der Lexikograph in gewisser Weise als Herr des Geschehens fungiert: Er findet hinreichend Möglichkeiten, seine individuellen Kenntnisse und seine Interessen einzuflechten, bei Ausdrücken wie glaube, liebe, minne, mund oder nütze etwa seine theologischen, literarischen Gewichtungen oder seine Kenntnis übereinzelsprachlicher antiker Traditionen spielen zu lassen. Er hat auch jederzeit die Möglichkeit, einen Kommentar anzubringen oder dies zu unterlassen; er kann die Bedeutung unterschiedlich fein gliedern oder unterschiedlich stark generalisieren oder typisieren; auch die Grenzziehungen des seiner Seinsweise nach offenen Feldes bedeutungsverwandter Ausdrücke liegen in seinem Ermessen, die Syntagmen können (sollten aber eher nicht) auf typische Beispiele beschränkt sein, können aber auch bis zur Unübersichtlichkeit dokumentiert werden.

An einem Artikel demonstriert (zum Lemma abrede in Bedeutungsansatz 2) sieht das Bild wie folgt aus:

abrede, die; $-\varnothing /-n$.

$[\ldots]$

2. >Absprache, Abmachung, Vereinbarung, Vertrag $<$; oft speziell: >Vereinbarung der Heirat, Heiratsabsprache<; resultativ zu abreden 1: Metonymie zu abrede 1. - Bdv.: beschlus 4, decret 1, pakt, teidigung, übereinkommung, vertrag, vergleichung. - Synt.: a. halten / fürbringen / tun / volziehen; a. (Subj.) beschehen; verfertigte a.; brief der a.

Kollnig, Weist. Schriesheim 272, 2 (rhfrk., 1556): Uff vorbemelten sambstag nach trium regum ist in beysein der erscheinenden volgente vergleichung und abred beschehen. LÖSCHER, Erzgeb. Bergr. 103, 31 (omd., 1548): das in gemeinen furfallenden teglichen hendeln abreden und mundliche vortrege zuweilen gemacht [...] werden. BoNER, Urk. Brugg 322, 10 (halem., 1513): nach anzöug darvmb vorgemachter abred. RINTELEN, B. Walther 69, 8 (moobd., 1552/58): so sein seine Erben die verlassne Praut [...] abzeferttigen oder die Abrede zu volziehen nit schuldig. Grossmann, Unrest. Öst. Chron. 73, 21 (oobd., 3. Dr. 15. Jh.): umb die [aynige tochter] was noch pey ires vaters leben durch den bischolff von Metz ain abred beschehen, das er die zw ee gab des kaysers sun. - KÜther, UB Frauensee 388, 27; Schmitz, Schiltb. 31, 8; MerK, Stadtr. Neuenb. 96, 21; RiNTELEN, a. a. O. 61, 13; MAALER 4 v; ROT 302; 334; WREDE, Aköln. Sprachsch. 33 a.
Abb. 2: Die Artikelstruktur des FWB am Beispiel abrede, Bedeutungsansatz 2 (aus: FWB, Band 1, Sp. 279-280). 
Auf eine Erläuterung wird hier deshalb verzichtet, weil die drucktechnische Gestaltung eine reibungslose Rezeption ermöglicht. Es sei lediglich zweierlei erwähnt: Erstens: Die Angaben „resultativ zu abreden 1“ und „Metonymie zu abrede 1“ sind Kommentare des Lexikographen, und zwar ersterer zur synchron gedachten Wortbildungsmotivation und letzterer zu signifikatinternen semantischen Bezügen des Stichwortes. Zweitens: Die Position ,Phraseme‘ fehlt, weil die Belege keine Phraseme enthalten, möglichweise aber auch deshalb, weil mir die Stellung und das Gewicht der Phraseme damals (1986) nicht so präsent waren wie später (Weiteres dazu S. 302).

Das gerade vorgeführte, am Beispiel abrede (in Bedeutungsansatz 2) veranschaulichte Bild repräsentiert den Standard des FWB seit der Publikation der ersten beiden Lieferungen im Jahre 1986 bis auf den heutigen Tag; dies wird sich auch für die folgenden 10 Jahre nicht ändern. Allen an der Artikelproduktion Beteiligten steht damit ein Rahmen zu Verfügung, der einschließlich einiger, hier wegen ihrer Beiläufigkeit nicht erwähnter Positionen ein rundes Dutzend Informationstypen umfasst. Das ist ein Stabilitätsfaktor hohen Wertes, da er dem mit der Artikelproduktion Befassten wie dem Rezipienten die Reihenfolge der Informationen vorgibt. Zusätzlich orientierungsverstärkend wirkt die vom Verlag mit dem Hauptherausgeber erarbeitete Druckgestaltung: Sie hat sich selbst für die 30 Jahre später erfolgte digitalisierte Fassung als gut handhabbare Voraussetzung für die schnelle technische Erfassung und Unterscheidung der verschiedenen Informationen erwiesen.

Nach der Darstellung der Konstanten geht es nun um die Erarbeitung des FWB, damit um die Inkonstanten, die Varianten, um all das, was am Gegenstand, immerhin an rund 100.000 lexikalischen Einheiten und mehreren Hunderttausend Bedeutungsansätzen, wohlgemerkt: jeweils einmaligen Gegebenheiten, geradezu danach schreit, jedes vorgegebene lexikographische Konzept zu sprengen. Dazu seien zwei Punkte besonders herausgehoben. Einmal die Komplexität der Sache und zum andern (in einem eigenen Kapitel, s. Ordnungspunkt 4) die soziale Realität der Arbeitsverhältnisse.

Die Komplexität der Sache wurde gerade bereits mehrfach angedeutet. Es ist in der Tat ein Gewaltakt, von ihrem Seinsstatus her im Gebrauchs- und Gestaltungsprozess befindliche Gegebenheiten wie lexikalische Ausdrücke einer wissenschaftlichen Behandlung zu unterwerfen, und zwar so, dass man diesen Status (also: im steten Werden zu sein) aufhebt und mehr oder weniger zu einer gegenständlich gedachten, z. B. irgendwie umgrenzten und zählbaren Identität macht. Auch wenn man weiß, dass dies unumgänglich das Schicksal aller historisch-sozialen Seinsverhältnisse ist, sobald sie Wissenschaftlern in die Hände fallen, wird man doch ein Gewissen für diese Statusveränderung entwickeln und darauf in den Grenzen des Möglichen reagieren. Dies kann z. B. dadurch erfolgen, dass man die kategorial statisierende ,Beschreibung'shaltung zugunsten anderer, z. B. eher erzählender und eher handlungsund beziehungsgesteuerter Schreib- und Redeweisen modifiziert. Die Zugriffsgewalt des Lexikographen steigert sich noch, wenn man lexikalisch-semantische Entitäten, 
selbst wenn man sie als Unikate im Werdensstatus auffasst, einer fixen, vielleicht auf eine halbe Textseite bemessenen allgemeinen, wenn auch flexibel handhabbaren Beschreibungsstruktur ausliefert und dadurch die Anbindung sprachlichen Handelns an den je einzelnen Gebrauch unterhöhlt, obwohl er doch als Basis der Ableitung eines Allgemeinen oder Typischen stets erkennbar bleiben müsste. Auch die gerade oben schon angedeuteten Zählungen (S. 289) sind eine Sünde wider den Werdensstatus desjenigen, was man trotz seiner Nicht-Zählbarkeit dennoch zählt, z. B. die sog. Bedeutungen eines Wortes. Die Problematik, Brisanz, Faszination, die in der Sache liegt, erfährt schließlich dadurch eine nochmalige Steigerung, dass die gerade aus Gründen der Darstellungsvereinfachung als ,sachlich“ attribuierte Komplexität im strengen Sinne ein historisch-soziales Konstrukt im Kopf und in der (natürlich metaphorisch verstandenen) Hand des Lexikographen ist. Je individueller dieser sich geriert, je intelligenter er ausgestattet und je beschlagener er sachlich ist, desto differenzierter wird sein Gegenstand, möglicherweise auch sein Arbeitsergebnis. Dies könnte natürlich auch dazu verleiten, wird hier aber nicht ernsthaft vorgeschlagen, Lexikographen nur dann anzustellen, wenn ihr Individualitäts- und Intelligenzgrad denjenigen des immer wieder ins Spiel gebrachten Normalrezipienten höchstens minimal übersteigt. ${ }^{14}$ In letzterem (man beachte: ,Normal-`) hat man die Individualitäts- und Intelligenzkappung wissenschaftlich ja bereits salonfähig gemacht. Kurz und gut: Auf die schärfst mögliche und natürlich nur zum Nachdenken formulierte Spitze gebracht: Eigentlich ist jedem lexikalischen Ausdruck (wie für jeden literarischen Text akzeptiert) für jedes seiner Vorkommen eine eigene Behandlung (nicht nur: Darstellung, Beschreibung) zu widmen, und zwar nicht nur mit dem Ziel, zeitlich rückwärtsgewandt ein Stück sprachlicher Wirklichkeit abzuarbeiten, sondern es zu allem Überfluss auch noch gegenwartszugewandt - den Rezipienten so vorzulegen, dass sie weiter darüber arbeiten und sogar Handlungskriterien für die ihnen eigene Kulturzeit daraus gewinnen könnten. Das oben mit positivem Unterton vorgestellte Schema würde dann selber der Veränderbarkeit und der tatsächlichen stetigen Veränderung unterworfen, seinen Beschreibungsimperativ jedenfalls in die historisch-soziale Verfügung stellen müssen. In der lexikographischen Praxis kann der methodische Zweifel auch befreiend wirken: Man kann das vorgegebene Schema jederzeit durchbrechen. Es hat sich inzwischen allerdings gezeigt, dass es auch für Neuerungen tragfähig ist.

14 Haltungen dieser Art werden in der Regel nicht rhematisch ausgesprochen, zeigen sich aber im Reden über Lexikographie als Handwerk, in der Abstufung des Lexikographen gegenüber ,wirklichen Wissenschaftlern (z. B. bei Zukunftsplanungen), schließlich auch in der Übernahme solcher Urteile durch die Lexikographen selbst. 


\section{Die Arbeitsverhältnisse und die wissenschaftliche Resonanz des Vorhabens}

In Fragen der vorgetragenen Art schlagen immer auch die Arbeitsverhältnisse hinein. Diese gestalteten sich für das FWB in seiner Gründungs- und Planungsphase wie folgt. Ich begann um 1977 herum selber mit der Exzerptionstätigkeit (eigenhändig; wie oben dargestellt nach den Ausgabenglossaren und zunächst beschränkt auf die Strecke $a$-) und führte diese bis rund 1990 (für die Strecke $b$-) weiter. Meine Absichten dabei waren verschiedener Art: (1) Ich wollte mich so intensiv in die frnhd. Textwelt einlesen, wie ich dies für die lexikographische Arbeit als unumgehbare Mindestvoraussetzung erachtete. (2) Ich wollte das schon in der Mitte der siebziger Jahre im stetigen inneren Monolog befindliche Wörterbuchkonzept auf seine Gegenstands-, d.h. Semantik- und Textadäquatheit sowie auf seine praktische Anwendungsmöglichkeit prüfen. (3) Ich wollte mir eine Vorstellung von der Zeitintensität verschaffen, die die Corpusexzerption und -annotation erforderte. ${ }^{15}$ (4) Ich wollte sicherstellen, dass ich als Initiator eines möglicherweise einmal finanziell geförderten Projektes über den gesamten Erfahrungsbestand potentieller Mitarbeiter verfügte, wobei ich mir diese als relativ langfristig angestellt und damit als Berufslexikographen vorstellte. Es kann und sollte eben nicht sein, dass der wissenschaftlich für ein Projekt Verantwortliche hinsichtlich lexikographietheoretischer Kapazität, Corpuskenntnis, Exzerptionserfahrung, Artikelredaktion und Produktivität pro Zeit (heute sagt man: hinsichtlich des Kosten-Leistungs-Verhältnisses) und damit hinsichtlich seiner Autorität seinen Mitarbeitern unterlegen ist. Parallel zur Exzerptionstätigkeit und den diese begleitenden Überlegungen verliefen die zunehmende Festlegung des Corpus, erste Versuche einer Artikelerarbeitung, anschließend die systematische Streckenarbeit. Die Universität Heidelberg stellte mir damals für fünf Jahre eine wissenschaftliche Mitarbeiterstelle zur Verfügung (aus Mitteln des Forschungsschwerpunktes Baden-Württemberg). Das Ergebnis der Arbeitsphase von 1977 (inkubierend seit 1975) bis etwa 1990 lautet: eine Konzeption auf der Basis der linguistischen Theoriebildung, eine zugleich standardisierte und flexible Artikelstruktur (zusammenfassend dargestellt in meiner „lexikographischen Einleitung“; FWB 1, 1986, S. 10-164), im einzelnen ein (weitgehend) abgeschlossenes Corpus, Exzerptionen, auf deren Basis ein Band des Wörterbuches (1989; 1632 Spalten; $a$ bis äpfelkern) und eine Lieferung (des 2. Bandes; 512 Spalten; publiziert 1991) aus meiner Feder erschienen.

Ich betrachtete dies alles als Erfolg, auch als den Beweis, dass Unternehmen vom Typ des FWB selbst in einem Massenfach eine Chance auf Realisierung haben, jedenfalls dann, wenn eine engagierte Einzelperson einen Großteil ihrer Arbeitskraft in den Dienst einer Idee stellt (in meinem Fall neben der Organisation, Mitherausgabe und Mitarbeit an den Handbüchern Sprachgeschichte und Wörterbücher,

15 Das Ergebnis lautet: 10 bis 20 Exzerpte pro Stunde; so jedenfalls das Maß für Hilfskräfte. 
Frühneuhochdeutschen Grammatik und des Frühneuhochdeutschen Lesebuches). Man verzeihe mir die Selbstbezüglichkeit dieser und einiger der folgenden Aussagen! - Im übrigen fanden die Konzeption und ihre Realisierung in der Fachwelt eine positive Aufnahme: In der Mediävistik wurde um 1990 ein Mittelhochdeutsches Wörterbuch (= MWB) ins Leben gerufen, offensichtlich motiviert durch die Existenz des FWB. Seine ursprüngliche Konzeption entsprach nach Ausweis des auf dem Internationalen Germanistenkongress in Tokio (1990) vorgestellten Zehn-PunkteProgramms (damals) weitestgehend derjenigen des FWB, wie sie in der lexikographischen Einleitung des FWB (1986) dargelegt war. - Der Publikation des MWB (seit 2006) ging ein Findebuch zum Mhd. (1992) voraus, wie ich es seit 1977 vorgeschlagen und zusammen mit meinen amerikanischen Herausgeberkollegen und mit finanzieller Unterstützung des National Fonds for the Humanities für das Frnhd. realisiert hatte (s. S. 275 sowie das Literaturverzeichnis). Das Ergebnis ist jederzeit in der Göttinger Arbeitsstelle einsehbar. - Die von Anderson/Goebel/ Reichmann 1983 unter dem Titelstichwort „onomasiologische Aufbereitung semasiologischer Wörterbücher“ vorgetragene und 1995 in Goebel/Lemberg/Reichmann unter dem Stichwort „versteckte lexikographische Information“ auf das Frnhd. bezogene Möglichkeit neuhochdeutsch-frühneuhochdeutscher/mittelhochdeutscher (usw.) Wörterbücher wurde zwar aufmerksam aufgenommen, aber für keine Sprachstufe des Deutschen realisiert; sie bleibt damit eine Forschungslücke. Wir haben kein onomasiologisches Wörterbuch in Printform, in dem ausgehend von nhd. lexikalischen Zeichen (pro Bedeutung) die frnhd., mhd., ahd. oder auch die mnd. (partiellen) Äquivalente aufgelistet wären. Genau dies leistete 2009 der Oxford Historical Thesaurus of the Oxford English Dictionary ${ }^{16}$ für das Englische. Das FWB bringt die entsprechende Information inzwischen in digitalisierter Form. - Das Institut für Deutsche Sprache (IDS, Mannheim) entwickelte einen elexico genannten Plan, der (wenn auch mit anderer Terminologie) auf den Beschreibungspositionen des FWB basierte. - Eine der zentralen Neuerungen des FWB, nämlich die Einhängung onomasiologischer Angaben in ein semasiologisch angelegtes Wörterbuch, genau gesprochen: mit Adressierung an den einzelnen Bedeutungsansatz, führte zur Systematisierung der Synonymennennungen, teils zur Aufnahme einer entsprechenden Informationsposition in verschiedene historische Bedeutungswörterbücher, so (nach meiner Wahrnehmung) - in das RWB, das Goethe-Wb., das Schweiz. Id. (jeweils mit je eigenen Adaptierungen).

Trotz dieser positiven Sicht der Entwicklung wurde mir in der zweiten Hälfte der achtziger Jahre zunehmend klar, dass das FWB bei allen (begrenzten) Hilfen von Seiten der Universität Heidelberg de facto nun mal immer noch nur als Indivi-

16 Die Realisierung dieses Werkes durch die Oxforder Kollegen verlief offensichtlich in Unkenntnis meiner eigenen onomasiologischen Bemühungen. Die Tatsache, dass man an zwei Stellen inhaltlich genau das Gleiche vorschlägt und konzipiert (dies auf deutscher Seite) bzw. realisiert (dies auf englischer Seite), lässt sowohl das allgemeine Forschungsbedürfnis wie das besondere Interesse Englands an seiner Sprache, der Weltsprache, erkennen. 
dual- und gar Privatunternehmen existierte. Hochrechnungen, wann es bei Fortschreibung der damaligen Verhältnisse abgeschlossen sein könnte, endeten in nackter Verzweiflung. Die schon seit den siebziger Jahren avisierte Möglichkeit, nach Festlegung der Konzeption und Vorlage eines fertigen Bandes lexikographisch interessierte Autoren zur Bearbeitung anderer Bände zu motivieren, führte zwar zum Abschluss von entsprechenden Verträgen, scheiterte aber mit jeweils akzeptablen Gründen teils schon vor Aufnahme der Arbeit, spätestens bei der zeitund interpretationsaufwendigen Gewinnung und Annotation der Belege. Lediglich folgende Ausnahmen sind zu erwähnen: Vibeke Winge (Kopenhagen) erarbeitete auf rein privater Basis sowohl Teile ihrer Belegmenge wie auch jeden Einzelartikel eines ganzen Bandes (Band 8, $i$ - bis kuzkappe; 1980 Spalten) bis in die letzte Formulierung hinein ohne jede finanzielle Unterstützung. Sie ist noch heute aktiv an der Vervollständigung der onomasiologischen Vernetzung der einzelnen Bedeutungsansätze beteiligt (im Rahmen der Digitalisierung der semantischen Netzwerke seit 2013). Jede Danksagung greift hier zu kurz. Ähnliches gilt für die private Weiterarbeit von Joachim Schildt nach seinem Eintritt in den Ruhestand; er ist der Verfasser der (privat erstellten) 2. Lieferung (gegensichtig bis gerecht; 512 Spalten) von Band 6. Eine Münsteraner/Hallenser Arbeitsgruppe (bestehend aus M. Denkler, D. Hüpper, O. Pfefferkorn, J. Macha, H. J. Solms) schrieb die erste Lieferung von Band 5; auch ihr sei hiermit gedankt.

Obwohl die Weiterarbeit am FWB in dieser Situation ernsthaft in Frage stand, wurde es in der wissenschaftlichen Öffentlichkeit doch als existent wahrgenommen und als relevant beurteilt, obwohl sich bis heute niemand an eine detaillierte und wissenschaftlich begründete Rezension herangewagt hat. Auffallend war jedenfalls, dass man es nicht mehr wie Ende der siebziger und in den beginnenden achtziger Jahren auch von ,offizieller' Seite mitleidig als Phantom belächelte oder dass man es wie nach dem Erscheinen der ersten beiden Lieferungen nicht mehr mit nur interessierter Aufmerksamkeit betrachtete, sondern es als neuartig, außerdem offensichtlich realisierbar und seinen Abschluss als absolut wünschenswert betrachtete. Jedenfalls häuften sich Anregungen von verschiedenen Seiten, darunter von Seiten der damaligen Leitung des Instituts für deutsche Sprache (IdS), den unmittelbar anstehenden wunden Punkt jeder weiteren Erarbeitung, nämlich die Corpusexzerption, auf das gesamte Alphabet auszudehnen. Da die Deutsche Forschungsgemeinschaft (= DFG) keine Langfristprojekte mehr förderte, sich aber für eine Anschubfinanzierung offen erklärte, kam es zu Empfehlungen der Art, ich solle doch einen Antrag auf eine Zentralexzerption stellen und bei deren erfolgreichem Abschluss über eine Zusammenarbeit mit dem IdS nachdenken. Der Antrag wurde formuliert und genehmigt: Das FWB erhielt für 8 Jahre die Stelle eines wissenschaftlichen Mitarbeiters zur Planung, Leitung und Kontrolle der Exzerption und genau die Anzahl an Hilfskraftstellen, die nach meinen Erfahrungen mit Exzerptionen und deren Annotierung als ausreichend errechnet worden war und sich in der Praxis als ausreichend erwiesen hatte. Arbeitsort war die Universität Heidel- 
berg, was bedeutet, dass sie bis heute über eine Reihe von Rechten über das Material verfügt. $\mathrm{Zu}$ dieser Bindung an die Ruperto Carola gehört auch, dass ich die Hilfskräfte der Zentralexzerption aus meinen Lehrveranstaltungen anwerben und damit ihre germanistische Ausbildung ergänzen konnte. Eine kurze Anschlussfinanzierung durch die DFG ermöglichte die hinreichende Korrektur der oben angesprochenen Idiotismenlastigkeit (S. 282) der Ausgabenglossare. Es war diese Unterstützung, die die Arbeit am FWB unter den Stern stellte, in der Tat einmal abgeschlossen werden zu können. Die Arbeitsgrundlage lautete von nun an: Es liegt eine hinreichende Menge von Exzerpten vor, das Werk zu Ende zu führen. Das heißt, dass man bei der Abfassung eines beliebigen Artikels, sagen wir mal: oberkeit, offenbarung oder recht, alle Belege mit kontextgestützten Annotationen in Karteiform vor sich liegen hat und sie nicht erst - auf welche Weise auch immer - aus einem Corpus gewinnen muss, das man sich möglicherweise vorher selbst als unbearbeitbar umfangreich aufgebaut hat. Man könnte also von „Herunterschreiben“ reden, wenn man diesen Ausdruck seiner negativen Konnotationen entkleiden würde. Eine arbeitstechnische lexikographische Einsicht könnte lauten: Lexikographie bedarf bereits für die Corpuserstellung und für seine Exzerption eines textgeschichtlichen Bildungsfundamentes, einer längeren semantikgeschichtlichen Unterfütterung, eines historisch-semantischen Arbeitsklimas, wie dies alles nur die universitäre Einbettung, nicht irgendein kurzfristiger Blockkurs, zu liefern vermag. Sie bedarf des weiteren einer zielgerichteten mitarbeitenden Leitung, nicht eines sog. Machers, der die Weichen ohne genaue Kenntnis des Arbeitsfeldes und ohne die Erfahrungen der eigenen Mitarbeit zu stellen versucht. Die zentralen Arbeitsphasen der über Technisches hinausgehenden Corpusexzerption und der anschließenden Artikelredaktion sollte sich auf gewisse personale Konstanten und anhaltende Interessen verlassen können.

\section{Die innere Geschichte und ihre Ergebnisse}

An dieser Stelle sei der Fokus des Berichtes kurz auf einige der Auswirkungen gerichtet, die sich aus der lexikographischen Praxis und der diese fortwährend begleitenden sprach- und speziell lexiktheoretischen Reflexion ergaben. Ich bezeichne dies hier mal als „innere“ Planung des Wörterbuches.

Die Festlegung des Umfangs auf drei Bände (Lexer-Vorbild) erwies sich aus dem Arbeitsprozess heraus als zunehmend illusorisch und schon bald auch als nicht mehr erstrebenswert; sie wurde deshalb bereits während der Arbeit am ersten Band aufgegeben. Dies hatte mehrere Gründe.

Einer der Gründe ergab sich daraus, dass man (mit man ist auch eine Hilfskraft gemeint) bei der Exzerption der Quellentexte schleichend ein ursprünglich nicht intendiertes Interesse am Corpustext gewinnt; Interesse wächst eben der Tätigkeit nach. Dies ist insbesondere dann der Fall, wenn man durch arbeitsmethodische 
Tricks die Punktualität der Ausgabenglossare in die Linearität der Exzerption überleitet und damit den Text als Ganzheit erlebt. Wenn man etwa die Anfangszeilen des Iwein (swer an rehte güete wendet sin gemüete, dem volget saelde und êre) oder des Parzifal (ist zwîvel herzen nachgebûr, daz muoz der sêle werden sûr) isoliert liest, dann wird man zu nur vagen und lexikographisch kaum verwendbaren semantischen Aussagen über die in Frage stehenden Wörter kommen, also zu (mhd. normalisiert) rëcht, güete, gemüete usw. Rücken diese Ausdrücke in den Gesamtzusammenhang des Textes, etwa wenn an späteren Stellen lexikalische Wiederaufgriffe begegnen, dann erschließen sich Kennwörter und Kennsemantiken des in diesem Falle Mittelhochdeutschen. Die quantitativ messbare Folge sind länger geschnittene Exzerpte und detailliertere Annotationen, die qualitative Folge ist die zunehmende textliche und semantikgeschichtliche Qualifikation der Exzerpierenden. Daraus entwickelt sich allmählich auch beim Artikelredaktor und in der Arbeitsstelle die Haltung, die immer wieder verblüffende semantische Feinfühligkeit der auch studentischen Exzerptannotationen im Wörterbuchartikel zum Ausdruck zu bringen. Das kostet Beschreibungsraum; Lexer kann unter diesem Aspekt kein Vorbild mehr sein. Vielmehr gilt, deutlich formuliert: Wörterbücher, die mhd. güete oder frnhd. gnade, barmherzigkeit, recht, oberkeit mittels eines nhd. Synonyms erklären zu können meinen, haben wir in Fülle. Wir brauchen anders ausgerichtete Werke.

Damit komme ich zum Thema ,Differenzlexikographie‘. Semantische Differenzen gehören zum Seinsstatus sprachlicher Tätigkeit bis in jede sprachliche Einzelsituation. Lexikographisch relevant werden sie synchron (z. B. innerfrühneuhochdeutsch) dann, wenn sie eine soziale Dimension nach Raum, Zeit, Gruppe, Schicht, Situationstyp erhalten, wenn also etwa glaube oder werk im katholischen Raum anders semantisiert wird als im protestantischen. Ein Wörterbuch hat Differenzen dieser Art tendenziell zwar nicht bis zum Einzeltext hin zu verfolgen (das wäre Aufgabe der Literaturwissenschaft bzw. gar eines Stellenkommentars), sie aber doch so zu dokumentieren, dass man als Wörterbuchbenutzer erkennen kann, wie unterschiedlich man im Beispielfall die Beziehung zu Gott semantisiert, faktisiert usw. und entsprechend handelt, generell gesprochen, wie man seine Sprachwelt (im weitesten, auch die Glaubenswelt einbeziehenden Sinne) lexikalisch einrichtet. Der systematische Ort, dies zu realisieren, ist die Bedeutungserläuterung, de facto sind es die einzelnen Bedeutungsansätze in ihrem Zusammenhang. Die Synonymenangabe ist dabei von ihrer kategorialen Leistung her ausgeschlossen; damit bleibt die phrastische Formulierung als eigentliche Möglichkeit einer synchron differenzbezogenen Erläuterung, und zwar bis zu jeder Nuance hin. Im übrigen gibt es auch noch die Position ,Syntagmen' sowie die Belege, die jeweils ebenfalls an den Einzelansatz adressiert sind und idealer Weise genau diejenige Feinheit zu erfassen erlauben, die dem Lexikographen als relevant erscheint.

Neben der geschichtlich-synchronen Varianz (also der z. B. innerfrühneuhochdeutschen) gibt es die diachrone Variante: Sie besteht darin, dass man die semantische Differenz zwischen einem geschichtlichen Zeichen und einem semantisch 
entsprechenden, oft gestaltgleichen Zeichen der Beschreibungssprache besonders heraushebt, also Vorkehrungen trifft, die stärkeren religiös, sozial, rechtlich begründeten Bedeutungskomponenten von z. B. frnhd. abenteuer oder arbeit gegenüber nhd. Abenteuer oder Arbeit bewusst zu machen.

Zur inneren Geschichte eines Wörterbuches gehört natürlich auch die Gewichtung und sprachgeschichtstheoretische Einordnung der zugrundeliegenden lexikographischen Theorie oder gar Philosophie. Damit ist ein außerordentlich umfänglicher und vielschichtiger Problemkomplex angesprochen. Zunächst ist an das oben genannte (bzw. suggerierte) geschichtliche Nacheinander von objektartig gedachten Sachen, soziomorphen Sachbildern (Gestaltungen, Fiktionen, Vorgaben usw. als Basis für folgende Sachprojektionen), an das Reden von Sachinhalten und soziokognitiven Inhalten (Kopfinhalten) und wie auch immer verstandenen Handlungssemantiken zu erinnern. Diese Gegebenheiten stehen nicht nur in einer Geschichtslinie (= Zeitlinie), sondern existieren im Sinne der Gleichzeitigkeit des Ungleichzeitigen verkappt oder offen - auch synchron nebeneinander pro Geschichtszeit im Kopf des Lexikographen. Das alles muss sich - ob bewusst oder unbewusst - in der Art der Bedeutungsformulierung niederschlagen. Selbst im Grammatisch-kritischen Wörterbuch des Aufklärers J. Chr. Adelung (1793) wimmelt es bekanntlich von Bewertungen, die als implizierte Handlungsempfehlungen gelesen werden können, so wie man umgekehrt in Grimms DWB rationalistische Elemente findet. In dem Maße, in dem Wissenschaft sich durch Selbstreflexion auszeichnet, steht lexikographische Tätigkeit also immer unter sprachtheoretischen und -philosophischen Vorgaben, die, ohne direkt ausgesagt worden $\mathrm{zu}$ sein, in den Beschreibungsformen erkennbar sind und aus denen sich eigene Entscheidungen herleiten, sowohl begründen wie verwerfen lassen. Außerdem haben Wörterbücher neben ihrem wissenschaftlichen Erkenntniszweck und ihrem pädagogischen Handlungszweck auch ganz praktische kulturpädagogische und grundwissenschaftliche Aufgaben als Nachschlagewerke selbst für punktuelle Verständnisfragen, auf die sie Antworten anbieten müssen. Die damit angesprochenen Entscheidungen hängen von vielen Bedingungen lexikographischer Arbeit und auch vom theoretischen Erkenntnis-, Einsichts- und Wollensstand der Wörterbuchleitung ab. Nochmals erschwerend kommt hinzu, dass bestimmte sprachtheoretische Aussagen, wie etwa das Verständnis des Sprechens als verbalsymbolische Handlung, sich im Laufe von einigen Jahrzehnten erheblich ändern können, darunter auch im Kopf des einzelnen Lexikographen. Für die seit den siebziger Jahren florierende Handlungsauffassung (Stichwort: pragmatische Wende) könnte das etwa wie folgt gelten (und damit werde ich wieder biographisch): zunächst leicht abschätzige Beurteilung als irgendwie interessant, aber mit dem herrschenden Languebezug der Sprachwissenschaft schwer vereinbar, dann allmähliche Entwicklung zunehmenden Interesses an der Handlungstheorie (vor allem aufgrund der neuen Gewichtung des Sprechens gegenüber der Systemhaftigkeit der Sprache), danach möglicherweise Auffassung des sprachlichen Handelns als Stein der Weisen und zum Schluss ein Nachdenken darüber, ob man nicht alle weiteren Funktionen des 
Sprechens als Handeln begreifen könne, dieses damit zum Orientierungspunkt der gesamten Sprachtheorie und aller ihrer Einzeldisziplinen erheben sollte. Was in dieser Formulierung aus Darstellungsgründen in eine Zeitlinie gestellt wurde, ist in Wirklichkeit natürlich eher ein fortwährendes Oszillieren des Einen neben dem Anderen, zeitweilig sicher auch über dem Anderen. Es gibt also eher ein fortwährendes Schwirren der Auffassungen mit jeweils wechselnder Gültigkeit als endgültige Festlegungen.

Für mich gilt dies in folgender Weise: Ich war mir der dargestellten Problematik seit Beginn der praktischen Arbeit in den frühen achtziger Jahren voll bewusst, tendierte aber zu einer Reihe von Gewichtungen:

(1) Die Darstellungsleistung der Sprache ist neutral anzuerkennen, und zwar in dem Sinne: Es „gibt“ ${ }^{17}$ nun mal - naiv realistisch gesprochen - vorsprachlich und vorkognitiv diskret vorhandene Sachen und dementsprechend schwer bestreitbare begriffliche Gegenstände; diese müssen lexikalisch bezeichnet und von anderen klar bis deutlich abgegrenzt werden. Und es „gibt“ ebenfalls - wieder bei naiv realistischer Vorgabe - Verknüpfungen der so angenommenen Sachen zu Sachverhalten, die ebenfalls zu bezeichnen sind, womit man - bei hinreichender Gewichtung des Gesamtsystems Lexik - beim Strukturalismus wäre. Mit diesem Ausdruck ist eine der zentralen und neuen Aufgaben des historischen Bedeutungswörterbuches während der gesamten Zeit der Bearbeitung des FWB genannt: der Einbezug der Systemhaftigkeit ${ }^{18}$ des Wortschatzes in seine lexikographische Behandlung. In diese gerade mit Strukturalismus im Sinne von Systemhaftigkeit terminologisierte Auffassung brechen zwei Entwicklungen ein, die sich als geradezu konstitutionell bedeutsam für die Lexikographie erweisen könnten. Das ist zum ersten die Informationstechnologie, die dem Wortschatz Ordnungszüge zu verleihen vermag, die alles bisher Dagewesene übertreffen. ${ }^{19}$ Das sind zum zweiten sprachtheoretische Strömungen der Art, wie sie oben (S. 284) bereits mehrfach mittels der Adjektive soziokognitiv und soziomorph sowie unter dem Substantiv Soziopragmatik gefasst wurden (S. 297). Durch die nachaufklärerische Philosophie des 19. Jahrhunderts vorbereitet bestimmen sie spätestens seit den sechziger Jahren des 20. Jahrhunderts die sprachtheoretische Diskussion im deutschsprachigen Raum, wurden allerdings eher in Zeitschriften und Sammelbänden diskutiert und an Einzelfällen veranschaulicht als in den größeren, vor allem lexikographischen Unternehmen. Das alles bedeutet: Es geht einmal um technisch neue Beschreibungsmöglichkeiten hinsichtlich aller Sprachfunktionen und zum anderen um ihre Ge-

17 Die Anführungszeichen haben hier den Zweck, das „Irgendwie-Gegebensein“ aus pragmatischen Gründen erst einmal zugunsten des „Gegebenseins“ außer Betracht zu lassen.

18 Systemhaftigkeit soll die Gefügehaftigkeit, Netzhaftigheit der Wortschatzordnung andeuten, ohne die ideologischen Vorgaben vor allem des Oppositionsstrukturalismus.

19 Damit ist auch der Hintergrund der jüngsten Auseinandersetzung um die Zukunft der historischen Bedeutungslexikographie angedeutet; vgl. A. Kirkness mit seinen Bezugstexten. 
wichtung untereinander, wobei dieses Untereinander auch ein Gegeneinander von Darstellung einerseits und Soziopragmatik andererseits sein kann.

Angesichts einer solchen Konstellation kommt es darauf an, ob man die neuen Vorgaben als solche irgendwie akzeptiert und ihre Irgendwie-Beachtung fordert (wie gerade oben gesagt: auf „Einzelfälle“ bezieht) oder ob man sie in einem Wörterbuch (bzw. in einer Grammatik oder einem Wortbildungsvorhaben) zum theoretischen Orientierungspunkt über die volle Breite des Materials erhebt. Letzteres würde zu entscheidenden Weichenstellungen führen: Man könnte die Sicht des Gegenstandes unter weitestgehend neue Aspekte stellen und dabei den alten Gegenstand in gewisser Weise aufgeben; man würde dabei den eingefahrenen, naiv realistischen Sockel einem neuen Behandlungstyp unterwerfen oder ihn gar durch neue Redeweisen ersetzen; dies würde auf die Neukonstitution des Sockels hinauslaufen. Man realisiere sich: Da gibt es einen Lexikographen alter Art; dieser hat seine Sozialisierung auf einem Fundament jahrhundertealter fester Einheiten und Regelwerke (metaphorisch: Uhrwerke, so passim in der Aufklärung) erfahren; diese sind von vorsprachlich und vorkognitiv gedachten Sachen abgeleitet, auch in begrifflicher Repräsentation sachbezüglich; sogar die Regeln zu ihrer Verknüpfung entsprechen den Sachbezügen (also der sog. natürlichen Ordnung im Großen, den Sachverhalten im Detail); es herrscht die Auffassung maximaler Erkenntnissicherheit auf anthropologischer Basis. Und nun gibt es eine als Wende aufgefasste weltanschauliche Richtung (eben die Soziopragmatik), in der bedeutungskonstitutive bzw. handlungsbezogene Aspekte, fortwährende Innovation, laufende Experimente, sprachontische Verläufe und Übergängigkeiten aller Art in den Mittelpunkt der Aufmerksamkeit rücken. Ausdrücke wie linguistic turn und pragmatische Wende bringen den Umschlag auf den Punkt. Diese Werdens-, Gestaltens-, Flussgegebenheiten wären dann nicht mehr nur dichterische Freiheiten, Lizenzen am Rande eines Regelsystems, die bezeichnenderweise nur e contrario von diesem her denkbar sind; sondern sie werden zur Basis, auf der sich die eigentliche Seinsweise sprachlicher Tätigkeit zu entfalten vermag. Die Erkenntnissicherheit würde einer allseitigen Relativität weichen; die strikte Regel würde zur Randerscheinung; der (alte) Grammatiker würde sich seines (alten) Gegenstandes selbst enteignen. Die Problematik stellt sich verstärkt für die historische Bedeutungslexikographie, jedenfalls stärker als für die Bezeichnungslexikographie.

(2) Es wundert wohl nicht, dass ich hier anschließe: Noch bedeutsamer als jedenfalls die Darstellungsfunktion erschien mir seit jeher die kognitive Funktion (als eine der soziopragmatischen Funktionen) der Sprache, bestehend darin, dass man sich seine Gegenstände im Sprechen gleichsam als Verhandlungsgrundlage so gestaltet, wie man sie gerade braucht, die Sprechenden also zu Bildnern je verschiedener, und zwar immer sozial (nicht nationalsprachlich) gedachter Art erhebt. Das Wörterbuch hat folglich die Aufgabe, diesen Prozess wissenschaftlich ernst zu nehmen, womit der Lexikograph natürlich in die Pflicht kommt, sowohl die synchron wie die diachron gesehene Differenzkomponente von Wörterbüchern stärker zu betonen, als es bei der Bezeichnung und Beschreibung von 
Wörtern und (tendenziell konstanten) Sachen oder von Begriffen im Sinne von (1) notwendig ist.

(3) Die Handlungskomponente als weitere Komponente des Sprechens schien mir bis weit in die neunziger Jahre eher im Sinne instrumentellen Handelns zu verstehen zu sein und damit im Zusammenhang mit der Darstellungsfunktion beschrieben werden zu können. In einem bis heute anhaltenden Prozess des Umdenkens erhielt die sprachliche Handlung aber zunehmendes Gewicht, und zwar als verbalsymbolische Interaktion (Kommunikation) eines Sprechers mit einem ebenfalls, am besten als gleichberechtigt verstandenen Hörer, der nicht nur reaktiv tätig ist. Es geht letztlich, hier noch einmal zugespitzt formuliert, um die Frage: Sieht man den Menschen phylo- und ontogenetisch als ein Wesen, das grundsätzlich durch die artspezifische Besonderheit bestimmt ist $\mathrm{zu}$ handeln? Dann stünde die Bildung kognitiver Einheiten im Sprechen in der Abhängigkeit des (hier: kommunikativpartnerbezogenen) Handelns. Oder sieht man (umgekehrt) den Menschen phylound ontogenetisch als ein Wesen, das durch die artspezifische Besonderheit bestimmt ist, sich kognitive Einheiten bilden zu können und dies gerade im Sprechen auch fortwährend zu vollziehen? In diesem Falle stünde das Handeln in der Abhängigkeit von vorgängigem Erkennen. Ins Lexikographische übersetzt heißt das: ,Ist“ Bedeutung bei aller Betonung ihres Werdens eine kognitiv bestimmte Größe (bzw.: fasst man sie als solche auf)? Oder ,ist‘ Bedeutung ebenfalls bei aller Betonung ihres Werdens eine handlungsbestimmte Größe (bzw.: fasst man sie als solche auf)? Jede dieser Entscheidungen muss sich bereits quantitativ, stärker noch qualitativ im Wörterbuchartikel niederschlagen. Dies gilt nicht nur für substantivische Ausdrucksfelder (etwa des Sozialbereiches; von herre und knecht über arbeit, nachbar, gewonheit bis zu liebe und minne), sondern auch für Adjektive oder Modalpartikeln. In einem strengen Sinne steht die soziokognitiv gestaltende Komponente wie die soziale Handlungskomponente jedes Stichwortes als Frage an, von der Modalpartikel bis hin zu frnhd. got. - Richtig kompliziert wird es dann erst, wenn man bedenkt, dass auch der Lexikograph kognitiv Gestaltender und als Handelnder auftritt, beides auch mit dem Blick auf seine Rezipienten (s. dazu die obigen Aussagen über Differenzlexikographie, S. 295 f.).

(4) Mit dem Vorgetragenen werden Unterschiede in der Handlungsinstruktion, die ein Ausdruck enthält, nicht geleugnet. Für geräme >Balkengerüst< oder geräsp $>$ von Weinreben abgeschnittener Trieb< wird man von vorneherein weniger Handlungswert erwarten als für z. B. gerechtigkeit. Selbst verschiedene Bedeutungsansätze eines einzigen Stichwortes unterscheiden sich unter Handlungsaspekten: gerecht im vertikalen Sinne von >gerade, aufrecht< ist zweifellos weniger handlungsrelevant als im Sinne von >rechtlich korrekt, ehrenwert< (als Charaktereigenschaft) und in anderer Weise handlungsrelevant (oder -irrelevant) als gerecht im protestantischen Sinne von >gerecht vor Gott<.

(5) Zur weiteren Einsicht in die Komplexität der Verhältnisse sei noch in Erinnerung gerufen, dass es mindestens eine Unterscheidung zwischen instrumentalem 
Handeln (einem Handeln mit und gegenüber Gegenständen) und reziprok partnerbezogenem Handeln gibt, ohne dass diese Unterscheidung oppositiver Natur wäre.

(6) Der Vollständigkeit halber sei außerdem angefügt, dass mit alledem auch noch die Symptomfunktion im Spiel ist (vgl. auch S. 301 und 305). Sie besteht darin, sich durch die Art des Sprechens, das heißt auch: durch die Art der Inhaltsbildung und deren Ergebnis als gruppenzugehörig zu erkennen zu geben. Sie ist mir seit meinem Studium in Marburg infolge meiner alten Verbindung zum Deutschen Sprachatlas ein bleibendes Anliegen, in vorliegendem Zusammenhang allerdings nur in einer auf die historische Bedeutungslexikographie angewandten Form. Es geht also nicht darum, ob man sich etwa durch den Gebrauch von Star bzw. Spree als Hochsprachesprecher bzw. als Dialektsprecher (aus einer westlich gelegenen Landschaft des deutschsprachigen Raumes; s. Karte ,Star' des DWA) kennzeichnet, sondern darum, dass man sich durch die Weise des Sprechens (und Schreibens) über gerechtigkeit, glaube, kirche, sünde als Protestant bzw. Katholik zu erkennen gibt.

(7) Hinsichtlich der Auswirkungen der gerade diskutierten Fragen auf die historische Lexikographie ist stets im Bewusstsein zu halten, dass rund 100.000 lexikalische Ausdrücke mit systematisch mehreren Bedeutungen nicht eine bloße Copia isolierter Einheiten bilden können, sondern als in irgendeiner Weise zusammenhängend beschrieben und vermittelt werden müssen. Dass es dabei einerseits unterschiedlich stark systemorientierte Auffassungen (teils mit der Annahme von Oppositionen auch in der Semantik) und andererseits eher Haltungen mit isolationistischen Elementen gibt, ist nicht weiter verwunderlich. Für die hier vertretene Lexikographie kann nur eine Behandlung in Frage kommen, die im Lexikon einer Sprache innere Ordnungsverhältnisse erkennt und diese nach bestimmten Kriterien zu beschreiben versucht. Infolge des primären Bezuges des FWB auf die Semantik ist von vorneherein klar, dass alle Aussagen auf Beleginterpretationen und deren In-Bezug-Setzung beruhen, also durchaus auch anders hätten vorgenommen werden können. Ebenso klar dürfte sein, dass jede lexikographische Beschreibung dazu tendiert, die jeweiligen Unterscheidungen bereits dadurch zu verstärken, dass sie vorgenommen und in je eigenen Beschreibungspositionen abgehandelt werden.

Als die vornehmsten Positionen, die der Vernetzung gewidmet sind, kommen in Betracht (zunächst als Aufzählung):

- das semasiologische Feld: Es beruht darauf, dass jede Bedeutung (im Sinne von Signifikat, Gesamtbedeutung) eines Wortes als untergliedert gedacht werden kann und sollte; dies kann mehr oder weniger differenziert erfolgen. Der so zustande kommende Bedeutungsansatz (auch Einzelbedeutung, Semem genannt), ist zeicheninterner Art und vielfach begründbar.

- das onomasiologische Feld (oft einfach Wortfeld genannt, im Deutschen auch als Triersches Feld bezeichnet; s. Trier 1931): Es ergibt sich daraus, dass systematisch zu jedem Semem des semasiologischen Feldes, also sememadressiert, 
(partielle Synonyme) angegeben werden. Da zwischen ,synonym‘, ,partiell synonym ' und ,nicht synonym ' nicht einmal klar, geschweige denn deutlich ${ }^{20}$ unterschieden werden kann, entscheidet der Lexikograph über die Grenzen des onomasiologischen Feldes. Die Relationen zwischen Semem und Synonym sind zeichenübergreifender Art: von Bedeutungsansatz $>1<$ eines Stichwortes $w$ z. B. zu Bedeutungsansatz $>\mathrm{n}<$ eines Stichwortes $x$.

- die Wortbildungshinweise, ebenfalls sememadressiert: Sie geben insbesondere für Komposita (teils für andere Wortbildungseinheiten) an, auf welches Semem eines anderen Lemmazeichens das Kompositum motivationell bezogen werden kann. Im Einzelnen bestehen verschiedene Regelungen, die der Komplexität auch dieser Verhältnisse gerecht zu werden versuchen.

Das soeben unter den Punkten (1) bis (7) Vorgetragene sei stichwortartig wie folgt in die Linie meiner Gewichtungen gestellt: $\mathrm{Zu}$ Beginn meiner lexikographischen Tätigkeit eher Betonung der Darstellungsfunktion, danach besondere Heraushebung der Erkenntnis- und zunehmend auch der Handlungsfunktion; relativ konstant bleibende Rolle der Symptomfunktion; ebenfalls seit Beginn meiner Tätigkeit hohe Gewichtung der Netzstruktur des Wortschatzes, dies theoretisch anfangs eher strukturalistisch, später zunehmend kognitions- und handlungsfunktional gesteuert. Hinzugefügt sei, dass die im Vorangehenden erfolgte Gegen- und teilweise Nebeneinanderstellung von Kognitions- und Handlungsfunktion mehr der darstellerischen Übersicht entsprang als einer ,sachlichen' Gegensätzlichkeit: Vielmehr ist sprachliches Erkennen immer auch Handlung; und sprachliches Handeln ist immer auch Erkennen. Dennoch ist die Unterscheidung analytisch notwendig und praktisch lexikographisch als Gegenstandsaspekt im Auge zu behalten. Die erkenntnistheoretisch hoch brisante Frage nach der Priorität des Einen gegenüber dem Anderen verliert bei dieser Sicht ihre Sprengkraft.

Spätestens hier sei die Diskussion der theoretischen Grundlegung des historischen Bedeutungswörterbuches FWB abgebrochen. Sie ist deshalb relativ ausführlich vorgetragen worden, weil ich in der verbreiteten Theorieabstinenz vieler Sprachstadienwörterbücher des Deutschen einen der Gründe für ihren Bedeutungsverlust sehe: In dem Maße, indem man darauf verzichtet, sich fortwährend auf die eigenen theoretischen Vorgaben (auch verstanden als kulturpädagogische Glaubensinhalte) zu besinnen und diese mit den Interessen möglicher Rezeptionsgruppen abzugleichen, verliert man zwar nicht seine positivistisch verstandene inhaltliche Stoßrichtung, wohl aber die eigene Mission und den interessierten Rezipienten. Noch provokativer, überspitzter und zugleich mit Sorge ausgedrückt heißt das: Wenn man sich über Generationen damit befasst, anhand unbearbeitbarer Materialmengen jedes jedermann kalt lassende Faktendetail möglichst unübersicht-

20 Mit diesem Adjektivpaar ist die alte rationalistische Unterscheidung gemeint: klar heißt >von anderem unterscheidbar<, deutlich heißt: >in der Lage, die Gründe dafür angeben zu können< (vgl. Reichmann 1996). 
lich, in vielbändigen Wälzern und überdrehtem Fachstil sowie in eingefahrenen Tradition zu beschreiben, mag man zwar seine Gelehrsamkeit - etwa im Sinne der archivalischen Geschichtsschreibung Friedrich Nietzsches - zur Schau stellen, man mag auch die hohe Rolle des Wörterbuches als Nachschlagewerk für bloß punktuelle Wissensfragen sichern, klinkt sich aber aus der eben auch bestehenden jeweils gegenwärtigen Aufgabe (und Existenzgrundlage) der historischen Geistesund Sozialwissenschaften aus, einen Beitrag zum kulturellen Gesicht der Rezeptionsgesellschaft zu leisten. Mit der Betonung der Kognitions- und Handlungsfunktion meine ich meine alte Absicht wachhalten zu können, Bedeutungen so zu beschreiben, dass sich Kulturhistoriker aller Sparten darin angesprochen fühlen. Das alte rhetorische tua res agitur gilt auch 500 oder 1000 Jahre später noch.

\section{Veranschaulichung an einem Beispiel}

Die obige Abb. 2 (S. 288), formuliert 1985, erschienen 1986, betreffend das Lemma abrede in Bedeutungsansatz 2, diene als Beispiel für den anfänglichen Theoriestand und die daraus resultierende Gestalt des Artikels. Realisiert sind folgende Beschreibungspositionen: das Lemma in Normalform, morphologische Angaben zu Genus und Flexion, 7 Bedeutungsansätze; speziell zu Ansatz 2 ein wortbildungsmorphologischer Hinweis, ein onomasiologisches Feld mit 5 (partiellen) Synonymen, 7 Syntagmenangaben, 1 Wortbildung, 5 Belege, 8 Belegstellenangaben. Die Tatsache, dass die Synonyme ohne Bedeutungsindikator stehen, ergibt sich daraus, dass diese Ausdrücke damals noch nicht behandelt waren (in der OnlineVersion ist dies inzwischen geleistet; soweit die jeweilige Strecke bearbeitet ist). Weiteres, bereits oben Gesagtes, wird hier nicht wiederholt. - In vorliegendem Zusammenhang bleibt zu bemerken:

Ansatz 2 des Stichwortes hat einen Umfang, der - gemessen an seinem Sitz im damaligen Sozialleben - als relativ gering erscheint (dafür gibt es arbeitstechnische Gründe).

Die Bedeutungserläuterung besteht aus 4 (partiellen) Synonymen. Auch die als „speziell“ charakterisierte Nuance $>$ Heiratsabsprache $<$ hat eine synonymische Basis, setzt insofern die oben (S. 285) als aufklärerisch beurteilte Gleichheit der Bezugsgegebenheit von frnhd. ,abrede“ mit nhd. ,Absprache [...]' voraus. Sie stellt diese allerdings gleich wieder dadurch in Frage, dass mehrere Synonyme und für die Spezialisierung ein durchsichtiges Kompositum, eben Heiratsabsprache, gebraucht wird. Die Brücke zur phrastischen Erläuterung deutet sich an, wird aber nicht geschlagen.

Die kognitive (semantikkonstituierende) Komponente scheint dem Lexikographen (de facto: mir) bei der Abfassung der Erläuterung auf den ersten Blick kein besonderes Anliegen gewesen zu sein; sonst hätte er es nicht bei der Häufung von Synonymen, d.h. bei dem Erläuterungstyp belassen, dessen kategoriale Leistung 
gerade darin besteht, wenn auch durch „partiell“ angetastete semantische Kongruenzen zwischen den Kulturzeiten vorauszusetzen und Inkongruenzen auszublenden. Dennoch fällt auf, dass drei der sechs gebrauchten Synonyme Verbalabstrakta mit der Endung -ung und die beiden anderen, nämlich Absprache (zweimal) und Vertrag, ebenfalls Verbableitungen sind, und zwar hochgradig durchsichtige. Entsprechend ausgerichtet sind die Angaben zur onomasiologischen Vernetzung, also etwa beschlus oder vergleichung. Wenn man darin einen gewissen Zeichenwert zu erkennen in der Lage und bereit ist, könnte man folgern: Es geht hier um das sprachliche Fixieren und teilweise Aushandeln von Zukunfts-, darunter Besitz-, Beziehungs-, Status-, zusammengefasst von Lebensentscheidungen bei der Heirat; absprache (usw.) ist dann das Resultat (genauer, wie im Artikel formuliert: die Metonymie) dieses Prozesses; und ein solches Resultat ist nun mal bei aller Konventionalität (wie man sagt: per se, qualitate qua) ein je besonderes kognitives Konstitut, ein einmaliger Wurf der Vertragspartner (bzw. deren Vertreter) für die gesamte Zukunft. Die lexikographische Lehre würde demnach lauten: Es muss nicht unbedingt eine phrastische Erläuterung sein, mit der die kognitive Seite des Stichwortes ausgeleuchtet wird. Es kann auch die Synonymenangabe sein, und zwar jeweils dann, wenn diese mit der Bezeichnung einer Sache deren Status als soziokognitives Konstitut (also als ,Sache') mitliefert. Ein derartiger Satz wird sich später mit Bezug auf die Handlungskomponente wiederholen. - Im übrigen wird dem kritischen Leser dieser Zeilen aufgefallen sein, dass ich mit dem Ausdruck Konstitut gemeint habe, die Kopfseite der in Frage stehenden Größe betonen zu können, dass ich aber dennoch, um jedem Missverständnis vorzubeugen, ein charakterisierendes Attribut, nämlich kognitiv, hinzugesetzt habe. Bei Argumentationen dieser Art steht man also gleichsam auf der Kippe: Man will irgendwie, z. B. kognitionsbezogen, argumentieren, unterläuft diese Argumentation aber von einem anderen Aspekt her, hier offensichtlich von der Handlungsseite her. ,Absprachen', ,Abmachungen“, ,Vereinbarungen', ,Würfe' usw. sind eben nicht nur kognitive Produkte, sondern bereits durch ihre wortbildungsmorphologische Motivation immer zugleich Handlungen.

Prüft man die zugehörigen Belege unter dem Aspekt ihrer kognitiv relevanten Nuancen, dann lässt sich höchstens anführen, dass frühneuzeitliche ,abreden“ im Sinne von vertraglichen Vereinbarungen einerseits offensichtlich nach eingefahrenen Gebrauchs- und gar nach Rechtsritualen verlaufen, damit einer gewissen sozialen Höhenlage zuzurechnen sind, dass sie andererseits und seltener zu den täglichen händeln gehören. In beiden Fällen könnte man zwar sagen, das seien die Gültigkeits- und Gelingensbedingungen von abrede 2 und diese Bedingungen seien kognitiver (speziell rechtlicher) Art. Aber man wüsste dann natürlich immer auch, dass es hier glaubwürdiger um Handlungsbedingungen geht.

Damit wäre ich bei der Frage, ob überhaupt und, falls ja, wie die Handlungskomponente von ,abrede‘ 2 im FWB zur Sprache kommt. Schon auf den ersten Blick wird deutlich, dass explizit nichts dazu ausformuliert ist. Bei näherem Hinsehen gilt aber das im vorigen Absatz Gesagte: Auch die synonymische Erläuterung (Sy- 
nonymenangabe) kann handlungstheoretisch relevante Auskunft geben, und zwar dadurch, dass sie mit der Bezeichnung einer Sache deren Handlungsaufladung mitliefert, so wie sie (s. gerade oben) die bezeichnete Sache als kognitive Größe mitlieferte. Man würde ein Semem demnach als eine bis zu diesem Zeitpunkt der Argumentation mindestens dreidimensional untrennbare Einheit von Bezeichnung einer Sache (die in Wirklichkeit Bezugssache ist), eines soziokognitiven Konstitutes und einer Handlungsinstruktion sehen können. An dieser Stelle entpuppt sich die ganze Macht (und Gewaltsamkeit) der synonymischen Bedeutungsangabe: In dem Augenblick, in dem ich - das Beispiel wechselnd - auch Ausdrücke wie frnhd. glaube mittels Glaube, Zuversicht, Vertrauen usw. erläutern zu können vermeine, sage ich dreierlei: Frnhd. ,glaube‘ ist sachlich (was immer das heißt) dasselbe wie nhd. ,Glaube، (usw.); es ist soziokognitiv dasselbe; und es enthält die gleiche Handlungsaufladung. Hier stellt sich die Frage: Wenn man über Historizität, Geschichtlichkeit, Zeitgebundenheit usw. von Semantik redet (nicht nur lexikalischer, sondern auch textlicher und aller angeblich textenthobener Semantik), wieweit kann ich dann voraussetzen, dass die genannten drei Komponenten sich in einem inneren Gleichschritt verändern? Immerhin unterscheiden sich diese drei Komponenten bereits innerzeitlich (also etwa in dem Zeitschnitt um 1520) sowohl im einzelnen wie in ihrem Zusammenspiel. Im Beispiel bleibend: ,glaube‘ eines Altgläubigen ist schon deshalb etwas deutlich Anderes als derjenige eines Neuchristen, weil er zumindest kirchlich dogmatisch (damit eher kognitiv) - in einer ganz bestimmten, eben altgläubigen Beziehung zu den Werken steht und weil seine Heilsrelevanz auch von der Kirche her begründet ist und weil er - handlungspraktisch gesehen $\mathrm{zu}$ anderen Verpflichtungen und damit z.B. zu einer anderen theologischen Begründung und gesellschaftlichen Organisation des Sozialwesens beiträgt. Zwei Denkmöglichkeiten liegen auf der Hand: Die eine würde lauten: Es geht bei allem Verständnis für analytisch sinnvolle Unterscheidungen doch um eine Einheit, die folglich auch nur als Einheit im Geschichtsverlauf steht. Die zweite würde bei aller Anerkennung der Einheit betonen, dass die Komponenten ihre Geschichtlichkeit in je eigener Weise entwickeln, etwa auseinanderdriften. Ich selbst neige, auch infolge meiner theoretischen Vorannahmen, zur zweitgenannten Auffassung: Jede Bedeutungskomponente steht in je eigener Weise in der Geschichte, die kognitive also anders als die handlungsbezügliche. Die sich von daher stellende Aufgabe für die Lexikographie liegt auf der Hand.

Nun zur Prüfung des Artikels: Die Informationsposition ,Syntagmen“ besteht mit tun, volziehen, beschehen (usw.), auch mit dem attributiv gebrauchten Part. Prät. abgefertigt mehrheitlich aus Handlungsverben. Das spricht eher für das Verständnis von ,abrede، als Handlungsinstruktion wie als kognitive Größe (s. wieder die diesbezügliche Diskussion gerade oben). Höchstens in brief der abrede kann abrede (genitivus explicativus oder objectivus) als statisch gedachtes Resultat einer Handlung gelesen werden, aber selbst dabei wird man seine Zweifel haben. An dieser Stelle sei mir die Frage erlaubt, ob es in der modernen Rechtswissenschaft 
(in Theorie und Praxis) eine Diskussion über die Gewichtung von Kognition und Handlung in Sememen des Typs abrede 2 oder glaube gibt und zu welchen Ergebnissen sie tendiert. - Die Position ,Belege‘ führt zu einem Ergebnis, das demjenigen der Syntagmenanalyse entspricht: Es geht in jedem Fall um ein Handeln, und zwar mit einer Ausnahme (s. den Beleg Löscher) um ein Handeln, in dem Daten angegeben, mitgestaltende Teilnehmer vorausgesetzt, Mitteilungen vorgenommen, Personen als Betroffene erwähnt werden und einmal sogar die hohe Gesellschaft eines personalstaatlich organisierten Verfassungssystems im Spiel ist. Das sind genau die Gegebenheiten, die rechtsrelevantes Sprechen konstituieren. Damit entpuppt sich abrede 2 zwar als Metonymie, aber als eine solche, die die Handlungszüge ihres Werdens erkennen lässt. - Dies alles zusammenfassend: den Wortschatz als Konstituente sprachlichen Handelns zu beschreiben, lag in den achtziger Jahren zwar in meinem Horizont, realisierte sich aber eher implizit in den Kommentaren, in Syntagmenangaben und in den Belegen.

\section{Zur zweiten Phase der Arbeit: Äußeres}

Ich lasse diese Phase mit dem Abschluss der Zentralexzerption im Jahre 1999 beginnen und mit dem Jahre 2013, also mit der Verlegung des Vorhabens an die Akademie der Wissenschaften zu Göttingen, enden. Großzügige zeitliche Übergänge seien bei dieser Terminierung vorausgesetzt. Die Göttinger Phase setzt, dies sei hier schon mitgeteilt, die Überlegungen und Entscheidungen der vorangegangenen Jahre fort und überträgt sie in die Praxis. Ihre Trägerschaft liegt bei der Arbeitsstelle (abgesehen von meinem eigenen Beitrag zur Streckenarbeit).

Die stillschweigende Absicht und Genehmigungsvoraussetzung bei der Beantragung der Zentralexzerption (also 1990; s. S. 293 f.) lautete (freilich ohne so dokumentiert zu sein): Da die Deutsche Forschungsgemeinschaft (DFG) keine Langfristprojekte mehr finanzieren kann, stellen Sie (gemeint ist der Hauptherausgeber als Ordinarius der Universität Heidelberg in Verbindung mit dem Institut für deutsche Sprache) einen diesbezüglichen Antrag; dieser wird als Anlauffinanzierung betrachtet; danach ist die DFG aus der Pflicht; die Zentralexzerption wird im Falle ihrer Genehmigung an der Universität Heidelberg erfolgen (und erfolgte dort); die Streckenarbeit übernimmt das IdS (in Mannheim), dies bei selbstverständlich vorausgesetzter aktiver Beteiligung des Hauptherausgebers und unter seiner wissenschaftlichen Leitung. Das Exzerptionsmaterial wurde nach Abschluss der DFGPhase in Schüben nach Mannheim gegeben, die lexikographische Arbeit dort begonnen. Im Laufe der Jahre hat sich das IdS dann stufenweise aus dem Projekt zurückgezogen: Was anfangs als Gesamtübernahme gedacht war, wurde zu einem mir nicht in Erinnerung gebliebenen, aber sehr frühen Zeitpunkt auf zwei Bände reduziert und vertraglich mit dem Verlag festgelegt. Einige Jahre später (2011) wurde die Aufgabe des Projektes am IdS beschlossen (zum Jahresende 2012). Ich hörte davon über die Wandelgänge der Wissenschaft. 
Die tatsächliche Arbeit am FWB führte zu folgenden Mannheimer Ergebnissen: Band 4 wurde von J. Schildt erarbeitet, Band 6, Lieferungen 1 und 2 ebenfalls von J. Schildt (Letzteres großenteils in Privatarbeit). Für Band 7, Lieferung 1 und die erste Hälfte von Lieferung 2 zeichnet A. Lobenstein-Reichmann verantwortlich, für Lieferung 3 und 4 O. Pfefferkorn; die Abschlusslieferung von Band 4, bearb. von A. Lobenstein-Reichmann und O. Pfefferkorn, ist im Manuskript weitgehend abgeschlossen, liegt inzwischen aber brach. Für die Erarbeitung von Band 12 (mit der Strecke f / v) stand 13 Jahre lang eine Mitarbeiterstelle zur Verfügung; eine Lieferung kam nicht zustande. Nach dieser Geschichte wird man ermessen, dass wir (die Herausgeber) es als Glücksfall betrachten, nunmehr in Göttingen längerfristig arbeiten zu können. Diese Aussage setzt allerdings voraus, dass eine konstant bleibende Anzahl und längerfristige Besetzung der Stellen zu erwarten ist. Wissenschaftliches Personal muss eine unter den heutigen Bedingungen höchstmögliche Sicherheit der Anstellung haben, um sich fachlich zu qualifizieren und in der Arbeit fachliche Leidenschaft $\mathrm{zu}$ entwickeln, anders ausgedrückt: um nicht schon nach ein bis zwei Jahren der Einarbeitung fortwährend Ausschau nach einer anderen Stelle halten zu müssen. Unabhängig davon sei mitgeteilt: Eine besondere Bedeutung kommt der Verlagerung nach Göttingen auch deshalb zu, weil wir zum ersten Male die Möglichkeit haben und sie voll ausschöpfen, die unermessliche Fülle der Information, die in einem Wörterbuch steckt, digital zugänglich zu machen (vgl. Abs. 10). Außerdem ist zum ersten Mal die gewünschte Homogenität der Bearbeitung sichergestellt (bei aller Anerkennung der Varianz der Interessen und Begabungen der Redaktoren und Redaktorinnen sowie der Niederschläge dieser Varianzen in der Praxis).

\section{Zur heutigen Praxis}

Der Ausgangspunkt des nun folgenden Abschnittes lautet nach allem Vorgetragenen wie folgt: Das Material der Zentralexzerption steht seit 1999 zur Verfügung; die Artikel müssen nicht jeweils isoliert aus einem z. B. digital zur Verfügung stehenden Corpus herausgeschnitten werden. Das heißt: Man ist nicht bei jedem Artikel gezwungen, seinen Belegen einen äußeren und inneren Schnitt zu geben, man muss nicht ihre Anzahl jeweils neu diskutieren, ihre je okkasionelle Bedeutung nicht immer gänzlich neu festlegen, ihr semantisches und sachliches Umfeld nicht immer unbedingt eigens eruieren, da die vorliegenden Exzerpte und ihre Annotationen ja auf einer einmal großenteils linear verlaufenen Auswertung und mithin auf der Kenntnis des Gesamttextes beruhen. Wenn man zum Beispiel (wie ich gerade in diesen Tagen) einen Artikel wie strafe schreibt, weiß man, dass rund 400 Belege zur Verfügung stehen, dass ihre Annotationen die Kommentierungen des Textherausgebers (im Ausgabenglossar) und die Anmerkungen des Exzerpierenden enthalten, damit die eigene Interpretation mit derjenigen Anderer und vielfach besserer Textkenner abzugleichen und gegebenenfalls zu modifizieren gestatten. 
Die Gestaltung des Artikels beruht auf der Kenntnis der Artikelstruktur, wie sie oben (S. 287 f.) einerseits als Korsett und andererseits als flexibel handhabbar dargelegt wurde. Im Hintergrund der Arbeit steht ein lexiktheoretisches Wissen, das sich teils aus der allgemeinen linguistischen Diskussion und teils aus einer jahrzehntelangen lexikographischen Erfahrung herleitet. Die Arbeitsergebnisse sind demnach so zu veranschaulichen, dass die Gewichtsverschiebungen erkennbar werden, die im Laufe der Zeit vorgenommen wurden. Gemeint sind einmal eher praktische und zum anderen eher theoretische Verschiebungen.

Unter praktischem Aspekt stellte sich mehr und mehr die Aufgabe, Stellung zur immer wieder vorausgesetzten oder gar geforderten Vollständigkeit zu beziehen. Obwohl ,Vollständigkeit‘ zum mindesten für die Lexikographie einer Großcorpussprache wie des Frühneuhochdeutschen und zum mindesten im inneren, aber auch im äußeren Sinne ein Unsinnsbegriff ist, wird doch jedes Wörterbuch, so auch das FWB, doch immer auch explizit nach seiner Vollständigkeit befragt; gemeint ist in aller Regel die äußere Vollständigkeit. Oder Vollständigkeit wird stillschweigend vorausgesetzt, dann zum Beispiel, wenn man sich wundert, dass etwa das Wort $w$ für eine Belagerungsmaschine oder das Wort $x$ für eine mystische Frömmigkeitshaltung nicht gebucht sei oder dass von den Wortbildungen mit auge trotz der Buchung von knapp 150 Einheiten die doch so interessante Einheit $z$ fehle. Selbst hinsichtlich des semasiologischen Feldes eines Stichwortes wird immer wieder mit kritischem Unterton festgestellt, dass die im Schweiz. Id. oder im DRW dicht belegte (lokale oder rechtssprachliche) Bedeutung $>\mathrm{a}<$ eines beliebigen Wortes im FWB fehle. Kurzum: Man kommt angesichts von Erwartungen dieser Art nicht darum herum, Stellung zu beziehen. Diese sieht hinsichtlich der äußeren Vollständigkeit für die Wortbildungen wie folgt aus: Die schon in der lexikographischen Einleitung formulierte Regel und die entsprechende Praxis, sog. durchsichtige Bildungen (außer bei dichter Belegung und einigen weiteren Bedingungen) nicht in die Lemmaliste aufzunehmen, wird strenger ausgelegt, also in Richtung auf weniger Ansätze. Hinsichtlich der inneren Vollständigkeit, also der Angaben zur onomasiologischen Vernetzung, der Phraseme und Syntagmen, bleibt es der Absicht nach beim Alten, allerdings mit einigen, nicht unwesentlichen, raumfordernden Zusätzen:

Die systematisch vorgenommenen onomasiologischen Vernetzungen gelten inzwischen allgemein als beachtenswerte Neuerung des FWB; sie haben sich als gestaltende Bestandteile des semantischen Gefüges des Wortschatzes erwiesen und werden aufgrund des Fortschrittes der Arbeit und der digitalen Verfügung über das gesamte Material teils so umfangreich, dass man Auswahlen treffen muss. - Mein Interesse an den Phrasemen hat sich im Laufe der Zeit deutlich erhöht, was dazu führt, dass mehr Wendungen als phrasematisch beurteilt werden als vor 30 Jahren. - Auch hinsichtlich der Anzahl der Syntagmen wird wegen deren Status als lexikographischer Innovationsfaktor und ihres zunehmend eingesehenen Sinnes eine größere Beachtung zu konstatieren sein. Dies alles gilt seit der Übernahme des Projektes in das Akademienprogramm natürlich auch für die Mitarbeiter. Damit soll auch gesagt sein, dass der weite vorgöttingische Realisierungsskopus inzwi- 
schen einem annähernd einheitlichen Maß gewichen ist. - Wie immer man all diese Raumforderungen auch genau bemessen mag: Die kognitive und die handlungssemantische Komponente des Wortschatzes erfahren eine zunehmend stärkere Berücksichtigung. - Dies ist im Folgenden für die heutige Praxis darzulegen und $\mathrm{zu}$ veranschaulichen.

Hinsichtlich beider Funktionen ist zunächst zu wiederholen, dass die Synonymenangabe als Typ der Bedeutungserläuterung deshalb in den Hintergrund tritt, weil sie Historisches mit Gegenwärtigem unhinterfragt gleichsetzt. Insbesondere mit dem Blick auf das Semem als soziokognitive und handlungssemantische Einheit, auf seine wesenhafte Historizität und Sozialität, auf die ihm inhärenten zeitund sozialtypischen Differenzen, wird man Synonyme (in diesem Zusammenhang natürlich Sememsynonyme, nicht Signifikatsynonyme) im strengen Sinne theoretisch kontrollierter Beschreibungssprache nur dann verwenden können, wenn die sememinterne Gewichtung der Bedeutungskonstitution und Handlungsaufladung zeitenübergreifend als deckungsgleich beurteilt wurden. Es sei denn, es komme dem Lexikographen nur darauf an $\mathrm{zu}$ sagen, dass ,gerechtigkeit‘, ,minne“ und ,glaube، (pro in Frage stehendes Semem) seit mhd. Zeit letztlich immer dasselbe geblieben sind, oder dass er im Sinne J. Grimms „auf einen Schlag“ sagen will, worum es in einem bestimmten Argumentationszusammenhang überhaupt geht. Zuzugestehen ist natürlich, dass die Praxis oft eine Großzügigkeit erfordert, die den gerade oben bemühten „strengen Sinn“ außer Kraft setzt. So wird man die Semantik bei schwacher Belegung eher großzügig behandeln. Unter thematischem Aspekt steht die phrastische Erläuterung jedenfalls absolut im Mittelpunkt.

Nun ist - so setze ich voraus - jede einzelne (also semembezogene) Bedeutungserläuterung in Normalsprache zu verfassen. Demnach lässt sie sich nicht in deutlich voneinander unterschiedene sprachliche Segmente gliedern, deren erstes etwa die kognitive, ein zweites die handlungsbezogene Komponente beträfe. Vielmehr ist das eine in aller Regel so mit dem anderen verwoben, dass jeder normalsprachlich interessierte Rezipient sich wundern würde, wenn man hier Trennungen vornähme. - Als Beispiel dafür diene folgender Text (Bedeutungsansatz 2 zum Lemma strafe; demnächst in Band 11):

2. >Strafe, Bestrafung unterschiedlicher Art und Höhe, die j. von befugter Seite jm. gegenüber als Reaktion auf unterschiedliche strafbare Handlungen ausspricht und/oder vornimmt<; konvers dazu: >Strafe, die j. aufgrund einer solchen Handlung zu erleiden hat<; zu strafen 3. - Als strafbar gelten Verstöße aus dem gesamten privaten und sozialen Verhaltens- und Handlungsbereich, z. B. diebstal 1; 2, laster 1-4, mord 1; 2, raub, Hexerei, Alltagsvergehen wie Feldfrevel, Zahlungsversäumnisse, Nichtbeachtung von Fristen, Ausbleiben bei Vorladungen, auch das Unterlassen der Züchtigung von Kindern (aus falsch verstandener elterlicher Liebe). Voraussetzungen solcher Handlungen sind das böse (s. böse, Adj., 6; 7), das übel. Teils besteht ein spiegelnder Zusammenhang zwischen Verstoß und Strafart, darunter Verstümmelung, Gefängnisstrafe, finanziellen Bußen (damit offen zu 4), Einziehung des Besitzes. Zur Bestrafung befugt sind z. B. der vogt, richter, die majestat, oft ein allgemeines man (Indefinitpronomen 1;3). Als Betroffene erscheinen diebe 1, mörder 1; 2, räuber, weibspersonen, kinder 1 und wieder das allgemeine man. 
Der Beginn des Erläuterungstextes hat die klassische Form von Genus proximum, also Strafe [...], die plus differenzierende nähere Bestimmung (differentia specifica). Sie verleiht dem Rezipienten erst einmal eine Basisorientierung in dem Sinne, dass ,Strafe“ etwas sei, das wohl jedermann kennt. Dabei dürfte das eingeschaltete Satzglied (das Präpositionalobjekt jm. gegenüber) den Fluss der Lektüre leicht stören; gleiches wird für die Substantivgruppe Reaktion auf [...] gelten. Als überladen wird aber der dann folgende zweite Teil mit den Angaben über den Verhaltens- und Handlungsbereich und mit den vielen komplexen Substantivgruppen aufgefasst werden. Insgesamt wird aber auch dieser Teil der Erläuterung dennoch als Mitteilung in dem Sinne rezipiert werden: Strafe bezeichnet / meint etwas, ontologisiert heißt das: Strafe ,ist` etwas, das so und so zu charakterisieren ist. Die Konverse, darin bestehend, dass jemand da sein muss, der sie erleidet, liegt ohnehin im Bereich der Erwartung und ist wohl deshalb eher beiläufig ${ }^{21}$ erwähnt, obwohl doch jedermann weiß, das ,Strafe', die ich ausspreche, etwas anderes ist als ,Strafe‘, die ich erleide. Das heißt: Mit der Angabe von genus proximum und differentia specifica ist erst einmal die Bezeichnungsfunktion bestimmt. Diese wird höchstens randständig mit soziopragmatischen Aspekten verbunden; Strafe ist und bleibt eben ,Strafe‘, von welcher Seite man sie auch sieht.

Nun kann die gesamte Erläuterung, insbesondere ihr zweiter Teil, aber auch anders gelesen werden, also nicht als Darlegung objektiv vorhandener Rechts- und Sozialverhältnisse (Darstellungsfunktion), sondern einmal als sprachliche Konstitution eines Teils der gesellschaftlichen Verhältnisse (einer Kopfgegebenheit; kognitive Funktion), zum anderen als Teil eines institutionell geregelten Systems von Handlungsinstruktionen (Handlungsfunktion; Handgegebenheit, übertragen gemeint), zum dritten als Hinweis auf Herrschaftsverhältnisse (Symptomfunktion). Ich lasse diese aspektuellen Möglichkeiten lexikographischer Fachsprache hier, um die Argumentation nicht zu überlasten, erst einmal ruhen. Also undifferenziert: Von den gemeinten Gegebenheiten weiß man, dass es jemanden mit bestimmten Eigenschaften geben muss, der sie handhabt, und jemanden, der sie erleidet. Im Detail wird also mindestens Folgendes gesagt bzw. vorausgesetzt (nach dem Gedankenstrich):

- Es müssen strafbare Handlungen gegen jn. oder einen sozialen Wert vorausgegangen sein und als solche angesehen werden, Strafe steht in einer Handlungsfolge;

- $\quad$ es muss einen Strafenden und einen die Strafe Erleidenden geben (= logische Voraussetzung für Strafe);

- Strafe aussprechen/vornehmen (aktiv) und erleiden (passiv) werden trotz/infolge der sich hinter diesen Verben verbergenden Verschiedenartigkeit der Handlungen sowie trotz/infolge der logischen Konverse mit einem einzigen Wort gefasst,

$21 \operatorname{Im}$ GWdS $(8,3762)$ ist die Passivseite von ,Strafe' entsprechend spartanisch zu Wort gekommen: Man hat etwas „zu tun oder zu erdulden“. 
obwohl man, wie z. B. bei geben und nehmen, verkaufen und kaufen doch auch hätte trennen können. Wenn zusätzlich zu strafe auch noch /-strafung gesagt wird, dann hat das den Grund, dass Bildungen mit -ung zwar die Ausblendung des Handelnden / Erleidenden gestatten, aber doch auch die Strafer- und die Bestraftenseite wach halten;

- $\quad$ wenn Strafe aussprechen und vornehmen (beides auf der aktiven Seite) in einer Hand liegen, könnte dies auf einer ganz normalen tropischen Assoziation, aber auch auf rechtssystematischen Eigenheiten oder der Verfahrenspraxis frnhd. Zeit beruhen;

- der Strafende muss befugt sein (s. die beschreibungssprachliche Formulierung von befugter Seite);

- dieser Befugte fungiert als Teil eines umfassenden Systems (mit Seite angesprochen), auch wenn dies eher thematisch vorausgesetzt als rhematisch ausgesagt wird.

Würde man die folgenden Teile der Erläuterung hinzunehmen, käme man auf weitere Aussagen, z. B. auf diejenige, dass auch Laster und Hexerei zu den Straftaten gehören, dass das ,Böse/Übel` in der Welt als Voraussetzung für Straftaten gesehen werden, dass übermäßige Liebe zu Kindern zu der Straftat ungenügender Züchtigung (als Unterlassung) führen kann, dass der Strafende wie der Betroffene auffallend oft in Form des Indefinitpronomens man erscheinen und dass dies alles eine Weltanschauung voraussetzt, in der der Teufel fortwährend sein Unwesen treibt, obwohl Gott zweifellos anwesend ist, sich aber oft versteckt hält. An dieser Stelle kommt es mir darauf an, dass Aussagen all dieser Art als Bestimmung eines soziohistorischen/soziopragmatischen/zeittypischen, oben mit soziokognitiv attribuierten Konstitutes namens strafe 2, bis hierher verstanden als Kopfgegebenheit (wenn auch als Darstellung gefasst), gelesen werden können. Konstitute dieser Art zählen zu den Schwerpunkten der lexikographischen Beschreibung im FWB. Selbstverständlich werden sie nicht als wohlbestimmte isolierte Einheiten innerhalb einer zählbaren, rein quantitativen Copia verstanden, sondern als semantische Verdichtungen, Knotenpunkte in einem in stetigen Übergängen und Neubildung begriffenen offenen Netz von bis zu mehreren hunderttausend Einheiten.

Bei aller Betonung des Verständnisses des Semems als soziokognitiver Gegebenheit stand im Vorangehenden doch immer auch schon seine Seinsweise als Handlungseinheit im Hintergrund und war nahezu in jeder Formulierung erkennbar. Dieser Status ist demnach eigens herauszustellen. Ich tue dies in einer Analyse des zweiten (längeren) Teils der Erläuterung von strafe 2 (beginnend mit dem Gedankenstrich), ohne dass ich damit suggerieren möchte, der erste Teil enthalte keine Handlungsbezüge und der zweite keine Kognitionsbezüge. Die Schwerpunkte von Teil 2 betreffen (jeweils in eigenen Hauptsätzen, durch Punkte voneinander getrennt): die Art der der Strafe unterliegenden Verstöße, deren teilweise religiöse Voraussetzungen, das mögliche Spiegelverhältnis von Verstoß und Art der Strafe; 
die Nennung einiger zur Strafe Befugten; die Identifizierung einiger der Betroffenen. Der Rahmen ist offensichtlich: Es gibt Handelnde und Handlungsbetroffene; der vorausgegangene Verstoß findet sich in einer Kombination objekt- und metasprachlicher Äußerungen gefasst, die nahezu ausnahmslos Verbalabstrakta sind und Handlungen betreffen; die Voraussetzungen, das Böse und das Übel, erscheinen zwar als Adjektivabstrakta, meinen aber dennoch weniger Eigenschaften als Wesenheiten im Sinne von >daseiend Wirkendem $<$. Das sind in ihrer Gesamtheit und in jedem seiner Teile Komponenten eines geschichtstypischen Handlungsrahmens: Ein rechtlich Befugter unterwirft jemanden, der strafbar gehandelt hat, aufgrund herrschender Bedingungen einer Strafe. Dies in voller Deutlichkeit, also mit der Nennung der Handelnden, auszuformulieren gehört zu den inzwischen zentralen Aufgaben der Redaktion der FWB-Artikel. Zur näheren Erläuterung sei noch hinzugefügt: Man tendiert immer mal wieder dazu, eine frnhd. Abstraktbildung mit der Nennung nhd. Abstrakta für hinreichend erläutert zu halten. Die Überprüfung erfolgt systematisch unter der Frage: ,wer tut was gegenüber wem unter welchen Umständen?“ Das Ergebnis sind längere Artikel.

Dabei sind immer bestimmte Details zu beachten. Davon seien zwei ihrer Typisierung halber erwähnt bzw. diskutiert: der Gebrauch des man sowie die Fachtextlichkeit der Wörterbuchartikel.

Es fällt auf, dass sowohl für den Strafenden wie für den Betroffenen das allgemeine man erscheint. Dies kann nur bedeuten, dass die Auferlegung einer Strafe, eigentlich ein je einmaliges Handeln, dazu tendiert, $\mathrm{zu}$ einem Handlungstyp, in diesem Fall zu einem standardisierten fachlichen Ritual mit einem eigenen Realitätsstatus, typisiert zu werden: Der Gegenstand ,Straferteilung', dessen kommunikativer Ort die Gerichtsverhandlung und deren textliche Fassung der Bericht ist, mutiert unter der Hand zu einem Seinstyp im Kopf von Juristen und zur textlichen Fassung im Rahmen frühneuzeitlich-juristischer Fachliteratur. Indem das indefinite man gleich zweimal erscheint, bereitet der Lexikograph den Ansatz einer Bedeutung 6 von strafe vor, nämlich: ,>Strafe als vom sozialen Tatbestand der Bestrafung gelöstes Ordnungs- und Erziehungsprinzip; [...] Allgemeinbegriff<; auch als Seinsgröße eigenen Rechtes auffassbar“. Der Ansatz ist schwach belegt, möglicherweise infolge seiner inhaltlichen Nähe zu mehreren der vorangehenden Ansätze. Er hätte deshalb auch als Metonymie an einen von diesen (bei hinreichendem Assoziationswitz de facto: an alle) angeschlossen und damit entproblematisiert in den Hintergrund der Aufmerksamkeit gestellt werden können. In der dargelegten Form ist er von den man-Erwähnungen her so vorbereitet, dass er ins Auge springt. - Unter dem Aspekt der Thematisierung der Systemhaftigkeit des Lexikons in den einzelnen Artikeln handelt es sich dabei um die Herstellung eines Bezuges zwischen einzelnen Sememen eines Signifikates. Deren Differenzen werden einerseits dadurch verstärkt, dass sie in eigenen Ansätzen stehen (hier also 2 und 6), andererseits wird die Differenz wieder unterlaufen, indem die in Frage kommenden Inhaltsähnlichkeiten und -übergängigkeiten systematisch in Detailformulierungen durchscheinen. 
Der oben zitierte Artikel zu strafe 2 wird - wie viele andere - in der Druckversion mehr als eine halbe Spalte umfassen. In Rezensionen des FWB wurden solche Fälle natürlich bemerkt und kommentiert, einmal z. B. mit kritischem Staunen, ein anderes Mal als Überdifferenzierung. Beiden Reaktionen liegt die Erwartung zugrunde, im FWB ein Nachschlagewerk zu finden, das möglichst viele lexikalische Einheiten beziehungslos aneinanderreiht und sie hinsichtlich ihrer Bezeichnungsfunktion beschreibt. Diese Auffassung verbindet sich mit der Vorstellung kurzer, im Kern auf die alte Trinitas von Stichwort, Bedeutung, Belegen beschränkter Artikel. Dazu sei hier gesagt (teils wiederholend): Das FWB verstand sich anfangs in gewisser Weise in diesem Sinne, hatte aber mit seiner Betonung der Semantik immer auch schon seinen nuancierte Ausdifferenzierung fordernden Schwerpunkt. Inzwischen hat sich diese Anlage teils schleichend verstärkt, in vielen Fällen wurde sie auch der Absetzung von anderen Wörterbüchern halber explizit gepflegt: Die alte Bezeichnungssemantik wird damit systematisch ergänzt durch die soziokognitiv orientierte Semantik und außerdem durch die Semantik sprachlicher und damit per se sozialer Handlungen.

Begründet sei dies mit mehreren, sehr verschiedenen Argumenten. Zum ersten: Die Dokumentation des deutschen Wortschatzes ist generell geleistet; man braucht das Bekannte nicht immer wieder in - wenn auch variierenden - Abschreibetraditionen $\mathrm{zu}$ wiederholen: Überdies liegt für die in den folgenden Jahren anstehende Alphabetstrecke unseres Wörterbuches im DWB eine hinsichtlich Lemmaanzahl, Bezeichnungsfunktion und vielem anderen auch für das Frnhd. kaum zu überbietende lexikographische Dokumentation und ein entsprechend wertvolles Forschungsinstrument vor; außerdem gibt es mit je besonderen Schwerpunkten das DFWB, das DRW, das Schweiz. Id. und eine Reihe ausgezeichneter, teils auch in die Geschichte zurückgreifender Mundartwörterbücher. Zum zweiten: Die Sprachtheorie des letzten Jahrhunderts (und schon vorher) unterliegt dem bereits oben ausgesprochenen Wandel von der Bezeichnungsfunktion zur Kognitions-, dann in einem neuen Ansatz zur Handlungsfunktion. Diese Paradigmenwechsel können in der Lexikographie nicht unbeachtet bleiben, so dass der alte Beschreibungssockel - wie ebenfalls bereits gesagt - in den Wandel zu setzen und sprachtheoretisch sukzessive anzupassen oder gar zu ersetzen ist. Das ist keine Aufgabe, die mit der Auflistung, Erlernung und Anwendung einiger neuer Muster zu bewältigen wäre. Man kann also das gute alte Prinzip der Angabe von genus proximum und einigen specifica nicht einfach verabschieden und durch neue Muster ersetzen, anders gesagt: die alte Textsorte ,Wörterbuchartikel` durch eine neue ablösen, ohne die dahinter stehende Philosophie zu verändern. Das wäre nur eine Übertragung der lexikographischen Copia-Vorstellung vom Wortschatz als Menge von Wörtern auf die Textprodukte des Lexikographen als Menge von Textsorten, die sich objektsprachlich mehr oder weniger bestimmt voneinander abgrenzen und als sich abgrenzende Erscheinungen beschreibungssprachlich letztlich wohlbestimmt darstellen ließen. 
Mit diesen Bemerkungen ist das Problem einer lexikographischen Fachsprache, die den erwähnten sprachtheoretischen Veränderungen in irgendeiner Weise gerecht wird, angesprochen. Offensichtlich ist zunächst nur, dass der Umfang der Artikel neu zu bemessen ist. Der Beispielartikel strafe 2 ist gekennzeichnet durch komplexe Satzglieder und Angaben, durch längere funktional demonstrative Relativsätze, durch die Aneinanderreihung von Hauptsätzen. Die jeweilige grammatische Struktur streift bei einmaligem Lesen die Grenze unmittelbarer Verständlichkeit, die semantische Verdichtung dürfte sie teils überschritten haben. Nun könnte man ja sagen, diese Art der syntax- und semantikbezogenen Fachlichkeit ließe sich auf ein handhabbares Ziel hin kultivieren, ohne dass man gleich fertige Textmuster im obigen Sinne des Copia-Gedankens erhielte. Das Wunschergebnis wäre eine Reihe von Mustern, die bei der Formulierung von Artikeln hilfreich sein und etwa von jungen, sich in die Artikelredaktion einarbeitenden Mitarbeitern gelernt werden könnten. So sicher dies einerseits zumindest begrenzt möglich, außerdem nötig und sinnvoll sein mag, so ist es andererseits doch vom Ansatz her fraglich. Letzteres aus mindestens zwei Gründen: Erstens bedarf jedes einzelne Wort aufgrund der Unikalität seines Signifikates wie jedes seiner Sememe und zusätzlich aus einer Reihe anderer Gründe (z. B. der Belegsituation, seiner Polyinterpretabilität, auch des kulturhistorischen Interesses des Lexikographen) genauso einer je einmaligen Behandlung wie jeder einzelne Text als Gegenstand der Literaturwissenschaft. Dort ist dies anerkannt, und niemand kommt auf die Idee, seinen Studierenden ein ausgearbeitetes Beschreibungsinstrumentarium zum Verständnis z. B. einer Novelle an die Hand $\mathrm{zu}$ geben, ohne dessen Wert gleichzeitig zu relativieren. Zweitens ist die Menge der sprachlichen Möglichkeiten, Unikalität auszudrücken, infinit: In einem sehr tiefen Sinne ist jeder sprachliche Ausdruck beschreibungssprachlich in jeder sprachlichen Form zu vermitteln. Die Spanne reicht vom Synonym bis zum phrastischen Ausdruck, vom Einzelwort bis zum Text, vom eigentlichen bis zum mehrfach uneigentlichen Ausdruck, von der Angabe eines genus und einer differentia specifica bis zu Formen der Epik, Lyrik und Dramatik und vielen, schwer einzuordnenden Formen wie etwa des Beispiels. Auf die Spitze getrieben hieße das: Man kann Wortartikel auch in die Form des Epos kleiden. Dennoch gibt es Üblichkeiten, erstens durch die langue mit ihren systematischen Möglichkeiten, zweitens durch die Norm als dasjenige, was man situationsangemessen üblicherweise tut. Lexikographie im hier diskutierten Sinne hat es mit der Norm zu tun; Ausfächerungen zur langue und zu parole hin sind möglich. Damit bewegen sich die folgenden Veranschaulichungen auf der Normebene, also zwischen den Extremen einer wohlbestimmten, lernbaren fachtextlichen Systematik einerseits und infiniter Gestaltungsfreiheit andererseits. Sie dienen nur als (ausdrücklich gesagt:) einzelne Beispiele der Auslotung des Rahmens. Im Fokus steht die Handlungsfunktion.

(1) die Handlungsfunktion kann explizit ausgesprochen sein. So heißt es in der Formulierung zu rebel >Aufrührer< (Band 10, demnächst; Formulierung von V. Harm), dass eine bestimmte Regierungsform eines Gemeinwesens „der göttli- 
chen und weltlichen Ordnung nicht entspricht und daher $\mathrm{zu}$ beseitigen ist“. Der Schlussteil dieses Zitates sagt beschreibungssprachlich genau dasjenige aus, was zeitgenössische Sprecher objektsprachlich mit rebel verbinden, nämlich dass sich die Regierungsform, auf die sich das Wort (in 1 Beleg) bezieht, als entsetzens würdig gentzlich abgethon werden müsse und durch eine gehorsam beliben erberkeit zu ersetzen sei. Derartige Möglichkeiten der Bedeutungserläuterung sind leicht eingängig, nicht besonders beschreibungsaufwendig und werden im FWB zunehmend häufig realisiert, um das Handlungspotential des Wortschatzes systematisch im Bewusstsein zu halten. Einige vergleichbare Formulierungen sprechen die mit einem Lemmazeichen verbundenen Handlungsaufrufe mit den Formulierungen glaubensheischend, Glaubens- und Lebenspflichten, heilsverpflichtender Orientierungsrahmen, Aufgabe, eigenes Zutun oder mit der dauernden Verwendung des Verbalabstraktums Handlung an (jeweils etwa s. v. ober 4). Selbstverständlich stehen diese Ausdrücke in je eigenem syntaktischem Zusammenhang. So heißt es z. B. unter minne 1 (Band 9, 2501, von mir), dass die Qualitäten des als mystisch verstandenen Gottes, nämlich frei, lauter 8, ledig $9 \mathrm{zu}$ sein, vom Menschen angenommen, „als Aufgabe für den Menschen verstanden werden“ könnten und dann im „Tugendkatalog der Zeit zu realisieren" seien.

(2) Teils wird die Handlungskomponente noch expliziter zur Sprache gebracht. So heißt es s. v. nütze 5 (Band 9, demnächst, Lieferung 8; von mir):

von Büchern, Lehren u. ä. gesagt, deren in der Regel positiv gesehener Inhalt kognitiv begriffen und in nutzbringende Handlung umgesetzt, d.h. in der Lehre verbreitet werden muss; die Erkenntniskomponente ergibt sich aus den Inhalt kognitiv begreifen, die Handlungsaufladung aus Ausdrücken/Formulierungen wie lere, warnung und verbreitet werden muss. Beide Komponenten sind hier beschreibungssprachlich durch und klar voneinander abgesetzt.

(3) In aller Regel sind Kognitions- und Handlungsfunktion allerdings aufs engste miteinander verwoben. Dazu sei das Beispiel oberkeit 1 (Band 9, Lieferung 8, Sp. 4002; von mir) etwas ausführlicher zitiert und diskutiert:

\begin{abstract}
1. >Hoheit, Souveränität als abstrakt gedachte herrscherliche Seins-, Gestaltungs-, Handlungs-, auch moralische Pflichtgröße, wie sie in Gott erkannt und/oder in der vernunft des einzelnen Menschen als gottgegeben angenommen oder (seltener) aus anderen Größen (z. B. aus dem herkommen) abgeleitet wird<; metonymisch: von der göttlichen Hoheit in Geschichtlichkeit und Sozialität übersetzte Macht- und Herrschaftsbefugnis< unterschiedlicher extensionaler Reichweite: von der Regierungs-, Verwaltungs-, Rechtsprechungsebene bis hin zur Alltagsgestaltung; dazu wiederum metonymisch: >Recht des Hoheitsträgers auf Einnahmen, Steuern, Privilegien, Leistungen wie dienste, reisen, renten, schatzung, wildban<; die verschiedenen Ebenen von oberkeit 1 werden hierarchisch gestaffelt gedacht; auch die tiefer liegenden Ebenen leiten ihre Existenz nahezu ausschließlich aus einer transzendenten Größe, Gott, ab.
\end{abstract}

Man erkennt auf den ersten Blick: Die gesamte Erläuterung ist phrastischer Natur, sogar die Grenze des Satzes wird nach oben, zum Text hin, überschritten. Am Anfang steht ein Erläuterungsteil, bei dem die Angabe von genus proximum (Hoheit) 
und differentia specifica (als [...]) Pate gestanden hat. Das bis dahin Gesagte und alles, was dann folgt, hat die Form komplexer Substantivgruppen, Aufzählungen, von Neben- und Hauptsätzen; mehrfach wird mit Reihungen und Steigerungen gearbeitet; wortbildungsmorphologisch herrscht das Kompositum; dominanter textlicher Zweck wären die Determination (etwas genau zu sagen) und Extension (möglichst alles im Bezugsbereich Liegende zu sagen). Offensichtlich hat der Lexikograph sich vor einer besonders schwierigen Aufgabe gesehen und gemeint, diese nur auf die angedeutete Weise bewältigen zu können. Dabei darf vorausgesetzt werden, dass ihm das Problem von Kognitions- und Handlungsfunktion bei der Formulierung des Artikels bewusst war. Die Frage lautet dann: Wo, in welchen Formulierungen steckt - objektsemantisch gesehen - die eine, also die Kognitionsfunktion, und in welchen steckt die andere, also die - wiederum mit dem Blick auf die Objektsemantik - unbestreitbare Tatsache, dass oberkeiten auch Handlungsinstanzen sind? Dies ist kurz zu prüfen: Die (objektsemantische) Kognitionsfunktion ist eher erkennbar in beschreibungssprachlichen Ausdrücken wie Hoheit, Souveränität, in den Verbformen erkannt, gottgegeben und in Weiterem. Die (objektsemantische) Handlungsfunktion ist eher in den beschreibungssprachlichen Komposita Gestaltungs- und Pflichtgröße und ebenfalls einigem Weiteren erkennbar. Wenn ich gerade zweimal „eher“ und „in Weiterem“ gesagt habe, dann zeugt das von Unsicherheiten der Zuordnung der meisten Wortbildungen, Wortgruppen, Aussagen zu einer der beiden Komponenten der (einzigen) Objektgröße: Hoheit und Souveränität implizieren ebenso bereits Handlungsaufladungen wie Gestaltungs- und Pflichtgröße Kognition implizieren, auf welche genaue Weise und mit welchen $\mathrm{Nu}$ ancen auch immer. Erst recht problematisch wird dies dann, wenn man sich den langen Rest der Substantivgruppen (d.h. der Nennelemente der Erläuterung) und die dahinter stehenden Aussagen ansieht: Ausdrücke wie „Hoheit, Souveränität als abstrakt gedachte herrscherliche Seins-, Gestaltungs-, Handlungs-, auch moralische Pflichtgröße, wie sie [...]“ können insgesamt ebenso als Aussage über ein kognitives wie über ein handlungssemantisches Semem aufgefasst werden; Gleiches gilt z. B. für „Recht eines Hoheitsträgers auf Einnahmen“. Wenn man gefragt würde, welche der beiden Komponenten denn nun dominiert, also die Orientierung vorgibt, von der zeitlich und/oder logisch die andere abhängt, dann würde ich sagen: So, wie ,oberkeit' erläutert wird, ist es eine insgesamt eher kognitive Größe; es ist die Orientierungseinheit, die das Handeln vorgibt. Dazu passt, dass die absolute transzendente Größe ,Gott‘ ist, von der sich ,oberkeit‘ ableitet. Das würde bedeuten, dass ich die besondere Berücksichtigung der Handlungssemantik, die auf den vorangehenden Seiten dieses Artikels mehrfach als ein Kennzeichen des FWB betont wurde, in der Praxis der Artikelformulierung in die Abhängigkeit der Kognition gebracht und offensichtlich selbst unterlaufen habe. Die Antwort auf die kritische Frage, wie dies, falls es denn stimmt, zustande gekommen sei, würde wohl in Richtung auf die rationalistische unterschwellig hohe Rolle der Erkenntnis im Vergleich zur Rolle des Handelns gehen; es wäre Horizontverschmelzung pur. 
Nun wurde oberkeit im FWB als bisem (zweideutig) interpretiert. Damit stellt sich die Frage, wie der zweite Bedeutungsansatz formuliert wurde. Er lautet:

2. >Hoheitsträger, herrscherliche Instanz bzw. Person [...], die die hoheitliche Befugnis (von Ansatz 1) in die soziale Realität umsetzt<; >[...] von Personen ausgeübtes Organ, das [...] das gesamte Sozialwesen (darunter die rechtliche, kirchliche, gesellschaftliche, soziale, wirtschaftliche, militärische Realität) [...] gestaltet<.

Auch dieser Erläuterungstext kann als erkenntnisfunktional bestimmt angesehen werden, etwa in dem Sinne: „Es gibt in den Köpfen der geschichtlichen Sprecher (also objektsemantisch) den Hoheitsträger als Teil der gesellschaftlichen Ordnung“; und das wird vom Lexikographen mitgeteilt. Diese Formulierung öffnet aber auch das Verständnis $\mathrm{zu}$ einer handlungsfunktionalen Interpretation, dann nämlich, wenn man sagen würde: Indem der Hoheitsträger seine Befugnis „,in die soziale Realität umsetzt“ und „das gesamte Sozialwesen gestaltet“, auch indem er der „Kritik“ unterliegt, erscheint er als Handelnder; man achtet nicht so sehr darauf, was er verfassungsbezüglich „ist“, sondern wie er verfassungsbezüglich „handelt“. Bei dieser Interpretation käme man zu dem Ergebnis: Der Lexikograph hat in Bedeutungsansatz 1 die kognitive Komponente, in Ansatz 2 die Handlungskomponente herausgehoben; er hätte seine Aufgabe damit gut gemeistert. Die Crux ist nur, dass man auch dieses tröstliche Ergebnis wieder in Frage stellen kann. Man brauchte es nur wie folgt aufzufassen: Das objektsemantische Handeln ist als integraler Teil eines soziopragmatischen semantischen Konstituts $\mathrm{zu}$ verstehen. Das Handeln würde gleichsam aus der Hand in die Regie des Kopfes getextet. Mir ist natürlich bewusst, dass gedankliche und verbale Spielereien mit Reaktionen rechnen müssen wie: „Die haben vielleicht Probleme“; das alles sei ein scholastischer Tanz, etwa so wie der berühmte Tanz des Teufels auf einer Nadelspitze. Ganz abgesehen davon, dass mir derartige Tänze Freude bereiten, gehört es zur wissenschaftlichen Basierung der Lexikographie, die im Schwange befindlichen sprachtheoretischen Prämissen in der lexikographischen Beschreibungssprache durchscheinen $\mathrm{zu}$ lassen. Es geht dabei immerhin auch um Folgendes: Wenn die historische Bedeutungslexikographie sich gerne als Grundwissenschaft für alle Sparten der Kulturhistorie betrachtet bzw. selbst Kulturhistorie ist, dann sollte sie prüfen, ob sie sich unter kognitivem Aspekt eher in dem Rahmen von Begriffs-, Ideen-, Mentalitäts-, Geistes-, Rechts-, Theologiegeschichte usw. sieht und ihre Redeweise eher deliberativ (mit argumentativem Unterton; übertragen gesprochen: vertikal von oben nach unten sehend) gestaltet oder ob sie sich eher im Rahmen von handlungsorientierter Geschichtsschreibung sieht (und dann in stark narrativem Grundton arbeitet, gleichsam horizontal von Mund zu Ohr). Der Unterschied liegt darin, dass Argumentation eher (wieder komparativ gemeint) auf der Ebene ,Lexikograph zu Sache/Sachkonstitut‘ erfolgt, Narration eher auf der Ebene ,Lexikograph zu Rezipient' (wenn auch über etwas). Dieser Punkt wird unten wieder aufgegriffen (s. Abs. 9). 
Hier ist vielleicht der systematische Ort, auf die sprachliche Beziehungstheorie $^{22}$ als eine besondere theoretische Nuance der Sprachtheorie hinzuweisen, die in den letzten Jahren im FWB verstärkt Beachtung findet. Das Denkschema lautet: Die soziale Zelle des Sprechens und damit von Sprache ist die Zweierbeziehung; sie reicht von der Wiege bis zum Grab. Demnach müsste erst einmal jede einzelne sprachliche Äußerung gerade hinsichtlich ihrer Semantik beziehungsrelational (also interpersonal) gesteuert sein. Nun stellt sich im Laufe des Spracherwerbs und der Spracherweiterung einmal eine stufenweise Verschiebung der Gleichgewichtigkeit der beiden Beziehungspole auf einen der Beteiligten ein, entweder den Sprechenden oder den Hörenden, zum anderen auf eine Verselbständigung des kommunizierten Inhaltes in Richtung auf das allgemeine ,man“ (siehe dazu LobensteinReichmann 2014). Dabei würde die für das Beziehungsdenken zentrale Symmetrie der Interpersonalität als Konstituens für alles Sprechen im ersten Falle zur Intrapersonalität mutieren, im zweiten Falle zur Trans- oder gar Extrapersonalität. Die Interpersonalität äußert sich im Gespräch (im allerweitesten Sinne), die Intrapersonalität im Monolog (wieder im weitest möglichen Sinne) und die Trans- bis Extrapersonalität in den als rein (gleichsam sprachfrei) vorgestellten Sachtexten. Das Bewusstsein dieser drei Gegebenheiten führt zu besonderer Wachheit im Hinblick auf die Sprechenden als sowohl Erkennende wie Handelnde. Der Monologisierende und die Sache würden zum Rand- oder gar Problemfall, was einerseits mit klammheimlichem Beifall quittiert werden mag, angesichts der breiten Realität des monologischen und des sachbezogenen Sprechens aber ausgeschlossen ist. In der Logik der Theorie läge eine Lösung des Problems, die sowohl den Monolog als auch die Sachlichkeit aus der Beziehung herleitet. Mit beidem ist ein Anliegen getroffen, das in der Arbeitsstelle des FWB stets präsent ist und das man in den Artikelformulierungen zum Ausdruck zu bringen versucht. Systematische Orte dafür sind die Bedeutungserläuterung und semantische Kommentare. Das Gemeinte soll am Beispiel stein (Band 11, $274 \mathrm{ff}$, aus meiner Feder) veranschaulicht werden, und zwar unter dem Aspekt, dass es systematisch aus der Position des Konkretums, eines unbestreitbaren Sachstatus (über das ,man' etwas weiß) heraus gehoben und in den Status einer zwar immer noch konkreten, aber doch durch Perspektivierung angetasteten Beziehungsgröße hinein getextet wird:

In Ansatz 1 geht es um den Stein als „loses Gesteinsstück“, zu dem aber einige uneigentliche Gebräuche hinzukommen, nämlich die Metapher >schwer Belastendes<, sodann eine als „bildlich“ charakterisierte Verwendung für >Gefühl-, Lebloses<, schließlich ein tropischer Bezug auf „Personen, denen Grobheit, Unempfindlichkeit gegen die Inhalte des Christentums o. Ä. zugeschrieben werden“. In Ansatz 2 betrifft stein die irgendwo anfangende Größe $>$ Fels, Felsgestein $<$, die aber wiederum mit tropischen Bezügen, und zwar auf Christus, auf den Gerichtsstein und den Zehntstein als den Ort für Naturalabgaben, einhergeht. In Ansatz 3 kommt der

22 Das Folgende in Anlehnung an Lobenstein-Reichmann 2019 (demnächst). 
Stein „als mineralisches Material“ ins Spiel, diesmal mit einer ebenfalls beziehungssemantischen Nuancierung, nämlich „zum Schmelzen zubereitet“. Das zugehörige Phrasem der dürre stein meint gar einen Menschen. So geht es bis zu Ansatz 18 weiter, und zwar jeweils nach dem Muster: am Beginn der einzelnen Erläuterung Angabe von Sachlichem, dann Aufweichung des Sachbezuges durch Verwendungen, die interpersoneller Provenienz sind. Auf die Spitze gebracht heißt das: Die Beziehungsbasierung des Sprechens hebt in letzter Konsequenz jede übereinzelsprachlich konzipierte Sachlichkeit auf und konstituiert ,Sachlichkeit‘ als Gegebenheit, die zumindest ihre Nuancierung nicht aus der Natur, sondern aus der sprachlichen Beziehung, damit aus der Historizität und Sozialität, erhält. - Dieser Gedanke durchzieht die Bedeutungserläuterungen des FWB und das weitere Informationsprogramm bis in Details: Ziel ist die gesamte lexikalische Semantik der Epoche ,Frühneuhochdeutsch“ als Gefüge des im Sprechen verlaufenden Erkennens und Handelns, und zwar sowohl in seinen Übereinstimmungen wie in seinen Unterschieden. - Weitere Beispiele finden sich unter geselle, herre, knecht, glaube, gnade, minne, liebe. Die neueren Lieferungen können bewusster auf die Fachsprache der Bedeutungserläuterung achten, als dies in den älteren Bänden möglich war. Selbstverständlich kann und soll nicht geleugnet werden, dass es Bedeutungsbestände gibt, die sich einer Herleitung aus Beziehungsverhältnissen entzieht, es sei denn, dass man mit F. Nietzsche (1874) der Meinung ist, dass selbst der Würfel (eine mathematische Größe) noch einen Rest von Anschauung (das heißt hier: des Werfens mit ihm) bewahrt habe.

Eine besondere Aufmerksamkeit in der heutigen Praxis findet die strukturelle Komponente. Strukturell wird dabei nicht im strengen Sinne verstanden. Vor allem der in seinem Ursprung phonologische Oppositionsbegriff ist auf historische Semantik nicht anwendbar. Im FWB geht es - das oben (S. 295) Gesagte noch einmal mit anderen Worten wiederholend - speziell mit dem Blick auf seine differenzsemantische Ausrichtung generell um den sprachlich verfassten geschichts- und sozialtypischen Weltentwurf des späten Mittelalters und der früheren Neuzeit. Im Mittelpunkt stehen die Sememe (in diesem Artikel auch Bedeutungsansätze, in früheren Publikationen meist Einzelbedeutungen genannt). Sie verdanken ihren Ansatz der Annahme gewisser, aus den Corpustexten erschlossener, geschichtlich fortwährend in Aushandlung begriffener semantischer Verdichtungen mit inneren Nuancierungen und Unterscheidungen von Seiten des Lexikographen, aber auch der Annahme zeichenintern und zeichenübergreifend offener Grenzen. Diese Verdichtungen müssen in irgendeiner Weise als aufeinander bezogen beschrieben werden. Dies zu leisten, ist Aufgabe verschiedener lexikographischer Informationspositionen: nacheinander des Kopfes zum Gesamtartikels, sememinterner Nuancierungen, einzelzeicheninterner (= signifikatinterner, also sememübergreifender) Bezugssetzungen, einzelzeichenübergreifender Angaben (zur sog. onomasiologischen Vernetzung), der Syntagmenangaben, beiläufig auch der Phraseme, der Wortbildungsvernetzung und der Belege. Dies soll im Folgenden in der gerade vorgetragenen Reihenfolge geschehen; der Deutlichkeit halber werden die einzelnen Punkte durch Kursive herausgehoben. 
Der Kopf zum Gesamtartikel kann als Ort für semantische Kommentare unterschiedlicher Art genutzt werden. Eine erste Möglichkeit ist in der Lexikographie des Deutschen meines Wissens bisher nicht einmal erkannt und auch im FWB nur vereinzelt zur Anwendung gekommen, sollte aber in Zukunft eine systematischere Beachtung finden. Hintergrund dieser Aussage/Hypothese ist die partielle semantische Europäizität des Deutschen. Genauer: Der deutsche Wortschatz ist viel stärker, als allgemein angenommen, kein national-, einzelsprachlicher Wortschatz, sondern ein hochgradig europäischer, in zweitausendjährigem Kontakt mit Nachbar-, Bildungs- und Klammersprachen entwickelter Wortschatz (Reichmann 2001 und öfter). Das wird man angesichts der üblichen Ergebnisse der Sprachlehnforschung hinsichtlich der Ausdrucksseite des Wortschatzes wenn auch mit einer Reihe von Abstrichen anerkennen, für die Inhaltsseite aber trotz der jedem Proseminaristen bekannten Ausdrücke Bedeutungsentlehnung, Lehnbildung usw. aber bestreiten. Hier sei dennoch betont: Es geht bei semantischen Entlehnungen nicht um gerichtet gedachte, von Klammersprachen wie vor allem dem Lateinischen ausgehende, historisch-genetisch zu denkende Übernahmen einer irgendwie bemessenen Anzahl von Lehnbedeutungen in eine andere Sprache, sondern es geht um ein wechselseitiges Assoziations- und Bildgeflecht zwischen allen Sprachen des europäischen Text- und Übersetzungsverbandes, wie es sich in der Semasiologie weiter Wortschatzteile aller an diesem Verband beteiligten Sprachen, auch der genetisch weniger eng oder gar nicht verwandten Sprachen (etwa des Ungarischen), niederschlägt. Die diesbezüglichen Überraschungen bei der lexikographischen Arbeit seien am Beispiel des Wortbildungsfeldes mit nutz-/nuz- veranschaulicht. Im Kopf des Adjektivs nütze heißt es (Band 9, 3918):

Die Ausdrücke des gesamten Wortbildungsfeldes mit nütz-, nuz- unterliegen semantisch generell der lateineuropäischen Trias von (m)lat. utilis/utilitas/prodesse - honestas/honestum/ bonum - dulce/dulcetudo/delectare/delectatio. [...].

Die weiteren Bemerkungen beziehen sich auf die Kriterien, nach denen sich die Belegvorkommen unterscheiden lassen und begründbare Sememansätze ermöglichen. In einer Reihe auffälliger Belege wird durch Belegkommentare eigens auf den (m)lat. Hintergrund hingewiesen. Das Fazit lautet: Die Semantik des nütze-/nuzWortschatzes wird in europäische Zusammenhänge gestellt; das ist ein einzelsprachübergreifendes, historisches Ordnungsverfahren wortgeschichtlicher Fakten.

Die Artikelköpfe sind außerdem der systematische Ort einer kurzen Übersicht über die Beziehungen, in denen die angesetzten Sememe in der Fassung des Lexikographen zueinander stehen. Sie lassen sich in verschiedene Reihenfolgen bringen, von denen die plausibelste dann ausgewählt wird. Um e contrario klar zu machen, um was es hier bereits von den Vorentscheidungen her geht: Die zentralen Interesseeinheiten des FWB sind die Sememe, nicht z. B. syntaktische Muster, in denen sie erscheinen. Letztere $\mathrm{zu}$ ordnen, würde etwa für das Verb $\mathrm{zu}$ folgendem Ordnungstyp führen: erst der absolute Gebrauch, danach transitive Muster mit 
einem, anschließend mit mehreren Objekten sowie mit Angaben; die Semantik würde bei dieser primär grammatischen Ordnung auf eine zweite Ebene rücken, wäre damit grammatikorientiert. Im FWB läuft es umgekehrt: Die Semantik steht im Mittelpunkt, bestimmt also die Gliederung; die Syntax und alles Weitere stehen auf einer zweiten Ebene und sind semantikadressiert. Das führt $\mathrm{zu}$ folgenden, jeweils pragmatisch $\mathrm{zu}$ beachtenden Leitlinien: Bei einem niedrigen Grad der Polysemie sowie bei offensichtlicher Durchsichtigkeit ihres Bezuges kann auf Explizierungen im Artikelkopf verzichtet werden; dies gilt für die meisten Artikel. Bei hochgradiger Polysemie und Durchsichtigkeitsproblemen, insbesondere dann, wenn der Lexikograph selbst mehrere Möglichkeiten gegeneinander abwägt und dabei vielleicht noch Relevanzurteile einbezieht, wird er sich nach semantischen Gesichtspunkten zu entscheiden haben und seine Entscheidung vor sich selbst begründen müssen. Dies ergibt sich bei der reihenden Anordnung (wie im FWB) zunehmend spätestens dann, wenn mehr als ein Dutzend Ansätze im Spiel ist, bei der generisch ausgliedernden Anordnung spätestens beim dritten oder vierten Unterordnungsgrad, also bei A, I, 1, a. Der Ehrlichkeit halber sei erwähnt, dass das Fehlen von Ordnungsangaben im Artikelkopf auch die Verzweiflung des Lexikographen hinsichtlich akzeptabler Sememanordnungen dokumentieren kann.

Ordnungsangaben können im Umfang, in den Kriterien und in ihrer Komplexität erheblich schwanken. Hier sollen nur zwei relativ komplexe Beispiele vorgeführt werden:

$\mathrm{Zu}{ }^{1}$ gleich (Adj.) heißt es:

Dem hier gebotenen Bedeutungsspektrum liegt folgende Gliederung zugrunde: 1-11 auf mehrere gleiche oder gleichgesetzte Gegebenheiten bezogen, und zwar: 1 allgemeines Spektrum von ,Gleichheit, Ähnlichkeit', daran 2a-2c als Spezialisierungen anschließbar; 3-6 auf die Vergleichsrelation bezogen, 7 >infolge von Rechtsgleichheit gerecht<, 8-11 Zeit- und Raumverhältnisse betreffend; 12 >in sich gleichförmig<; 13-15 tropisch daran anschließbar; 16-17 konjunktionale und adverbiale Eigenentwicklungen.

$\mathrm{Zu}$ mitte (die) heißt es:

Ansatz 1 räumlich bestimmt, 2-6 dazu in tropischen Beziehungen stehend; 7 zeitlich bestimmt; 8-10 instrumental; 11 und 12 eher räumlich motiviert; im einzelnen außerordentlich vielschichtige motivationelle Vernetzung.

Man erkennt nachträglich: Es gibt kleinere logische Unstimmigkeiten in beiden Texten, ferner Vagheiten; die Vielschichtigkeit (von mitte) wird ohne nähere Angaben betont; einiges ist nur dann verstehbar, wenn man den gesamten Artikel kennt; es herrscht ein Wechsel der Kriterien; es gibt ein Rechtfertigungsargument des Lexikographen; das Suffix -bar im Sinne von $>$ kann werden $<$, nicht $>$ muss werden<, begegnet zweimal (s. v. ${ }^{1}$ gleich). Trotzdem gilt (zusammengefasst): Historische Bedeutungslexikographie beschreibt die Sememe eines Lemmazeichens als Teil einer Ordnung, an der der Lexikograph nicht nur einen Anteil hat, sondern die seine Ordnung „ist“. 
Sememinterne Nuancierungen setzen Sememe voraus. Diese erscheinen im FWB bereits durch die Ordnungszahl, mit der sie versehen sind, als in sich ganzheitliche, ungegliederte, eigenständige Einheiten; dies oder funktional Ähnliches wird sich in keiner Lexikographie vermeiden lassen. Folglich begegnet man immer wieder Zählungen oder Aussagen der Art: Das Wort $w$ hat im Frnhd. x Bedeutungen, bei minne sind es z. B. 9, bei mitte (die) 12. Oder: Das Wort $w$ ist hochgradig polysem, das Wort $z$ dagegen nur bisem (wie oben auch von mir hinsichtlich oberkeit gesagt). Hinter solchen Redeweisen steht die Übertragung des Copia-Gedankens auf die Semantik der Einheiten des Signifikates. Dem ist außer durch die gerade besprochenen Ordnungsangaben auf zweierlei Weise entgegenzuwirken, einmal durch die Antastung des Gedankens der inneren Ungegliedertheit der Sememe, zum anderen durch kürzere semantische Kommentare.

Die innere Ungegliedertheit des Semems wird im FWB zum Beispiel im Ansatz 5 von minne deutlich gemacht: Wenn minne dort

$>[. .$.$] in ihrer Qualität als erotische, teils versittlichend verstandene, den Menschen erhebende,$ teils auch als Lust thematisierte, teils als moralische Verfehlung, Verstrickung des Menschen betrachtete Kraft< $[. .$.

erläutert wird, dann verliert sie die Einheitlichkeit, wird genau $\mathrm{zu}$ dem, was im Laufe dieses Artikels immer wieder als geschichtstypisches Konstitut vermittelt wurde, in dem sich unterschiedliche geschichtliche und synchron gebrauchte Fäden des Sprechens und Schreibens zwar vereinen mögen, aber nicht ihre unterschiedlichen Facetten verlieren. Dieser letzte Erläuterungsteil findet eine Verstärkung dadurch, dass es zusätzlich heißt: „minne im Sinne moralischer Verfehlung ist mehrfach ex negativo an religiöse Orientierungswerte sowie an den Teufel gebunden“. Es wundert dann auch nicht, wenn noch eine Metonymie angeschlossen wird: nämlich >Geliebte; Ehefrau< (ohne dass deren Verhältnis thematisiert würde).

Einzelzeicheninterne Bezugsetzungen durch semantische Kommentare betreffen weniger die innere Verfasstheit der Sememe als ihr signifikatinternes Verhältnis zueinander. Sie enthalten Urteile des Lexikographen über Bezüge, die er nunmehr nicht innerhalb der Nuancen eines Semems, sondern zwischen zwei oder mehreren Sememen eines Lemmazeichens gegeben sieht. Dies sei mittels folgender Beispiele veranschaulicht:

- offen $\mathrm{zu}>2<$ “ (passim, z. B. unter mörder 1),

- „als Spezialisierung von 1 auffassbar“ (so unter misbrauch 2; ähnlich unter morden 2),

- „Motivierung von den Negativzuschreibungen von mor 1 her“ (so unter mor 2),

- ,breite Überlappung zu 1“ (so unter minne 3; ähnlich unter mord 1),

- „im Unterschied zu minne 1 Herausstellung der Gerichtetheit der Liebe vom Menschen auf Gott bei gleichzeitiger Schwächung des Absolutheitsgedankens von minne 1 und Betonung ihrer moraltheologischen gebothaftigkeit für den Menschen, des Gradierungsgedankens und des Eigenzutuns [...] des geistlichen Menschen“ (so unter minne 4). 
Formulierungen dieser Art sollen - so könnten sie gelesen werden - den Ansatz eines Semems nicht unter der Hand aufheben, sie sollen aber den Status seiner Wohldefiniertheit durch Betonung ihrer Offenheit zueinander im Bewusstsein halten.

Die onomasiologische Vernetzung dient der zeichenübergreifenden Bezugsetzung von Sememen mehrerer lexikalischer Ausdrücke. Es geht also um Sememsynonymie (z. B. zwischen Semem 1 zu Lemmazeichen $a$ und Semem 2 zu Lemmazeichen $b$ ), und zwar in aller Regel partieller Art. Das typische Bild hat die Form (formal):

Lemmazeichen $a$ in Bedeutungsansatz $>\mathrm{x}<$; dazu bdv. (= bedeutungsverwandt) partielles Synonym 1 (oder 2 oder 3 oder [...] n, jeweils wiederum pro Bedeutungsansatz).

Dem entsprechen die Realisierungen:

mindern [...] 4. >jn. erniedrigen, demütigen, jn. (die Personen der Dreifaltigkeit) herabwürdigen; [...]. - Bdv.: kränken 5, zerbrechen, zernischen; vgl. armen 1, beglimpfen 3, beschmahen 2, geschänden 3, mägern, peinigen 6.

Diese Beschreibungsposition ist dem Anspruch nach für jeden Bedeutungsansatz $\mathrm{zu}$ füllen, sie gehört also zu den zentralen Bauteilen des FWB und gilt als eines seiner allgemein beachteten Merkmale. Es wird eben nicht nur beschrieben, was rund 100.000 Wörter alles bedeuten, die Absicht ist ambitionierter: Jeder Bedeutungsansatz wird (wiederum dem Anspruch nach) in Relation zu semantisch ähnlichen Ansätzen anderer Lemmazeichen gesetzt, so dass der gesamte Wortschatz als vernetzt verfasst beschrieben wird, von mindern 4 etwa zu kränken 5, von dort zu noch nicht geschriebenem vermühen, oder ebenfalls von mindern $4 \mathrm{zu}$ peinigen 6 , von diesem zu einem knappen Dutzend weiterer Sememe und von diesen zu jeweils immer anderen. - Die Realisierung dieses Anspruchs unterliegt einer Reihe von Differenzierungen mit entsprechenden darstellerischen Formen, was hier aus Raumgründen nicht dargelegt werden soll. - Einiges sei dennoch bemerkt: Lücken der Füllung der Informationsposition erklären sich aus der Beleglage, wie sie im Corpus repräsentiert ist. - Der dem Semem eines (als polysem interpretierten) Ausdrucks beigefügte sog. Bedeutungsindex (bei mindern also die Zahl 4, bei kränken die 5) kann immer nur für die bereits bearbeitete Strecke angegeben werden; das ist eine rein arbeitstechnische Aussage. - Jedes Reden von „der“ (bestimmter Artikel) onomasiologischen Vernetzung, von „den“ Synonymen, erst recht die damit suggerierte Auffassung, dass „das“ (wieder bestimmter Artikel) ebenfalls gerne vorausgesetzte semantische Netz bei hinreichendem Fleiß und mit Hilfe des Computers irgendwann einmal vollständig oder gar endgültig dargestellt sein könnte, unterschreitet selbst das Stammtischniveau. Was dagegen geleistet werden kann, sind Vernetzungen, Angaben zur Onomasiologie usw., aber bitte jeweils ohne den bestimmten Artikel und in dem Bewusstsein, dass ,Vernetzungen' das Produkt des Vernetzens sind, das von Lexikographen vorgenommen wird. Bei Beachtung der 
vorhandenen wissenschaftlichen Standards darf dieser allerdings (schon aus Gründen der Motivierung seiner Tätigkeit) durchaus der Meinung sein, dass ein historischer Sprecher/Schreiber seinen Vernetzungen zustimmen würde. Wäre er dies nicht, würde seine Tätigkeit zur reinen Konstruktion von sinnvollen oder willkürlichen Gegenwartsinhalten (mit historischen Bausteinen) mutieren. Dieser Punkt wird später wieder aufgegriffen (Abs. 9). - Eher beiläufig sei noch erwähnt, dass jeder Lexikograph, der seine Inhalte eigenständig erarbeitet, fortwährend im Zweifel darüber steht, wie stark er abstrahieren bzw. typisieren und wie er die Grenzen zwischen Sememen legen soll. Es gehört zum Tagesbetrieb und ist zeitaufwendig, einmal angesetzte Sememe bei näherem Hinsehen lieber zusammenzunehmen oder ein einmal ausformuliertes Semem doch lieber zu trennen oder gar seine Formulierungsdetails in mehrere andere Sememe zu integrieren.

Seit etwa einem Jahrzehnt erscheinen die Angaben zur onomasiologischen Vernetzung oft in Verbindung mit Orientierungsfeld, also in der Form Bdv. (bzw. Orientierungsfeld); teils steht auch einfach Orientierungsfeld. Der Grund für diese Neuerung liegt einmal darin, dass bedeutungsverwandte Ausdrücke in der Folge des von J. Trier geprägten Terminus Wortfeld handlungsunabhängig gedacht und in der strukturalistisch orientierten Lexikologie höchstens beiläufig soziosemantisch verstanden wurde. Der Ausdruck Orientierungsfeld soll beides verbinden, die soziokognitive und die handlungssemantische Komponente. So verstanden öffnet er dem Lexikographen die Möglichkeit, sein Wortfeld in Richtung auf die frames ${ }^{23}$ $\mathrm{zu}$ öffnen und damit den gesamten sprachlichen Denk- und Handlungsrahmen zu umreißen, in dem der Wortgebrauch steht. Beispiele sind:

müssiggang; [...]. 2. >Untätigkeit, Nichtstun, Trägheit, Faulheit als Ausdruck, Form und Ursache der Laster der Menschen<. [...]. - Bdv. (bzw. Orientierungsfeld): bosheit 1, gebreste 1, eitelkeit, faulkeit, hoffart, laster 1, lauigkeit 2, ruhe, sorglose, sünde, trägheit, wollust.

mut, der/die/das; [...]. 1. >mittleres Getreidemaß [...]<. [...]. - Orientierungsfeld: eich, imi 1, malter 3, ${ }^{1}$ masse / ${ }^{2}$ mas 5, ${ }^{1}$ metze 2, schaf, scheffel, sechster, sumer, viertel.

Auch die Syntagmenangaben sind an das Semem adressiert; sie werden also nicht in irgendeinem autonom gedachten grammatisch-syntaktischen Zusammenhang in entsprechend ausgerichteter Fachsprache beschrieben, sondern zu dem Zwecke, etwa für die Substantive alles das zusammenzutragen, was man in geschichtlicher Zeit über bestimmte Bezugsgegenstände, z. B. über ,oberkeit‘ 1, gesagt, wie man sie konstituiert, charakterisiert und bewertet, auch personifiziert, tropisiert, z. B. in Bildern instrumentalisiert hat. Über die anderen Wortarten wäre je Entsprechendes

23 Hierzu umfassend Konerding 1993. 
zu sagen. Realisiert wird das Programm am ehesten durch Auflistungen, die den Beleginhalt mittels der üblichen Tilgungsverfahren auf genau dasjenige reduzieren, was die Bezugsgröße des Semems betrifft. - Am Beispiel oberkeit 1 demonstriert ergibt sich dann folgendes Bild:

Synt.: (die) o(berkeit) haben/brauchen/aufheben, got die o. in uns setzen, j. jm. oberkeiten verleihen; die o. (Subj.) regieren (z.B. über leib und gut), die gewalt zu gebieten/richten haben, den freien willen von got haben, die o. eine götliche ordnung sein; got die höchste o. sein (usw., noch 20 Spaltenzeilen).

Der Wert der Syntagmen auch für die genaue Ausrichtung und die Details der Bedeutungserläuterung dürfte schon deshalb auf der Hand liegen, weil sie primär semantisch, an der Belegaussage, höchstens in zweiter Linie an syntaktischen Mustern orientiert sind. Die genaue Methode ihrer Gewinnung, ihre Anordnung, generell: alles eher Technische kann hier außer Betracht bleiben. Entscheidend ist ihre Funktion im Rahmen der lexikographischen Philosophie des FWB: Indem sie je Einzelnes zusammenstellen, auch das Typische als Einzelnes darbieten, und indem dieses je Einzelne immer anders ist als jedes andere Einzelne, ahmen sie - ohne dass der Lexikograph sich dessen bewusst sei - gleichsam den Spracherwerbsund Spracherweiterungsprozess nach, den ein Sprachlernender im Laufe seines gesamten Lebens vollzieht. Das ist Verschiedenheit, aber eine solche, die der Lexikograph verwaltet. Die unter der Position ,onomasiologische Vernetzung b besonders betonten Sememüberlappungen gelten in analoger Weise für die Syntagmen. Ihr Verknüpfungswert ergibt sich daraus, dass sie auch in vielen anderen, meist an buchräumlich weit entfernter Stelle stehen. Nur der Computer kann damit fertig werden; und er wird es: angreifen z. B. begegnet in 23 Syntagmen, und zwar nicht an Lemmazeichen adressiert, sondern an Sememe. Diese werden dadurch zu Identitäten unter dem Blickwinkel, dass man sie angreifen kann, und fungieren in dem Maße, in dem sich solche Prädikationen bündeln, synomymiebegründend.

Hier ließe sich wieder auf eines der Tagesprobleme des Lexikographen verweisen: Welche Belege nehme ich aus welchem Grunde zusammen und welche schließe ich aus? Überlappungen sind die Vorkommensform von Syntagmen und Sememen; sie verlangen vom Lexikographen die stetige Bereitschaft, einmal Festgelegtes zu verändern, und erweisen ihn insofern als Gestaltenden des semantischen Netzes.

Zur Demonstration des Verfahrensverlaufes sei exkursartig die Probe aufs Exempel vorgenommen: Zur Debatte steht wieder der Artikel oberkeit, nunmehr aber nicht (wie oben, S. 314 f.) mit dem Blick auf das Verhältnis von Kognition und Handlung, sondern mit Blick auf die Syntagmen und ihren Aussagewert für die semasiologische Gliederung. Die Regel lautet: Je deutlicher sich die Syntagmen in unterschiedliche Gruppen gliedern lassen, desto begründeter unterscheidet man sich für mehrere Sememansätze. Dazu hole ich etwas weiter zu einem Exkurs aus: 
Der Artikel oberkeit ist zweifellos ziemlich schwierig. Eine Anzahl von - je nach Zählung - 700 bis 800 Belegen will erst einmal überhaupt gelesen sein (das kostet Zeit) und gleichzeitig bzw. nach dem Lesen auf mögliche semantische Unterscheidungen abgeklopft werden. Man erwartet hochgradige Polysemie. Ein klares Ergebnis kam nicht zustande. Immerhin aber schien mir eine Trennung zwischen ,oberkeit‘ als abstrakter und als eher personaler Größe nicht ausgeschlossen zu sein. In einer solchen Situation sucht man nach Gliederungshilfen in anderen Wörterbüchern. Das DWB $(7,1115)$ bringt unter obrigkeit eine Unterscheidung von (gekürzt) $>$ herrschaftliche Gewalt< und >Regierung, Behörde<; das DRW (10, 215-223) hat vier Ansätze, und zwar I. >Herrschaft, Hoheit<, II. >Hoheitsträger<, III. >Gerichtsbarkeit<, IV. > Gebiet einer Obrigkeit<. Das lief hinsichtlich der ersten beiden Ansätze auf eine Bestätigung meines Leseeindruckes hinaus, den ich denn auch weiter verfolgte. Es zeigte sich aber bald, dass eine hohe Anzahl von Belegen verschieden interpretierbar war: Das gesamte Bedeutungsspektrum ließ immer wieder eine ansatzweise oder offen erkennbare metonymische Lesart der einzelnen Belege zu, also eine Lesung als Grenzverschiebungstropus, nicht als Sprungtropus ${ }^{24}$ (wie bei der Metapher). Das bedeutete sowohl die Infragestellung der Zweiergliederung zugunsten von Homonymie wie die Möglichkeit des Ansatzes hochgradiger (im Grund: endloser) Polysemie.

Die Abwägung lief schließlich auf die Zweiergliederung hinaus. Die Metonymie, die das gesamte Gebrauchsspektrum von oberkeit durchzieht, dient dabei als Kriterium sowohl für den signifikatinternen Ansatz zweier Sememe wie für die sememinterne Erwähnung einiger Bedeutungsnuancen. Aufs einfachst Mögliche reduziert:

1. $>$ Hoheit< (in Ansatz 1) ist unmittelbar einsichtig etwas anderes als >Hoheitsträger< (in Ansatz 2); deshalb stehen 2 Sememe; beides hängt aber ebenso einsichtiger Weise miteinander zusammen. Diese (metonymische) Relation wird beschreibungssprachlich nicht explizit ausgedrückt, weil sie offensichtlich ist.

2. Im Unterschied dazu wird die Metonymie sememintern für beide Ansätze betont, unter Ansatz 1 mit „metonymisch“ und einige Spaltenzeilen später mit „dazu wiederum metonymisch“ (dies erinnert an das bekannte romantische Dictum von der Metapher der Metapher), in Ansatz 2 mit „kaum trennbares Metonymieverhältnis“.

Mir ist natürlich bewusst, dass es nicht gerade souverän ist, sememintern dauernd von Metonymie zu sprechen und eine klare Metonymie zwischen den Sememen nicht explizit zu nennen.

An dieser Stelle kommen die Syntagmen ins Spiel: Die Unterscheidung zweier Sememe muss sich in den Syntagmenangaben spiegeln oder auch nicht (in diesem Falle würde ich den Artikel haben umschreiben müssen). Ich beschränke mich bei der Prüfung auf die Syntagmen, in denen oberkeit als Subjekt fungiert:

24 Beide Termini im Sinne Lausberg, z. B. 1993. 
Synt. (zu Ansatz 1 von oberkeit): [...]; die o. (Subj.) regieren (z. B. über leib und gut), die gewalt zu gebieten / richten haben, den freien willen von got haben, die o. eine götliche ordnung sein; [...].

Synt. (zu Ansatz 2): die o. (Subj.) gebieten / richten / strafen / tyrannisieren, zu etw. gesezt sein, die o. christlich sein mogen (>können<), gewalthaber auf erden, gottes dienerin, gleich dem hirten sein, das schwert haben, das wild (>den Wildbann<) haben wollen, schos fordern, das volk beschirmen, böse buben hinweg räumen, das übel bestrafen, die hoffart steuern, gesetze gebieten, die zucht verwalten, ordnung machen / handhaben (und so noch 8 Spaltenzeilen weiter).

Es gibt in beiden Ansätzen Syntagmen, die in die gleiche Richtung gehen, z. B. die Gottgegebenheit der ,oberkeit‘, oder die Aufgabe betreffen, zu gebieten und zu strafen. Dennoch springen die Unterschiede deutlich in die Augen: In 1 ist die Aussagenreihe zur Subjektgröße kürzer, ideologischer (freier wille), allgemeiner. In 2 ist sie umfänglicher, praxis-und handlungsbezogener (z. B. schos fordern), konkreter (das schwert haben), sie enthält Konfliktandeutungen (das wild haben wollen), steigt in den Alltag hinab, liest sich insgesamt wie ein Aufgabenkatalog der ,oberkeit‘. Die Subjektgröße ist weit deutlicher als in 1 eine Handlungsinstanz mit sogar persönlichen Zügen.

Damit scheint mir der Ansatz zweier Sememe von den Syntagmen her gesehen zwar nicht zwingend, aber doch aspektuell besser begründet zu sein als ein monosemistischer Ansatz; die Prüfung der Synonymenangaben unter der Position „Bdv.“ führt zu einem entsprechenden Ergebnis. Die sememinternen Nuancierungen beider Sememe sind selbstverständlich diskutabel, lassen sich aber ebenfalls als aspektuell gut begründet nachweisen. - Diese gesamte Diskussion steht unter dem Stern der lexikographischen Fassung der sprachtheoretischen Vorannahme, dass der Wortschatz einer Sprache Systemhaftigkeiten habe, die vom Lexikographen in jeweils bestimmter Weise, gleichsam als >solche $1<$ und als >solche $2<$ gestaltet und vermittelt werden müssen. Die Syntagmen zeigen Ruhepunkte und Differenzen.

Das FWB ist auch als wortbildungsbezogenes Wörterbuch konzipiert. Unter dem Aspekt ihrer Systemhaftigkeit erscheinen Wortbildungen an folgenden Stellen und in folgender Art:

- Unter einem selbständigen Lemma, für das das volle Beschreibungsprogramm wie für ein Simplex gilt. Dieser Fall betrifft all diejenigen Bildungen, die der Lexikograph als semantisch lexikalisiert (im üblichen Sinne) interpretiert, und für die einiges Weitere gilt (z. B. dichte Belegung, kulturhistorische Relevanz),

- in einer Position Wbg. (= Wortbildung) im Anschluss an die Syntagmen, und zwar dann, wenn das in Frage stehende Wortbildungselement als semantisch weitgehend deckungsgleich mit einem Simplex oder einer Wortbildungsbasis interpretiert wird (und weitere Kriterien gelten),

- im einzelnen bestehen Sonderregelungen (dazu Reichmann 2012, S. 412-432). 
Die Beschreibung besteht aus einem Kommentar, in dem der Lexikograph jede Wortbildungseinheit (ein Bestimmungswort, ein Grundwort, eine Basis, ein Affix) in Bezug zu einer freien Einheit (meist zu einem Simplex) oder zu mehreren solcher Einheiten setzt. Erfolgt die Bezugsetzung mittels der Partikel $z u$, so heißt dies: Die jeweiligen Einheiten werden vom Lexikographen als semantisch deckungsgleich (kongruent, synonym) angesehen. Erfolgt sie mittels vgl., so heiß das: Sie werden als semantisch ähnlich (partiell synonym) angesetzt; in diesem Falle sind logischerweise mehrere Bezugsetzungen möglich. - Eigens betont sei, dass alle Bezugsetzungen als Remotivationen des Lexikographen zu sehen sind, also auf der Voraussetzung beruhen, dass er die geschichtliche Motivation von Sprechern und sogar mögliche Mehrfachmotivationen zu erkennen vermag. Der Lexikograph tut also für das Frühneuhochdeutsche genau das, was G. Augst für das Neuhochdeutsche getan hat, und zwar über rund fünf Jahrhunderte zurückgreifend. Dieses motivationssemantische Handeln des Lexikographen entspricht ebenso wenig der üblichen historisch-genetischen Vorgehensweise der Wortbildungslehre (die freilich meist selbst geschichtlich vorgeprägt ist), wie die Sememe aufgrund ihrer synchronen Semantizität nicht mehr auf der Bedeutung einer möglichst alten Wurzel (einem sog. Urbegriff, einer Urbedeutung; s. Reichmann 1991) aufbauen, die in allen neueren Sprachstadien noch irgendwie (z. B. resthaft, abgeblasst, vergeistigt) erkennbar ist, ${ }^{25}$ sondern auf Unterscheidungen des Lexikographen, für den diese geschichtliche Linie aber durchaus eines von mehreren Unterscheidungskriterien liefern kann.

In der Realität ergeben sich dann wortbildungsbezogene semantische Kommentare folgender Art (jeweils am alphabetischen Ort):

mülgang 2 [...]; zu müle 1, gang (in einer dort nicht gebuchten Bedeutung),

mülgang 3 [...]; zu müle 1, gang 1 (ütr.).

mülgeschir [...], zu müle 1; vgl. geschir 1; 6.

mülgrabe [...]; zu müle 1, grabe 4.

In Fällen, die nach Ansicht des Lexikographen besondere Aufmerksamkeit verdienen, können Erweiterungen vorgenommen und in die Bedeutungserläuterung eingegliedert werden:

minnewerk [...]; minnewerk steht im Spannungsverhältnis zwischen minne 1-4 einerseits und minne 6 andererseits, [...].

Im Ergebnis wird die Gesamtheit frnhd. Wortbildungen pro jeweilige Einheit (meist: lexikalische Morpheme pro Semem, auch Präfixe, vgl. z. B. er-, nach-) ähnlich in Motivationszusammenhänge gestellt, wie dies für die Sememebene zeichenüber-

25 Dass dies möglich ist und zu einsichtigen Bildern eines semantischen Stammbaums führen kann, belegen sowohl BMZ wie das Schweiz. Id. von ihrer ganzen Anlage her. 
greifend durch die onomasiologische Vernetzung geschieht. Dieses Verfahren ersetzt die ältere stammwortbezogene Lexikographie (prototypisch realisiert im Schweiz. Id., speziell in seinem Terminus Sippenleitwort) mit ihrer Betonung der Zeitlinie auf geschichtlich synchrone Verhältnisse, hier also auf das Frühneuhochdeutsche. Das ist ein weiteres Moment der Beschreibung bzw. Schaffung von synchroner Systemhaftigkeit des Wortschatzes durch den Lexikographen. Von besonderer Relevanz ist dabei die leichte Erkennbarkeit, welches Semem welcher Wortbildungskomponente die Grundlage welcher Wortbildungen liefert. Für die gerade gebrachten Beispiele ist es jeweils müle 1, dessen Bedeutung >Getreidemühle< eine ganze Wortbildungsreihe eröffnet. Auch die jeweiligen Zweitglieder können hinsichtlich der Wortbildungsmotivation zusammengestellt werden, zeitaufwendig durch einzelnes Nachschlagen, auf digitalem Wege durch einfache Suchbefehle. Bleibt man im Bild der schon mehrmals bemühten, ,semantischen Verdichtungen“, so lassen sich ganze Stränge des Bezuges von Wortbildungen auf einen der Bedeutungsansätze beziehen; zu steuer $1>$ Leistung zum Zwecke der Finanzierung obrigkeitlicher Aufgaben< sind im FWB 34 Bildungen nachgewiesen. Der gesamte Rest der acht Ansätze von steuer bringt es auf nur 15 Einheiten. Das wären dann keine Stränge, sondern lediglich Linien. ${ }^{26}$ Würde man das Gesagte in ein Bild bringen, so hätte dieses wohl folgende Gestalt (generalisiert):

Lemmazeichen

Semem 1:

Semem 2:

Semem 3:

Abb. 3: Die Wortbildungsfruchtbarkeit von Semen.

26 Diese Verhältnisse verbinden sich bei mir mit einer ganzen Reihe weiterer, aber hier nicht relevanter Überlegungen. Dennoch sei die Möglichkeit angedeutet, ein Wörterbuch zum Grundwortschatz des Deutschen, das in den siebziger Jahren des 20. Jahrhunderts wiederholt im Gespräch war, zu begründen: Im Mittelpunkt der Lemmaliste hätten all diejenigen Einheiten zu stehen, die sich durch eine hohe Wortbildungsfruchtbarkeit auszeichnen. Innerhalb dieser Auswahl wären diejenigen Sememe aufzunehmen, die in die meisten Wortbildungen eines großen Bezugswörterbuches eingegangen sind und ihrerseits wieder neue Wortbildungen angeregt haben. Ein z. B. als Basiswörterbuch „Deutsch als Fremdsprache“ verstandenes Ausgangswerk für einbändige zweisprachige Wörterbücher (mit der linken Seite ,deutsch` und der rechten Seite ,anderssprachig‘) läge gleichsam auf der Hand. Für historische Sprachstufen, also das Althochdeutsche, Mittelhochdeutsche, Frühneuhochdeutsche ließen sich Werke entwerfen, die die Glossare nach dem üblichen Billigmuster überflüssig machen würden. 
Für die Belege gilt verstärkt das zu den Syntagmen Gesagte. Sie werden nach den vom Lexikographen erkannten Gebrauchsähnlichkeiten des gerade behandelten Lemmazeichens sortiert. Sie dienen der Herausarbeitung von Sememen, und zwar so, dass sowohl deren Unterschiedenheit wie ihre Offenheit einsichtig wird. Dass die Belege selbstverständlich auch andere Zwecke erfüllen, ist ohne Weiteres so einsichtig, dass es hier nicht näher erläutert werden muss. - Dies gilt mit ganz anderer Begründung auch für die Phraseme: ${ }^{27}$ Sie sind eigentlich lexikalische Einheiten, müssten insofern genau wie diese nach dem gesamten Informationsprogramm des FWB abgehandelt, z. B. auf ihre Systematizität (ihre Polysemie und Synonymität, auch ihre Symptomwertigkeit usw.) befragt werden. Da das FWB dafür keine systematische Basis liefert, sei hier nicht weiter auf sie eingegangen.

An dieser Stelle seien auch noch einige Hinweise auf die sog. Symptomwertangaben angebracht. Es handelt sich dabei um sememadressierte Angaben, in welchen Räumen des frnhd. Sprachgebietes, in welchen genauen Zeiten und in welchen Textsorten ein Lemmazeichen pro Bedeutung nach Ausweis des Corpus gebraucht wurde. Damit heben die Symptomwertangaben die Sememe aus dem Status frei im Verfügungsraum aller Sprechenden und Schreibenden, gleichsam über den Straßen schwebender kognitiver und handlungssemantischer Inhalte heraus und stellen sie in einen räumlichen, zeitlichen und textsortenbezüglichen, damit auch situationstypischen Rahmen. - Zeichentheoretisch gesehen sind sie nicht Symbole, sondern Anzeichen, indexikalische Zeichen im Sinne von Ch. S. Peirce; sie beschreiben nicht die Bedeutungsbildung, sondern setzen das erarbeitete Semem in einen Verweiszusammenhang mit Raum-, Zeit- und Textsortengegebenheiten. Wenn also das Eine (das Semem) gegeben ist, dann ist auch das Andere zu erwarten; genauer: Wenn ein Lemmazeichen $a$ in einem irgendwie umrissenen Raum, in einer irgendwie abgegrenzten Zeit und in irgendwie verstandenen Textsorten in der Bedeutung $>\mathbf{x}<$ begegnet, dann gilt dieses Verhältnis so, wie Rauch auf Feuer (und umgekehrt) hindeutet. In dem Maße, in dem man bei den geschichtlichen Sprechern/Schreibern ein Bewusstsein dieser Raum-, Zeit-, Textsortenlagerungen voraussetzt und auch bei den Hörern/Lesern Entsprechendes annimmt, wird man den Symptomwertangaben ein Identifikationspotential in dem Sinne zuschreiben können: Das ist mein Raum, meine Zeit, meine Textwelt, nicht die des Anderen. Das bedeutet Gliederung von Sprechergruppen. Pragmatisch verteilte semantische Identitäten (im hier diskutierten Fall Sememe; nicht Wörter) tasten die Einheitsvorstellung des Sprachgebrauchs an, darunter die Konstitution einheitlicher sprachinhärenter Inhalte und Handlungsvorgaben, und ersetzen sie durch ein mehrdimensional organisiertes Mit- und Gegeneinander. $\mathrm{Zu}$ beachten ist, dass es

27 Phraseme werden lediglich genannt und - falls notwendig - mit keiner kurzen Bedeutungsangabe versehen; das weitere lexikographische Beschreibungsprogramm würde die Artikelstruktur überlasten. Die Alternative, einen eigenen Ansatz für jedes Phrasem oder für alle Phraseme zusammengenommen einzurichten, scheitert daran, dass die partielle Motiviertheit eines Phrasems besser zum Ausdruck kommt, wenn man es an das Semem bindet. 
hier nicht, wie prototypisch im Deutschen Wortatlas (DWA) institutionalisiert, darum geht, wer welche Zeichengestalt, Sonnabend oder Satertag oder Samstag, Spree oder Star, Peitsche oder Geissel gebraucht, sondern darum, wer welche Inhalte eines einzigen Wortes wie ertextet (am besten von kulturell relevanten Einheiten des weiteren Sozialwortschatzes, also von sog. culture bound words). - Das sei am Beispiel abenteuer (in den Ansätzen 1, 3 und 9) kurz veranschaulicht:

abenteuer; [ ...].

1. $>[. .$.$] ritterliche Bewährungsprobe [. .]<$.. - Vorwiegend obd., gehäuft wobd.; 14. / 15. Jh.; fiktionale, archaisierende und historisierende Texte.

3. >militärische Auseinandersetzung [...]<. - Vorwiegend md. / nobd; 15. Jh.; Fachliteratur zum Kriegswesen.

9. $>[. .$.$] Gaukelspiel, Narretei, Zaubertrick [...]<. - Spätes Frnhd.; agitatorische und$ erzählende Texte, Fastnachtspiele.

Das Beispiel abenteuer (FWB, Band 1, 61-68; publiziert 1986) enthält für 13 von insgesamt 17 Bedeutungsansätzen Symptomwertangaben. Auch wenn diese nach den heutigen Regeln des FWB teils als unzureichend begründet anzusehen sind, zeigt sich doch: Die Bedeutung 1 >ritterliche Bewährungsprobe< passt zu der Raum-, der Zeit- und der Textsortenverdichtung der höfischen Epik und setzt sich mit mannigfach veränderten Nuancen in späterer Zeit, in anderen Textsorten und in einem teils erweiterten Raum fort; der Ansatz 3 zeigt eine räumliche Beschränkung auf das Mitteldeutsche und Nordoberdeutsche; Ansatz 9 ist zeitlich beschränkter belegt und findet sich in eigenen Textsorten; semantisch scheint er keine Fortsetzung zu finden. Das alles liest sich im Kern wie ein Segment einer zeit- und raumbezogen sowie literarisch-textgeschichtlich differenzierenden Skizze mitteleuropäischer Kulturtradition, natürlich auf lateineuropäischer Basis.

\section{Die wissenschaftliche Ebene historischer Lexikographie}

Der Gegenstand dieses Abschnittes wird in kleinen Schritten ${ }^{28}$ entwickelt; er ergibt sich aus der Situation, in der jeder Lexikograph steht. Das heißt:

1. Er zielt - vergangenheitsbezogen - auf den Wortschatz eines bestimmten Sprachstadiums, etwa des Mittelhochdeutschen oder des Frühneuhochdeutschen.

28 Teils werden Aussagen gemacht, die sich aus anderen ergeben. Die damit gegebene Ausführlichkeit bitte ich als Zeichen dafür zu werten, dass mir das Folgende als besonders relevant erscheint. 
2. Er richtet sich - gegenwartsbezogen - mit seinen Ergebnissen an ein irgendwie bemessenes Publikum seiner eigenen Zeit, speziell an die im weitesten Sinne verstandenen Kulturhistoriker. ${ }^{29}$

Beide Aspekte dieser Situation sind untrennbar miteinander verbunden. Selbst wenn man der Meinung wäre, man löse sich als Historiker mit seiner Rückwärtsgewandtheit im Sinne von (1) doch selbstverständlich aus seinen gegenwartsbezogenen sozialen Einbindungen, Interessen, Ideologien und arbeite rein objektiv mit dem Blick auf die Nachzeichnung von Vergangenem, so wird man dies schon deshalb mit schlechtem wissenschaftlichem Gewissen vollziehen, weil man ja gerade als Historiker weiß, dass es den unhistorischen Menschen nicht gibt. Schon dadurch, dass er in Sprache, d. h. immer: in einer bestimmten Sprache forschend tätig ist und seine Ergebnisse in einer bestimmten Sprache vermitteln muss, ist jede Form von Sprachunabhängigkeit ausgeschlossen.

$\mathrm{Zu}$ dem gerade genannten Punkt (1) stellt sich die Frage, was es heißt, auf einen geschichtlichen Wortschatz zu „zielen“. Diese Formulierung enthält die Präsuppositionen, dass es den Wortschatz in anerkannten Umrissen gibt und dass er bestimmte Funktionen habe. Objektsprachlich gesehen bedeutet das (hier rufe ich mehrfach Gesagtes in Kurzform wieder auf):

- Wortschatz bezeichne etwas wie auch immer, z. B. sachlich oder begrifflich Vorgegebenes. Seine Einheiten seien durch den Lemmaansatz zu dokumentieren, und die bezeichnete Sache sei zu beschreiben; man spricht in diesem Sinne von der Darstellungsfunktion.

- Lexikalische Inhalte (Bedeutungen) würden im (nicht: durch, instrumental gesehen) Sprechen/Schreiben irgendwie situationsadäquat gestaltet, unterlägen insofern grundsätzlich der Veränderung; das wäre die Kognitionsfunktion.

- Wörter seien Einheiten, in denen man soziosituativ handle, was ebenfalls Veränderung impliziere; dies wäre die Handlungs-, Kommunikationsfunktion.

- Wörter seien auch Symptome (Indices) für bestimmte Dimensionen des Sprechens/Schreibens, damit Möglichkeiten, sich und den anderen über bestimmte Inhalte des Sprechens/Schreibens als Gruppenzugehörige zu erkennen; dies wurde als Symptomfunktion bezeichnet.

29 Verwiesen sei auf eine ganze Liste von Aussagen, die in diesem Artikel für die Lexikographie als gegenwärtige wissenschaftliche Tätigkeit gebraucht wurden; sie betrafen das Wörterbuch als Gegenstand gegenwärtiger Rezeption, die kulturelle Tätigkeit des Wörterbuchbenutzers, den diachronen Differenzgedanken, den wissenschaftlichen Erkenntniszweck und den pädagogischen Handlungszweck, den Lexikographen als kognitiv Gestaltenden sowie als Handelnden, das Verhältnis von Vorgaben des Lexikographen und gegenwärtiger Lexikographie, das kulturhistorische Interesse des Lexikographen. 
Diese Bestimmungen der objektsprachlichen Leistungen des Wortschatzes können selbstverständlich ergänzt oder gar durch andere ersetzt werden. Wenn man sie als Verhandlungsbasis akzeptiert, dann würde ${ }^{30}$ „auf etwas zielen“ bedeuten können:

- Ein heutiger Lexikograph beschreibe metasprachlich das lexikalische Bezeichnen von Realitäten durch geschichtliche Sprecher (z. B. Frühneuhochdeutsch Sprechende).

- Er beschreibe metasprachlich das Konstituieren (das Gestalten, Fingieren, Ersemantisieren) von Bedeutungen (wiederum durch geschichtliche Sprecher).

- Er beschreibe metasprachlich das Handeln (Kommunizieren, Erpragmatisieren) in lexikalischen Einheiten (durch geschichtliche Sprecher).

- Er beschreibe metasprachlich den Wortschatz als Rahmen, in dem sich geschichtliche Sprecher wechselseitig als mittel- oder oberdeutsch, als ripuarisch oder bairisch oder elsässisch sprechend oder als katholisch bzw. protestantisch redend oder als schreibfähig bzw. schreibunfähig erkennen und damit Gruppenidentifikation und Weiteres betreiben können.

Dies in eine optisch fassbare Form gebracht, führt zu folgendem Bild:

geschichtliches Bezeichnen

geschichtliches Prägen/Bilden

geschichtliches kommunikatives Handeln wird heute (historisch) dargestellt/beschrieben

Gleichgültig, was auf geschichtlicher Ebene geschieht: Es wird dargestellt/beschrieben. Dies kann unbewusst oder bewusst, unbetont oder mit besonderer Gewichtung, je einzeln oder zusammen vollzogen werden.

Nun arbeitet der historisch orientierte Lexikograph - jetzt im Sinne des einleitenden Punktes (2) verstanden - rund ein halbes Jahrtausend später bei aller Betonung der Freiheit von Forschung und Lehre und bei aller zugestandener Metasprachlichkeit ja nicht im freien, sondern im sprachsozialen Raum von Wissenschaft, Kulturpädagogik usw. In diesem Moment mutiert er, wie immer man seine Tätigkeit sehen und wie immer man sie als metasprachlich, als rein erkenntnisbezogen (usw.) von normalsprachlicher Tätigkeit unterscheiden zu müssen meint, selber zum normalsprachlichen Sprecher. Es gibt eben keine klare Trennungslinie zwischen dem

30 Man achte auf den Konjunktiv, der zwar eine Aussage zulässt, diese aber in kritische Distanz rückt. 
Einen und dem Anderen. Kein Historiker schreibt nur zum Zwecke wertfreier Erkenntnis, die in einer Bibliothek sicher, am besten unzugänglich aufbewahrt wird, sondern für interessierte und zu interessierende Rezipienten. Insofern tut er dasjenige, was auch jeder geschichtliche Sprecher tut: Er stellt dar, beschreibt (a); er prägt, bildet, fingiert soziokognitive Inhalte (b); er kommuniziert/handelt in diesen Inhalten (c); und er trägt durch die Art, wie er das alles vollzieht, zur Gruppenbildung und -identifikation bei, und das alles beziehungsgesteuert, mit dem Blick auf den Anderen, in fundamentaler Relation zu einem Zweiten und gar zum allgemeinen ,man' mit seinem Rest von Persönlichkeit. Diese Überzeugung prägt den gesamten hier vorgelegten Artikel. Sie wurde im Laufe meiner Ausführungen wach gehalten durch die dauernde Herausstellung des Lexikographen als eines systemhaft Gestaltenden, durch die mehrfache Erwähnung seiner Vermittlungsleistung.

Um auf die Bedeutung des Verbs zielen zurückzukommen: Der Lexikograph „zielt“ auf alle vier Funktionen des geschichtlichen Wortschatzes, indem er sie als Bausteine für sein eigenes Beschreiben, sein Prägen/Bilden, Fingieren, sein Kommunizieren/Handeln und Gruppenbilden nutzt. Damit öffnet sich sein Tun (und seine Aufgabe) vom sog. reinwissenschaftlichen Darstellen/Beschreiben, einer rezeptionsorientiert gesehen sehr schmalen Basis, in die volle Weite des sozialen Interessehorizontes einer Gesellschaft. Dies kann (nicht: muss) heißen:

- Man vollzieht geschichtliches (also: rückwärtsgerichtetes, sachbezogenes, höchstens beiläufig partnerorientiertes) Darstellen auch gegenwartsbezogen als Darstellung (das soll hier zum Beispiel heißen: ohne explizite Partnerorientierung).

- Der Bezug auf geschichtliches Prägen/Bilden/Fingieren wird gegenwartsbezogen wiederholt, also ebenfalls als Prägen usw.

- Der Bezug auf geschichtliches Kommunizieren/Handeln wird in gegenwartsbezogenes Handeln umgesetzt.

- Der Bezug auf geschichtliches Gruppenbilden wird als gegenwartsbezogenes Gruppenbilden betrieben; die Bildung einer Gruppe ,Protestanten“ im 16. Jahrhundert wird in die Gegenwart verlängert, verstärkt, als Identifikationskriterium aktiviert.

Diese Aussagen beinhalten, dass die geschichtlichen vier Funktionen sich in entsprechenden wissenschaftlichen Redeweisen fortsetzen. Obwohl dies erst einmal einsichtig sein dürfte, sei kurz und mit kritischem Unterton auf einige Konsequenzen hingewiesen, die ebenfalls einsichtig sein dürften: Wenn ich geschichtliches Darstellen in der Gegenwart darstellend wiederhole, werde ich wohl kaum das primäre Interesse von Rezipienten finden. ${ }^{31}$ Auch wenn man geschichtliches Prägen/ Bilden/Fingieren (etwa die kognitiv relevante Auseinandersetzung zwischen Rea-

31 Mit dieser Aussage wird man wohl die Situation vieler Sparten der Geschichtsschreibung, damit auch der Sprachgeschichtsschreibung, erkennen. 
lismus und Nominalismus) illokutiv äquivalent in die Gegenwart transferiert, wird man auf eingeschränktes Interesse stoßen, da der Konflikt entschieden ist (oder doch nicht?). Und wenn man M. Luther als reformatorisch Handelnden begreift und dieses Handeln in der Gegenwart fortzusetzen gedenkt, agiert man zumindest nicht im Zentrum des heutigen Interessestromes, vielleicht aber doch am Rande. Entsprechendes gilt für historische Kontinuitäten bei der Gruppenbildung; die Konfessionsspaltung mag irgendwie noch vorhanden sein, hat aber ihre Schärfe verloren. Gegen jede dieser Aussagen wird es berechtigte Einwände geben. Diese werden möglicherweise die Rolle der sog. reinen Erkenntnis, vor allem im Verhältnis zur heutzutage großgeschriebenen interessegeleiteten Handlung betreffen. - Das Fazit lautet: Alles, gleich was und wie es geschichtlich ist, zu beschreiben bzw. alles, was geschichtlich irgendwie ist, in entsprechender historischer (vgl. Anm. 3) wissenschaftszeitlicher sprachlicher Fassung fortzusetzen, was und wie es ist, bereitet bei aller auch möglichen Einsichtigkeit erhebliche Zweifel.

Die Reihe möglicher illokutiver Konstanten zwischen objektgeschichtlicher und historischer Tätigkeit sollte deshalb besser durch eine Kreuzklassifikation folgender Art aufgelöst werden. Ich demonstriere sie am Beispiel des geschichtlichen Darstellens durch unterschiedliches lexikographisches Behandeln. „Behandeln“ stehe dabei als übergeordneter Ausdruck für darstellen, prägen, handeln, Gruppen bilden (s. die obige Viererreihe).

Ich stelle geschichtliches Darstellen (also etwa das Sprechen vor 500 Jahren) in heutiger lexikographischer Fassung erneut dar; oder ich stelle geschichtliches Darstellen als soziokognitives Erkennen dar, oder ich stelle es als kommunikatives Handeln oder als Gruppenbilden dar. Diese Aussagen werden erst einmal akzeptiert werden, obwohl das geschichtliche Darstellen von etwas als z. B. kommunikatives Handeln eine geschichtliche Tätigkeit ja einem weitestgehend anderen Zweck (einer anderen Illokution) unterwirft. Wenn man es dennoch bejaht, wird das daran liegen, dass ,Darstellung/(reine) Beschreibung‘ in der deutschen Wissenschaftssprache und -ideologie den aufklärerisch begründeten und tröstlichen Nimbus der Erkenntnissicherheit, Objektivität, Vollständigkeit, Genauigkeit, Abschließbarkeit hat. Dieser enthebt den Wissenschaftler und seine Rezipienten der Unruhe, die von einem Bewusstsein ausgeht, das die Seinsweise historisch sozialer Gegenstände vom stetigen Werden, von Dynamik her bestimmt. Das ist fundamental eine Sache der Textlinguistik, nach der bestimmte Formen auch bestimmte Inhaltsprägungen sind und umgekehrt. Es geht hier offensichtlich um die kategoriale Funktion der Rede- und speziell der Schreibweisen. ${ }^{32}$ Um das Gemeinte nur anzudeuten:

32 Gemeint ist dasjenige, was alle Leser dieses Beitrags in der Mittelstufe des Gymnasiums gelernt und ausprobiert haben, indem die Lehrkraft ihren Schülern die Aufgabe stellt: Fasst das gerade in allen Zeitungen Thematisierte als Beschreibung, setzt es in einen Bericht oder eine Erzählung um, thematisiert es als Kritik, macht daraus einen Dialog! Und achtet dabei darauf, was Ihr sprachlich tut, zu welchem Zweck Ihr es tut und wie es die Zeitung A im Unterschied zu Zeitung B tut. Achtet darauf, ob dasjenige, was Ihr da tut, den Inhalt des Gesagten verändert, und falls ja, wie. 
Die Fachsprache der Darstellung hat bekanntlich die kategoriale Leistung zu statisieren, d.h. auch dasjenige zu ,verdarstellungen', seiner Lebendigkeit zu entkleiden, festzusetzen, zählbar und sogar beherrschbar zu machen, was dauernd im Fluss ist. Das Prägen fordert eine Fachsprache, die deliberativ ausgerichtet ist, Bewundernswertes heraushebt, damit kognitives Abwägen und Urteilen einbezieht, weniger Statik und vor allem eine andersartige Statik, außerdem weniger Sicherheit suggeriert. Das Handeln verbindet sich mit Prozesshaftigkeit, wird zu Handlungsentscheidungen und aktiven Eingriffen anregen und dem Zeitablauf gerecht werden, dabei z. B. Auswirkungen auf den Tempusgebrauch, die Zeitadverbien, die Menge von Verbalabstrakta usw. haben. Dass Gruppenbilden wird wohl mit Identifikationsindices wie unser, wir im Gegensatz zu euch, zu den Anderen, den Ausgegrenzten arbeiten und die Satzformen Aussage, Frage, Aufforderung anders dosieren als z. B. ein Erzählender. Der Verdeutlichung halber seien einige Fragen an die Geltung der Darstellungshaltung (gleichsam als Generalillokution) gestellt: Was wäre, wenn ein Lexikograph eines denkbaren Luther-Wörterbuches den Reformator als theologischen Neuerer (kognitiv gesehen) betrachten und ihn als Vorbild für heutige theologische Neuerungen oder $\mathrm{zu}$ gänzlich anderen Zecken ${ }^{33}$ vermitteln, oder unter Handlungszwecke wie ,propagieren', ,bewundern'stellen, also tatsächlich ,entdarstellungen' würde? Wo gäbe es eine akzeptierte Fachsprache, die dies ermöglichen und es nicht etwa mittels Ausdrücken wie ,Instrumentalisierung“ abwerten würde? Warum sollte man bei einem Wörterbuch eines geschichtlichen Autors unbedingt ,nur beschreiben' wollen (im hier dauernd unterstellten Sinn) und damit seine ästhetischen Glanzleistungen, seine inhaltlichen Fiktionen, seine theologischen und gesellschaftlichen Mobilisationswerte als seine eigentlichen Leistungen neutralisieren, indem man sie dem Darstellungsaspekt unterwirft? Eine Lexikographie, die etwa im Sinne einer Mobilisationsimpulse auswählen und damit bewusst gegenwartsbezogen handeln würde, hätte zwar keine Tradition, keine akzeptierte Fachsprache und keine Chance institutioneller Anerkennung, könnte gesellschaftlich aber gerade deshalb Aufmerksamkeit erfahren.

Probleme dieser Art gehören nicht zu den Alltagsgesprächen der Arbeitsstelle des FWB, wohl aber zum sprachtheoretischen Bewusstsein bei der Artikelgestaltung. Es kann nicht sein, dass geschichtliche Hochwertausdrücke, Fahnenwörter, Beziehungsausdrücke, lexikalische Diskriminierungen, Dehumanisierungen, Verallgemeinerungen, Nuancierungen, Überhöhungen, Säkularisierungen, Konfessionalisierungen, Tropen, Tropenfelder, -traditionen und -umbrüche aller Art, darunter speziell Metaphorisierungen, der versteckten Gewalt einer statisierenden Fachsprache unterworfen werden und dass damit die prozesshaft funktionale Vielschichtigkeit des Wortschatzes unsichtbar gemacht wird. In dem Ansatz über die hohe Rolle der kognitiven und kommunikativen Leistung lexikalischer Einheiten wurde die

33 Etwa als Lehrmaterial für totales Denken im Sinne von J. Assman, Totale Religion, in dem es um „puritanische Verschärfung“ geht. 
Richtung des Gemeinten angegeben. Auf jeden Fall halten wir es für unsere Aufgabe, die Umfänge und den Differenzierungsgrad unserer Artikel und ihrer einzelnen Informationspositionen hochgradig flexibel zu gestalten.

\section{Zur Online-Stellung des Wörterbuches}

Die eigentlich längst fällige Online-Stellung des FWB wurde erst nach der Veränderung seines Status vom Privatunternehmen zum Akademienprojekt im Jahre 2013 möglich. Die für die Digitalisierung zuständigen Mittel und die notwendige Personalstelle (100 \% für $1 \mathrm{Jahr}, 50 \%$ für den Rest der Zeit; einige Zusatzhilfen für spezielle Zwecke; dies Letztere aus Mitteln der Göttinger Akademie) haben es uns ermöglicht, eine unseren Ansprüchen genügende digitale Fassung ins Netz zu stellen. Sie ermöglichen es außerdem, diese kontinuierlich auszubauen. - Da die genauen technischen, juristischen und wissenschaftlichen Aspekte der Digitalisierung, auch ihr Zeitrhythmus Gegenstand eines eigenen Artikels in diesem Journal sein werden, soll hier nur der wissenschaftliche Erkenntniswert der Online-Version angedeutet werden.

Ausgangspunkt ist der Wunsch, die gesamte Information eines Wörterbuches digital zugänglich zu machen und damit Mehrwerte und Überschaubarkeitsgewinne zu erzielen, die aufgrund der normalen alphabetischen Anordnung unverbundener lexikalischer Zeichen nur mit unverhältnismäßig hohem Zeitaufwand oder gar nicht möglich wären. Mit Bezug auf das FWB bedeutet dies, dass die Aussagen aller seiner Informationstypen erfasst und kombinierbar zur Verfügung gestellt werden. Gemeint sind außer dem Lemmabestand und den an diesen adressierten morphologischen Angaben vor allem die Bedeutungserläuterungen, die Symptomwertangaben, die Phrasemnennungen, die Angaben zur Onomasiologie, die Syntagmenlisten, die Wortbildungen samt Bedeutungen und die Belege; außerdem wären die verschiedenen Formen lexikographischer Kommentare zu erfassen, zum Beispiel zum assoziativen (tropischen) Bezug der einzelnen Bedeutungsansätze untereinander. Jede Beschreibungsposition dieser Informationstypen ist durch besondere typographische Markierungen, auch mit dem Blick auf eine mögliche spätere Digitalisierung, bereits in der ersten Lieferung (anno 1986) systematisch gekennzeichnet und auf den ersten Blick erfassbar, so beispielsweise das Lemma durch Einrückung und Halbfettsatz, jeder Bedeutungsansatz durch Einrückung, sein Inhalt (die sog. Bedeutungsangabe) durch einen Typ des einfachen Anführungszeichens, die onomasiologischen Angaben, die Syntagmenangaben usw. je durch den vorangestellten Gedankenstrich, die nicht lexikalisierten Wortbildungen durch ihre Nennung direkt hinter den Syntagmen, die Belege durch Petitsatz. Zusammengefasst: Die Kombination von Schriftart, Schriftgröße, Interpunktionszeichen, Einrückungen und Situierungen einer Information im Textganzen garantieren die technische Identifizierung eines Textsegmentes als eines bestimmten Informations- 
typs. Der Computer kann eben von demjenigen, was im Text steht, nur dasjenige erfassen, was als ein besonderes Etwas formal ausgezeichnet ist. - Im Folgenden bringe ich einige Beispiele, wie die Ergebnisse aussehen. Es wird niemanden wundern, dass diese die Bedeutungsansätze in ihrer allseitigen semantischen Vernetzung, die räumliche Lagerung des Wortschatzes und die Zuordnung zu Textsortengruppen betreffen.

Zur semantischen Vernetzung sei ein Theologe angenommen, der sich über den Wortschatz der Mystik in frnhd. Zeit informieren möchte. Nutzt man die technischen Möglichkeiten aus, die zu diesem Wortschatz führen, so erhält man mittels der üblichen Suchwege ${ }^{34}$ und allein für die bisher behandelten Strecken des Alphabets (etwa 70\% des zukünftigen Gesamtumfanges) folgendes Ergebnis: ${ }^{35}$

- Zum Exklusivwortschatz der Sinnwelt ,Mystik‘ zu zählende Ausdrücke der Art: angenommenheit, ausgebären, ausgossenheit, durchgründlichkeit, gesastekeit, istigkeit, kennelos, vergotten, vermenschen (usw.),

- Wortbildungen nach Mustern, die in der Mystik hoch frequent begegnen: ankleblichkeit, begriffenheit, behagenheit, durchflossenheit, einförmigkeit, entsunkenheit, entwordenheit, materielichheit, mitnatürlichkeit, mitwesenheit, wiederingeflossenheit, zugekertheit (usw.). Die Gesamtzahl der hier exemplarisch angeführten -heit-/-keit-Bildungen, die im FWB in irgendeiner Weise gebucht sind, beläuft sich auf über 1300 Types. Der mystische Anteil daran ist auffallend hoch; genaue Zahlen anzugeben, bedürfte zeitaufwendiger Einzelprüfungen, wäre überdies stark entscheidungsabhängig,

- Ausdrücke mit mystiktypischen semantischen Verdichtungen: anhänglichkeit $>$ Verhaftung des Menschen mit der Welt $[. .]<$., persönlichkeit $>$ Personhaftigkeit, Status der Person innerhalb der Dreifaltigkeit $<$, ${ }^{1}$ beschaulich $>[. .$.$] visionär er-$ kennend< (usw.),

- Allgemeinsprachlich-polyseme Ausdrücke mit mystischer Semantik: abfal 7, abgrund 5, abschälen 4, anhaften 3, beschäude 2, durchgründen 1, gesicht 6 (usw.),

- Mystisch-tropische oder sonstige uneigentliche Wortgebräuche: Aus der Fülle der möglichen Beispiele sei nur das vermutlich unerwartete mist herausgegriffen: Als Zeichen für >Gestank, Fäulnis< steht es zugleich für ,Nichtigkeit‘, mit der Nuance >Bodensatz, unterste Schicht natürlicher Verfallenheit< wird es in Texten der Sinnwelt ,Religion/Didaxe“ metaphorisiert; bei Meister Eckart gibt es denn auch das mistwürmlein; der zugehörige Beleg sagt „die untrennbare einigkeit des mystischen Menschen selbst mit dem mistwürmlein“ aus (FWB, Band 9, 2, 2627).

34 Diese werden hier nicht eigens dargestellt; es sei nur angedeutet, dass es selbstverständlich um Suchausdrücke wie mystisch geht, ferner um Namen wie Eckart, Tauler, auch um lexikographische Suchfelder wie die Bedeutungserläuterung, die Symptomwertangaben, die Syntagmen usw.

35 Hier nur auszugsweise zusammengestellt; Quelle: Lobenstein-Reichmann (2018). 
Das Bild, das alle die genannten Fälle zusammenstellt, hat folgendes Aussehen (es dient lediglich der Dokumentation der Ergiebigkeit historischer Bedeutungswörterbücher vom Typ des FWB; wird also nicht näher erläutert):

\begin{tabular}{|c|c|c|c|}
\hline abend (m) & abfal (m) & abfallen (vu) & abgescheiden (vu) \\
\hline abgescheiden (adj) & abgescheidenheit (f) & abgrund $(\mathrm{m})$ & abgründekeit (f) \\
\hline abgründig (adj) & abker (m) & 2abkeren (v) & ablegen (v) \\
\hline abschälen (v) & abscheiden (vu) & abscheuern (v) & abstreichen (vu) \\
\hline abziehen (vu) & $\operatorname{acker}(\mathrm{m})$ & almosen (n) & 1alt (adj) \\
\hline anblik (m) & andacht $(f)$ & anderheit (f) & anfang $(\mathrm{m})$ \\
\hline 1angel (m) & angenommenheit (f) & anhaft (m) & anhaften (v) \\
\hline anhang $(\mathrm{m})$ & anhangen (v) & anhänglichkeit (f) & anheben ( $v$ ) annemung $(f)$ \\
\hline anschauung (f) & ansehen (n) & arbeit (f) & arm (adj) \\
\hline auferheben (vu) & aufgeben (vu) & aufgehen (v) & aufklimmen (vu) \\
\hline aufsehen (vu) & auftragen (vu) & aufziehen (vu) & auge $(n)$ \\
\hline ausblüjen (v) & ausbrechen $(\mathrm{vu})$ & ausbrehend (adj) & ausbruch (m) \\
\hline ausfliessen (vu) & ausfliessung $(f)$ & ausflus (m) & ausgang (m) \\
\hline ausgeberen (vu) & ausgehen (v) & ausgiessen (vu) & ausgiessung $(f)$ \\
\hline ausgossenheit (f) & ausker (m) & 1auskeren (v) & auslauf $(m)$ \\
\hline auslaufen (v) & ausleiden (vu) & auslugen (v) & ausquellen (vu) \\
\hline ausschlag (m) & ausschmelzen (vu) & ausser (adj) & ausserkeit (f) \\
\hline äusserlich (adj) & ausspriessung (f) & austragen (vu) & austun (v) \\
\hline auswendig (adj) & auswendigkeit (f) & auswirken (v) & bau $(m)$ \\
\hline bedecken (v) & befälligkeit (f) & befinden $(n)$ & befinden (vu) \\
\hline befindlich (adj) & befindlichheit (f) & befindung (f) & begegen (n) \\
\hline begeren (v) & begerenlich (adj) & begerlich (adj) & begerung $(f)$ \\
\hline begier (f) & begierde $(f)$ & begierig (adj) & begierlich (adj) \\
\hline begierlichkeit (f) & begin $(\mathrm{mn})$ & beginnen (n) & begraben (vu) \\
\hline begreifen (vu) & behalten (vu) & beheften ( $v$ ) & behende (adj) \\
\hline behörlichkeit (f) & beibleiben (vu) & beiwort (n) & bekantheit (f) \\
\hline
\end{tabular}

Abb. 4: Mystischer Wortschatz im FWB (Ausschnitt aus: Lobenstein-Reichmann [2018]).

Es ist offensichtlich, dass Zusammenstellungen dieser Art auch Auskünfte zu geben vermögen über das viel diskutierte Verhältnis M. Luthers zur Mystik; sie liefern Anknüpfungspunkte für das Auslaufen dieser Spiritualitätsbewegung mittelalterlicher Prägung in der beginnenden Neuzeit sowie für ihr - wie immer zeittypisch 
geprägtes - Fortleben im neuzeitlichen Pietismus oder gar weiterhin. Sie sind für alle historischen Disziplinen nutzbar.

Die Angaben zur räumlichen Lagerung des frnhd. Wortschatzes sind entsprechend seiner grundsätzlich semantischen Anlage des FWB an die Sememangabe adressiert. Der Aussagetyp lautet also (wiederholend): Das Semem $>\mathrm{x}<$ des Lemmazeichens $w$ findet sich nach dem Corpus des FWB in Teilraum R (zu weiteren Zusammenhängen s. oben; S. 300).

Die Angabe von Sememräumen der Form mitteldeutsch oder hochpreußisch oder niederalemannisch usw. setzt eine diesbezügliche Charakterisierung aller Corpusquellen voraus. Dieser Arbeitsgang wurde in der Vorbereitungsphase des FWB vollzogen; er hatte zum Ziel, die für die meisten Rezipienten amorph wirkende Masse von Corpustexten einschätzbar zu machen, das heißt in diesem Falle: räumlich einordnen zu können. ${ }^{36}$ Er gab viele Fragen auf und war relativ zeitaufwendig. Sein Ergebnis wurde in Lieferung 1 des ersten Bandes (1986; S. 163-224), ergänzend in Band 3 (Lieferung 1, 1995, S. XV-XXII) dokumentiert. Jede Quelle enthält also eine Annotation, in welchem Raum sie zu verorten ist. Für Ausnahmen gab es Gründe, die hier unbeachtet bleiben können.

Zur Veranschaulichung diene das Lemma ${ }^{1}$ lippe (u. a. wegen seiner Bedeutung für die viel diskutierte Rolle M. Luthers im Prozess der Herausbildung der nhd. Hoch- und Schriftsprache). Es wurde als monosem interpretiert; die zugehörige Symptomwertangabe lautet (ausgeschrieben): „norddeutsch, mitteldeutsch, nordoberdeutsch“; das ist - einfacher formuliert - das weitere Mitteldeutsche; jedenfalls fehlen wobd. und oobd. Belege. Die computergenerierte kartographische Darstellung in Abbildung 5 dokumentiert diese Lagerung.

Für lefze, als dreifach mehrdeutig interpretiert, zeigt sich, dass es hinsichtlich des hier zur Debatte stehenden Ansatzes 1 für den gesamten deutschen Sprachraum belegt ist, und zwar in relativ gleichmäßiger Dichte. Die Karte in Abbildung 6 veranschaulicht die Lagerung.

Die oft wiederholte Aussage, dass der Gebrauch von lippe durch M. Luther dafür spreche, dass er aus Verständlichkeitsgründen immer nach dem sprachgeographisch verbreitetsten Wort gesucht und deshalb lippe bevorzugt habe, ist demnach in ihr Gegenteil zu verkehren: Er greift mit lippe zu einem Regionalismus. Es kommt hinzu (sei hier aber nur nebenbei angeschlossen), dass die relativ hohe Zahl der Belege und die Tatsache der Mehrdeutigkeit von lefze dieses als das auch pragmatisch gebräuchlichste Wort ausweisen. - Generalisiert bedeutet das hinsichtlich der Raumlagerung von lippe und lefze Gesagte: Das FWB bietet mit seiner Online-Publikation die Möglichkeit, jedes behandelte Lemmazeichen mit jedem sei-

36 Erinnert sei insbesondere an eine verbreitete Sitte der Datentarnung. Sie besteht darin, die Quellenzitate mit Siglen zu kennzeichnen, die in keiner Weise sprechend sind und sich im Ernstfall in keiner Quellenliste finden. Man weiß dann auch als Texthistoriker oft nicht, ob das Zitat aus dem 14. oder 16. Jahrhundert stammt, welcher Textsorte und welchem Raum es angehört. 


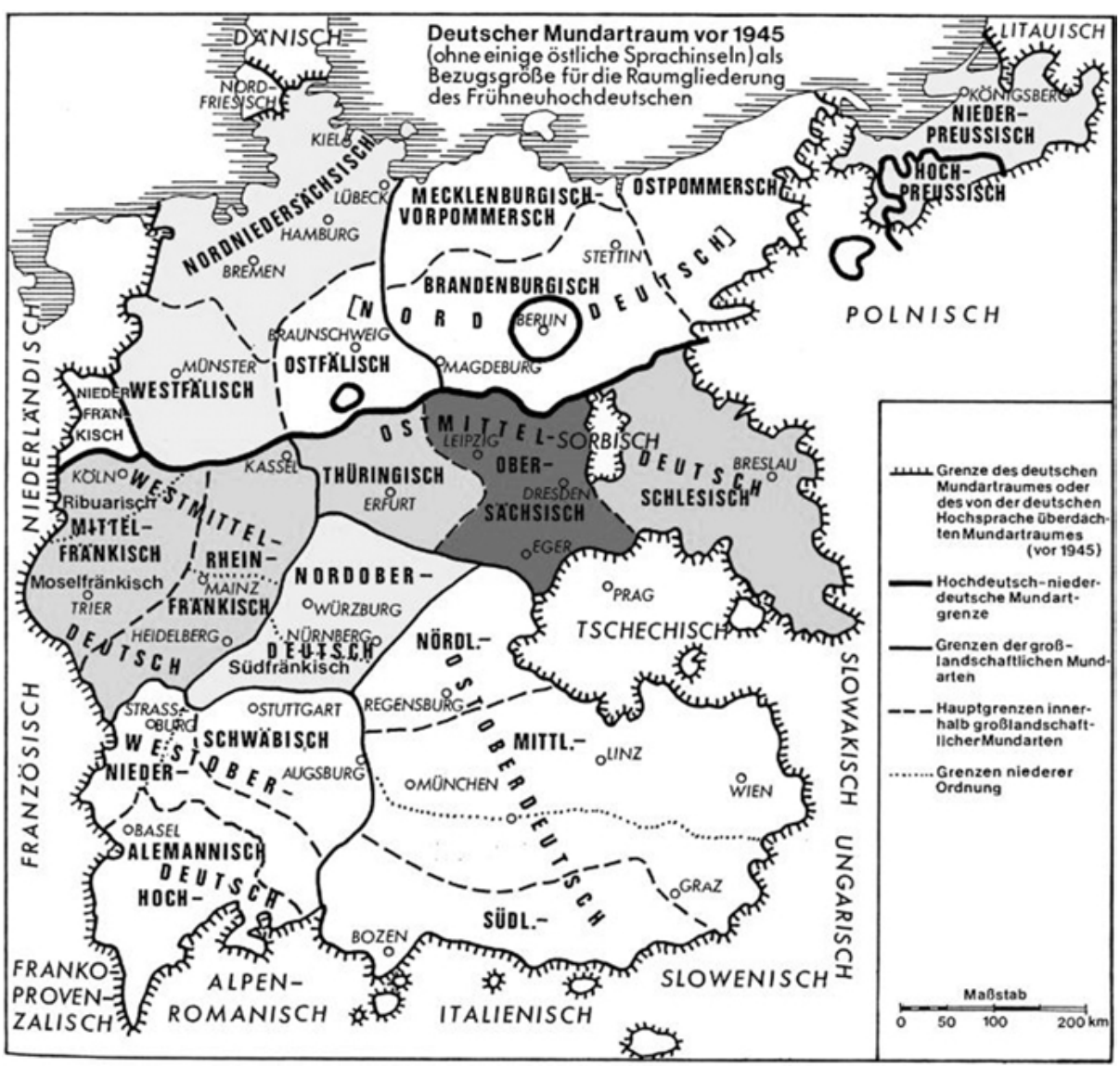

Abb. 5: Die geographische Lagerung von frnhd. lippe.

ner Bedeutungsansätze bedeutungskartographisch $\mathrm{zu}$ umreissen und nach $\mathrm{Ab}$ schluss dieser (wohlgemerkt:) bedeutungsgeographischen Tätigkeit eine Karte der Lagerung des gesamten Signifikates zu erstellen. Diese letztere enthielte folglich eine bezeichnungsgeographische Aussage darüber, wo eine Lemmazeichengestalt sprachgeographisch begegnet. Projiziert man dies z. B. auf den DWA (den Deutschen Wortatlas) oder auch auf alle anderen wortgeographischen Projekte im deutschsprachigen Raum, dann ist der Fortschritt der Erkenntnismöglichkeiten gegenüber all diesen in ihrer Zeit verdienstvollen Unternehmen unverkennbar. Statt rund 200 (für den DWA) Bezeichnungskarten sind auf technischem Wege rein rechnerisch hunderttausend Bezeichnungskarten und mehrere hunderttausend Bedeutungskarten generierbar; der Beitrag der Sprachlandschaften nicht nur zum Vorkommen von Bezeichnungen, sondern zum Nachweis ihres geschichtlichen Anteils an der Bedeutungsbildung des gegenwärtigen Deutsch kann nur mit Staunen 


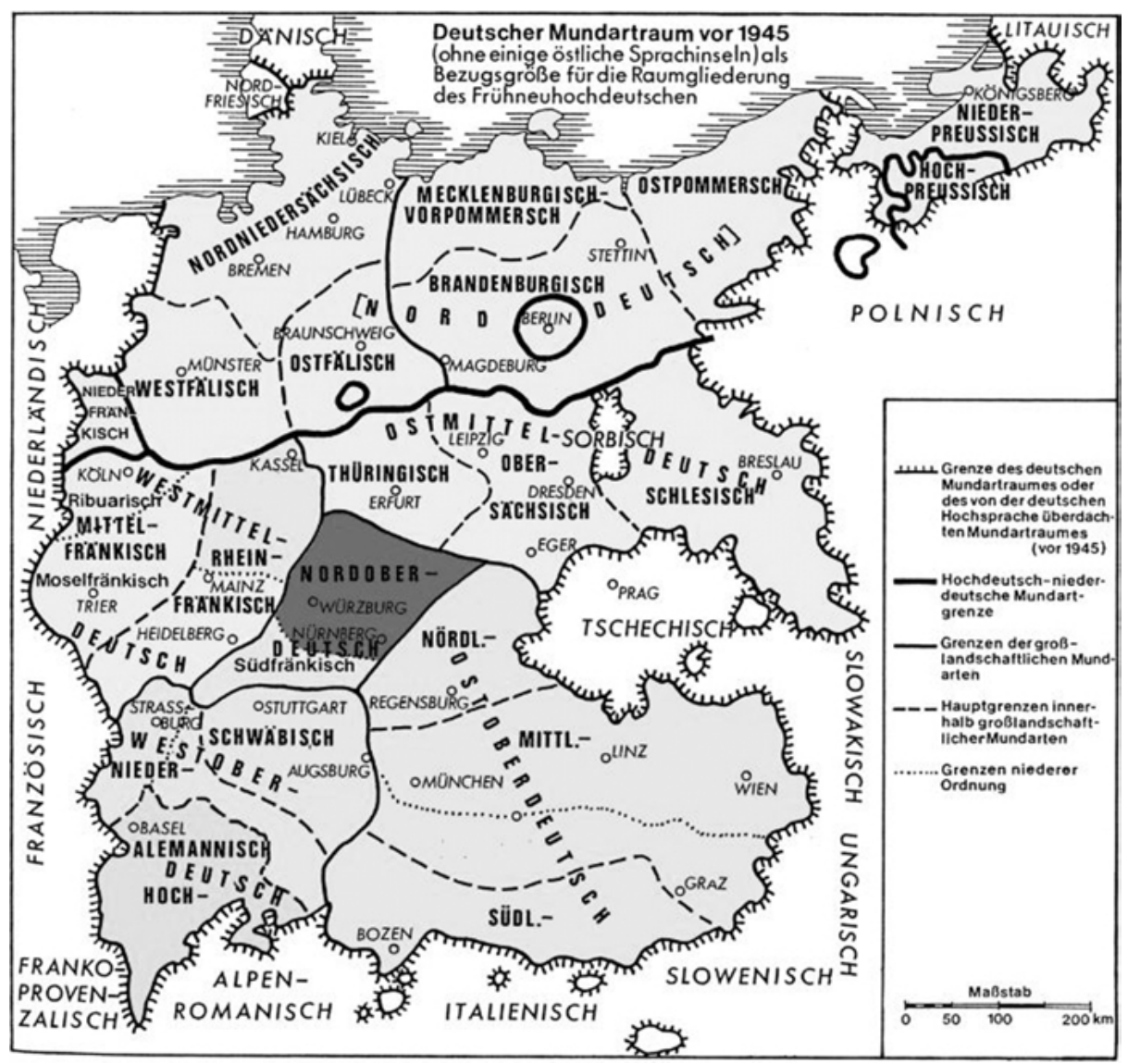

Abb. 6: Die geographische Lagerung von lefze 1.

aufgenommen werden. Vorausgesetzt ist immer, dass ein Wörterbuch vorhanden ist, das die Inhalte liefert.

Zum dritten Beispiel, den Textsortengaben, gilt das zu den Raumangaben Gesagte: Festlegung im Corpus für praktisch jeden Quellentext (gemeint als Leitlinie für variierende Einzelformulierungen im Rahmen der Symptomwertangaben), Adressierung an das Semem (wieder mit Ausnahmen im einzelnen). Ihre wissenschaftliche Fassung und damit ihre digitale Verwertung ist wesentlich schwieriger als bei den Raumangaben: Während man bei letzteren auf anerkannte sprachräumliche Einteilungen ${ }^{37}$ zurückgreifen kann, sind Textsortenangaben das Ergebnis le-

37 Das wird im einfachsten Fall eine Sprachkarte des Frnhd. sein. - Bei Zeitgliederungen, die hier nicht Gegenstand sein sollen, wäre es die physikalische Zeit, überlagert durch historische Grenzziehungen. 
xikübergreifender Wertungen, die in einem Wörterbuchprojekt natürlich lexikographisch standardisiert und formuliert werden müssen, wenn sie in der Produktion und in der Rezeption des Werkes handhabbar sein sollen. Dabei verbinden sie Mehreres: die soziale Höhenlage, die soziale Gruppe, die Situativität, die Textsorte. Das sind pragmatische Gegebenheiten, die in den als Textsortenangaben bezeichneten Beschreibungseinheiten weitgehend zusammenfallen. Mit einer Formulierung wie „chronikalische und berichtende Texte“ sind also solche gemeint, die man sowohl als Textsorte wie als situativ bestimmte wie als einer sozialen Höhenlage zugehörige Textgruppe wie als gruppentypische Besonderung auffassen kann. Diese Komplexität ist für uns der Grund zu differenzieren. Wir (d.h. in diesem Falle H. Wolf und M. Schütze) haben erkannt, dies in einer Weise tun zu können, die der angedeuteten Gebrauchskomplexität wenigstens annäherungsweise entspricht. Die dazu angewandten Kriterien lauten: ,Textsorte‘, „Klassifikation“, ,Sinnwelt‘, ,Kommunikationsintention‘. - Diese Viererliste basiert in ihrer Anlage, nicht in den Einzelheiten, einerseits auf Listen, die in der Sprachgeschichtsforschung ${ }^{38} \mathrm{zu}$ je bestimmten Zwecken entworfen wurden, andererseits auf den lexikographischen Einsichten der heutigen Arbeitsstelle des FWB.

,Textsorte، setzt eine Masse an schriftlicher Überlieferung voraus, die man sich als Spektrum vorstellt, die aber schon deshalb kein Spektrum „ist“, weil dieses nicht Spektrum „Seiende“ mit der ihm zugeschriebenen Eigenschaft, soziohistorischer Konvenienz zu sein, immer soziohistorisch ,real‘ gegliedert ist, und zwar gleich doppelt: in geschichtlicher Zeit (man wusste um 1500, was ein Bibeltext und was eine Urkunde ist) sowie in der Gegenwart des Lexikographen (man weiß das auch heute noch, nur anders). Für die Praxis des Lexikographen heißt das: Er versteht Textsorte im heutigen normalsprachlichen Sinne und klassifiziert seine Belegtexte pro Semem nach den jeweiligen Einsichten sowie nach seinen Interessen bei der Ausformulierung seines Artikels. Das schließt selbstverständlich nicht aus, dass man sich schon in der Planungsphase, danach fortlaufend gewisse Leitlinien zusammenstellt, die die je einzelne Formulierungsentscheidung erleichtern. - Im einzelnen werden folgende ,Textsorten“ angesetzt (verstanden als Leitlinien zur Gruppierung von Texten): chronikalische und berichtende Texte, didaktische Texte, erbauliche Texte, unterhaltende und literarische Texte, Realientexte, wirtschaftsgeschichtliche Texte, kirchliche und theologische Texte, Wörterbücher. Wir können aber durchaus auch abweichend, nach unserem Urteil formulieren und erhalten dann (fiktiv): „Vorwiegend mitteldeutsch, 16. Jh., gebundene Texte“ (immer pro Semem).

$38 \mathrm{Zu}$ nennen sind: Für die Textsorten die Textgliederung der Bonner Grammatik des Frühneuhochdeutschen, in ihrem Gesamtrahmen beschrieben von Hoffmann/Wetter 1985; für die Klassifikation die arbeitsstelleninterne Zusammenstellung von Wolf/Schütze; für die Sinnwelten: z. B. Kästner/ Schütz/Schwitalla 1985, 1357-1359; für die Kommunikationsintention: Reichmann/Wegera 1988. 
,Klassifikation“ (als Arbeitsterminus) bezieht sich auf die Wissenschafts- und Praxisbereiche, deren Vertreter sich auf einer gehobenen Sozialebene tendenziell mit einem je bestimmten Interessen- und damit zugleich Kommunikations- und Gegenstandsbereich einer geschichtlichen Gesellschaft (etwa der Theologie, der Medizin) befassen. Mit dem Attribut gehoben verbindet sich die Möglichkeit, gewisse zeitliche Linien zwischen ,geschichtlich gehoben', und ,gegenwärtig gehoben“ zu ziehen. - Gemeint sind: Texte der Geowissenschaften, zur Gesellschaft, der/zur Kunst, der/zur Literatur, der Medizin, der Naturwissenschaften, des Rechtes/zum Recht, zur Religion, zur Wirtschaft, lexikographische Texte.

,Sinnwelt ${ }^{39}$ sei hier in Anlehnung an das Freiburger Sinnweltenkonzept als diejenige Textwelt verstanden, aus der heraus lexikalische Einheiten ihre Bedeutungen gewinnen: ,Krankheit‘ oder ,Gesundheit‘ gibt es nicht als diskret vorhandene Naturerscheinungen, sondern immer nur unter einer Perspektive, die von der Gesellschaft geliefert wird, im Beispielfall etwa von der Religion, natürlich auch vom Alltag. - Folgende Sinnwelten werden angenommen: Alltag, Dichtung, Institution, Religion, Wissenschaft.

,Kommunikationsintention' sei diejenige (z. B. agitative oder legitimierende) Absicht, die einem geschichtlichen Autor vom heutigen Lexikographen (oder Texthistoriker usw.) philologisch begründet zugeschrieben wird und von der man annimmt, dass sie sich in der Bedeutungsgebung und ihrer Nuancierung niederschlägt. - Die folgende Zusammenstellung enthält die autorseitigen ${ }^{40}$ Leitlinien: agitierend, anleitend, belehrend, dokumentierend, erbauend, informierend, legitimierend, sozial bindend, unterhaltend.

Damit entstanden, in Form des Kreises veranschaulicht und farblich herausgehoben, Bilder des folgenden Typs (am Beispiel lefze 1, Abbildung 7).

Beim ersten Blick auf die vorgenommenen Unterscheidungen fällt einiges auf, das als nicht hinreichend bedacht beurteilt werden wird. Ich meine z. B. die Wiederholung von Religion im zweiten und dritten Kreis, von unterhaltend im ersten und vierten Kreis, aber auch die inhaltliche Nähe von kirchlich und theologisch im ersten und Religion im zweiten und dritten Kreis. Diese Überschneidungen sind der Arbeitsstelle bewusst. Wenn wir sie trotzdem beibehalten, dann gibt es dafür Argumente: Religion steht im zweiten Kreis in einem anderen Zusammenhang als im dritten (was wiederum zu Gegenargumenten führen kann). Entscheidend für

39 Zum Terminus s. Anm. 38.

40 Das Adjektiv autorseitig soll den Unterschied zu hörer-, rezipientenseitig betonen. Damit wird selbstverständlich nicht in Abrede gestellt, dass ein Autor seinen Text so formuliert, dass er in seinem Sinne verstanden wird, und auch nicht, dass ein Hörer versucht, einen Text so zu verstehen, wie ihn ein Autor gemeint hat. Rein theoretisch und eben oft auch praktisch sind aber beide Seiten zu unterscheiden: Das vom Autor intendierte Verständnis wird vom Rezipienten als Baustein seiner Welt funktionalisiert. 
1: >Lippe<, als pars pro toto für: >Mund, Sprechwerkzeuge insgesamt<; metonymisch dazu: >Sprachfähigkeit des Menschen; Rede des Einzelnen, Einzelsprache<.

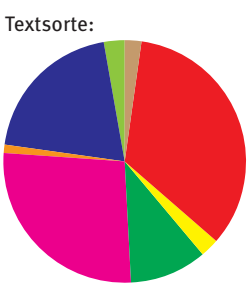

Chonikalische und

berichtende Texte: $2.2(2.5 \%)$

Didaktische Texte: 17

(20.0\%)

Erbauliche Texte: 1 (1.2\%)

Unterhaltende und literarische

Texte: 23 (27.1\%)

Realientexte: 8.7 (10.2\%)

Rechts- und

wirtschaftsgeschichtliche

Texte: $2.2(2.5 \%)$

Kirchliche und theologisch

Texte: 29 (34.1\%)

Wörterbücher: 2 (2.4\%)

Gesamt: 85 (100\%)
Klassifikation:

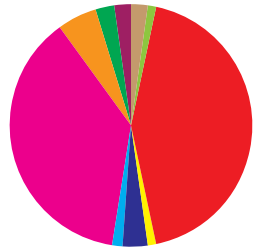

Geowissenschaften: 1.8 (2.2\%)

Gesellschaft: 2 (2.4\%) Kunst: 4.7 (5.5\%)

Literatur: 31.7 (37.3\%)

Medizin: $1.3(1.6 \%)$

Naturwissenschaften: 2.8

(3.3\%)

Recht: $1(1.2 \%)$

Religion: 36.7 (43.1\%)

Wirtschaft: $1(1.2 \%)$

Wörterbuch: $2(2.4 \%)$

Gesamt: 85 (100\%)

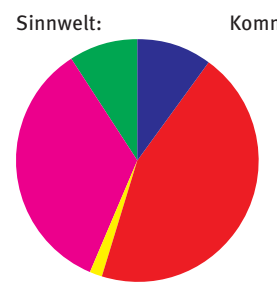

Kommunikationsintention:

Alltag: 7.7 (9.0\%)

Dichtung: $29.2(34.3 \%)$

Institutionen: $1,5(1.8 \%)$

Religion: 38 (44.7\%)

Wissenschaft: $8.7(10.2 \%)$

Gesamt: $85(100 \%)$

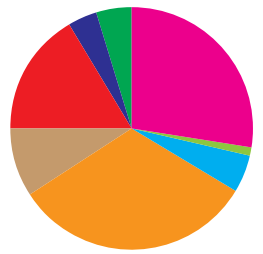

gitierend: $4(4.7 \%)$

anleitend: $3.2(3.7 \%)$

belehrend: 14 (16.5\%)

dokumentierend: 7.7 (9.0\%)

erbauend: $27.5(32.4 \%)$

informierend: $4.2(4.9 \%)$

legitimierend: $0(0.0 \%)$

sozial-bindend: $1(1.2 \%)$

unterhaltend: $23.5(27.6 \%)$

Gesamt: 85 (100\%)

Abb. 7: lefze 1, Vorkommen des Zeichens in den Textsorten.

die Arbeitsstelle ist, dass die oben (S. 342) als ,Spektrum“ ins Spiel gebrachte, aber kein Spektrum seiende Menge von Quellentexten in ihrer Komplexhaftigkeit von vier Aspekten nicht erschöpfend, richtig, vollständig usw. angeschnitten werden kann, sondern aufgrund ihres soziohistorischen Status immer der Aspektgebundenheit des Betrachters unterliegt. Dies durch mehrere Zugänge im Bewusstsein zu halten, scheint mir angemessener zu sein als der Zugang über einen einzigen Aspekt (d.h. durch den Ausschluss aller anderen).

Inhaltlich liefert der Einzelfall lefze 1 folgende Erkenntnisse: Das Wort ist in allen Textsorten (hier verstanden im weiteren, oben explizierten Sinne) belegt; dies gilt nicht spektrumsartig, sondern betrifft gewisse Gebrauchsverdichtungen; diese liegen in verschiedenen Kommunikationswelten, und zwar:

- In Kreis 1 sind sie erstens ,kirchlich/theologisch“, zweitens ,unterhaltend-literarisch' und drittens ,didaktisch' bestimmter Art,

- im zweiten Kreis begegnet erstens die Religion, an zweiter Stelle die Literatur,

- im dritten Kreis erscheinen die Religion und die Dichtung,

- im vierten Kreis nehmen erbauende, unterhaltende und belehrende Texte die ersten Plätze ein.

Zusammenfassend: Es ist offensichtlich die Religion im Verbund mit Literatur/ Dichtung und Didaxe, die den Wortgebrauch bestimmt. Dies passt genau zu dem Bild des Vorkommens von lefze im gesamten Sprachraum des Deutschen. Wenn man diesen Einzelfall zum Beispiel erhebt, also auf die immer im Bewusstsein anwesenden rund 10.000 Simplizia und die rund 100.000 Wortbildungen mit mehre- 
ren hunderttausend Bedeutungsansätzen hochrechnet, dann geht das methodisch auf gar keinen Fall. Dennoch lässt einen der Gedanke nicht los, dass die Religion derjenige Kommunikationsbereich sein könnte, der zum mindesten auf die Didaxe und die Literatur ausstrahlt, also die Zubereitung der Welt als eine unter dem Dach der Religion erfolgende kognitive Handlung bestimmt. $\mathrm{Zu}$ lippe gilt dies in noch stärkerer Weise. In Analogie zu dem oben unter geographischem Aspekt Gesagten kann hier formuliert werden: Den Anteil der einzelnen Textsorten/Sinnwelten/ Kommunikationsverbünde und ihrer Trägerschichten zur geschichtlichen Bedeutungsbildung des Deutschen zu erkennen, rückt hier in den Bereich des Möglichen.

Der Ductus des Vorangehenden war teils beschreibend, teils argumentierend ausgerichtet und insgesamt positiv unterlegt, etwa in dem umgangssprachlichen Sinne: Es ist faszinierend zu sehen, was „der Computer“ - entsprechende Inhalte und Darbietungsformen einer Buchfassung vorausgesetzt - ,alles kann“. Nun können Bilder wie die hier vorgelegten natürlich auch als Argumentationsgrundlage für ein gänzlich anderes Sprachspiel fungieren: Sie können nämlich in kaum widersprechbarer Weise auf etwas hinweisen, was schlicht und einfach nicht sein kann. Ich meine nicht die Tatsache, dass Prädikationen wie die über lippe und lefze gemachten in einem strengen Sinne nichts über das Frühneuhochdeutsche aussagen, sondern nur etwas darüber, was das FWB über dieses Sprachstadium sagt. Das ist eine Plattitüde, die für jede Beschäftigung mit einem sozialhistorischen ,Gegenstand‘ gilt. Ich meine vielmehr Fälle wie den folgenden, am Beispiel got (Band 7, 2001, 113-135) veranschaulichten:

Das Lemmazeichen got wurde im FWB (Band 7, 113-135) als achtfach polysem interpretiert. Das Raumbild (die Bezeichnungskarte) zu got generell (also hinsichtlich des gesamten Bedeutungsspektrums) weist auf die Belegung im gesamten deutschsprachigen Raum. Die Farbskala (hell/dunkel) deutet für des Mitteldeutsche, dass Nord- und das Westoberdeutsche eine stärkere Belegung an als für das Norddeutsche ${ }^{41}$ und für das Ostoberdeutsche. Die auffallend dichte Belegung für den weiteren obersächsischen Raum ergibt sich wohl aus der Druckgeschichte der Lutherzeit (siehe Abbildung 8).

Das alles gibt zwar Fragen auf, ist aber irgendwie einsehbar. Ein anderes Bild ergibt sich für got speziell in Bedeutungsansatz $6>$ Teufel, Beelzebub, Antipode zum christlichen Gott<, [...] >Abgott<, also in einer Bedeutungskarte (siehe Abbildung 9).

Sieht man wieder vom sog. Norddeutschen ab, dann ist die Belegung auf einer Nord-Süd-Linie vom Thüringisch-Obersächsischen über das Nordoberdeutsche zum Schwäbischen hin kaum aus sprachgeschichtlichen Verhältnissen zu erklären: Es gibt keine einleuchtenden Gründe dafür, dass man im in Teilen des Westmittel-

41 Dieses ist aus sprachgeschichtlichen Gründen (als Überlagerungssprache) im Corpus des FWB ohnehin schwach vertreten. 


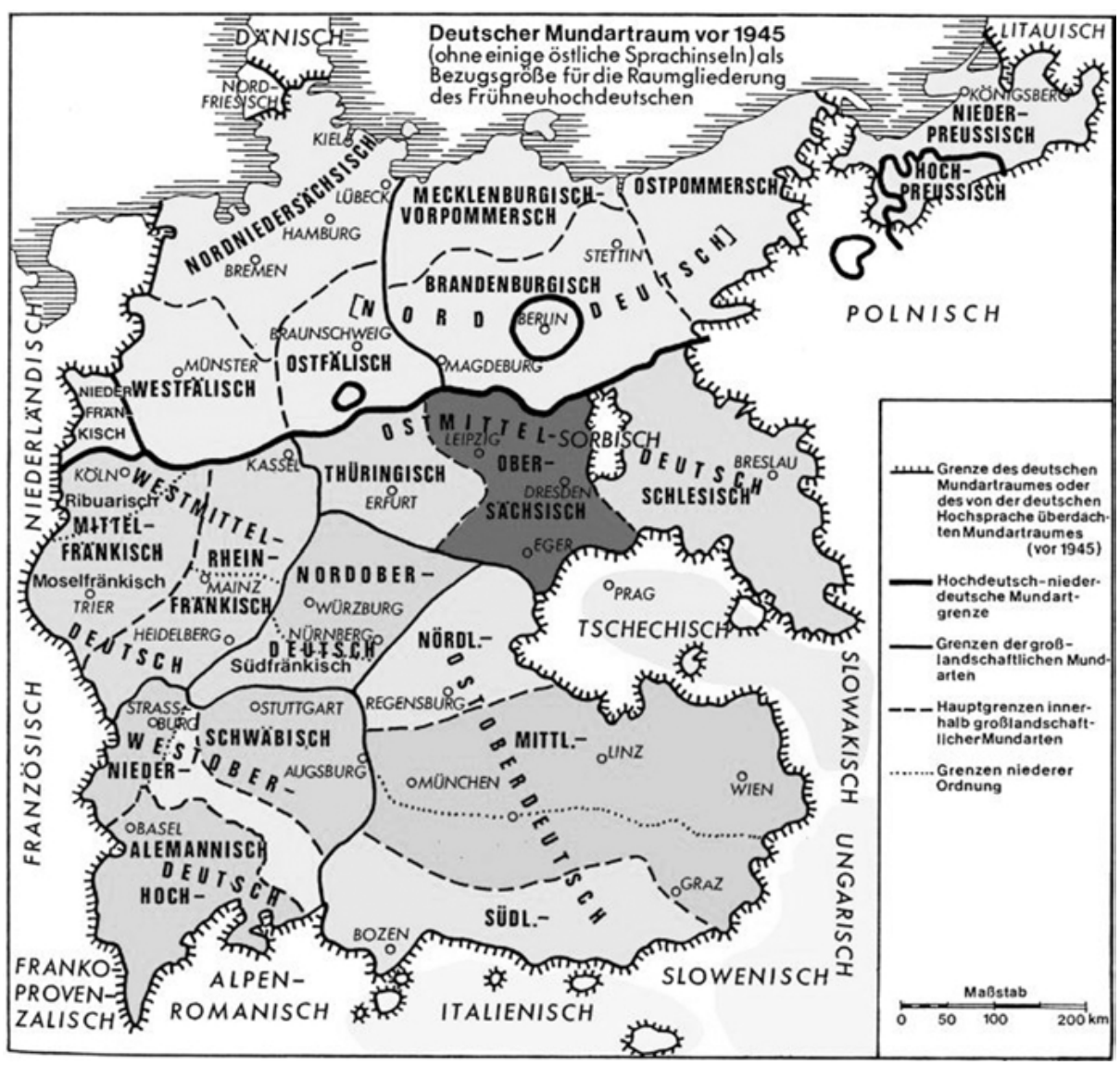

Abb. 8: Das Raumbild der Belegung von got (insgesamt; Bezeichnungskarte).

deutschen, im Schlesischen, Alemannischen und Ostoberdeutschen den ,teufel ${ }^{\text {‘ }}$ oder irgendwelche als abgot gefassten, als personenähnlich ertexteten Identitäten e contrario nicht ebenso als got semantisiert und pragmatisiert haben sollte wie auf der angegebenen Nord-Süd-Schiene. Auch die Möglichkeit, sprachgeographische Unterschiede für die Raumlagerung von got 6 verantwortlich zu machen, scheitert. Es bleibt nur die Erklärung, dass sich hier Defizite des Corpus niederschlagen. Auch wenn diese in der Zeit der Abfassung des Artikels (2001), speziell hinsichtlich der Rolle, die M. Luther bei der Bildung des Teufels- und Abgottsemantik gespielt hat, geringer $\mathrm{zu}$ Buche geschlagen haben dürften als heute, sind sie nicht wegzudiskutieren. Noch deutlicher gesagt: Die digitale Erfassung des FWB-Materials am Ende des gesamten lexikographischen Prozesses legt Corpusschwächen offen, die zu Beginn dieses Prozesses zumindest nicht so erkennbar waren, wie sie jetzt erscheinen. Dass diese Aussage den in vorliegendem Artikel mit Vehemenz vertrete- 


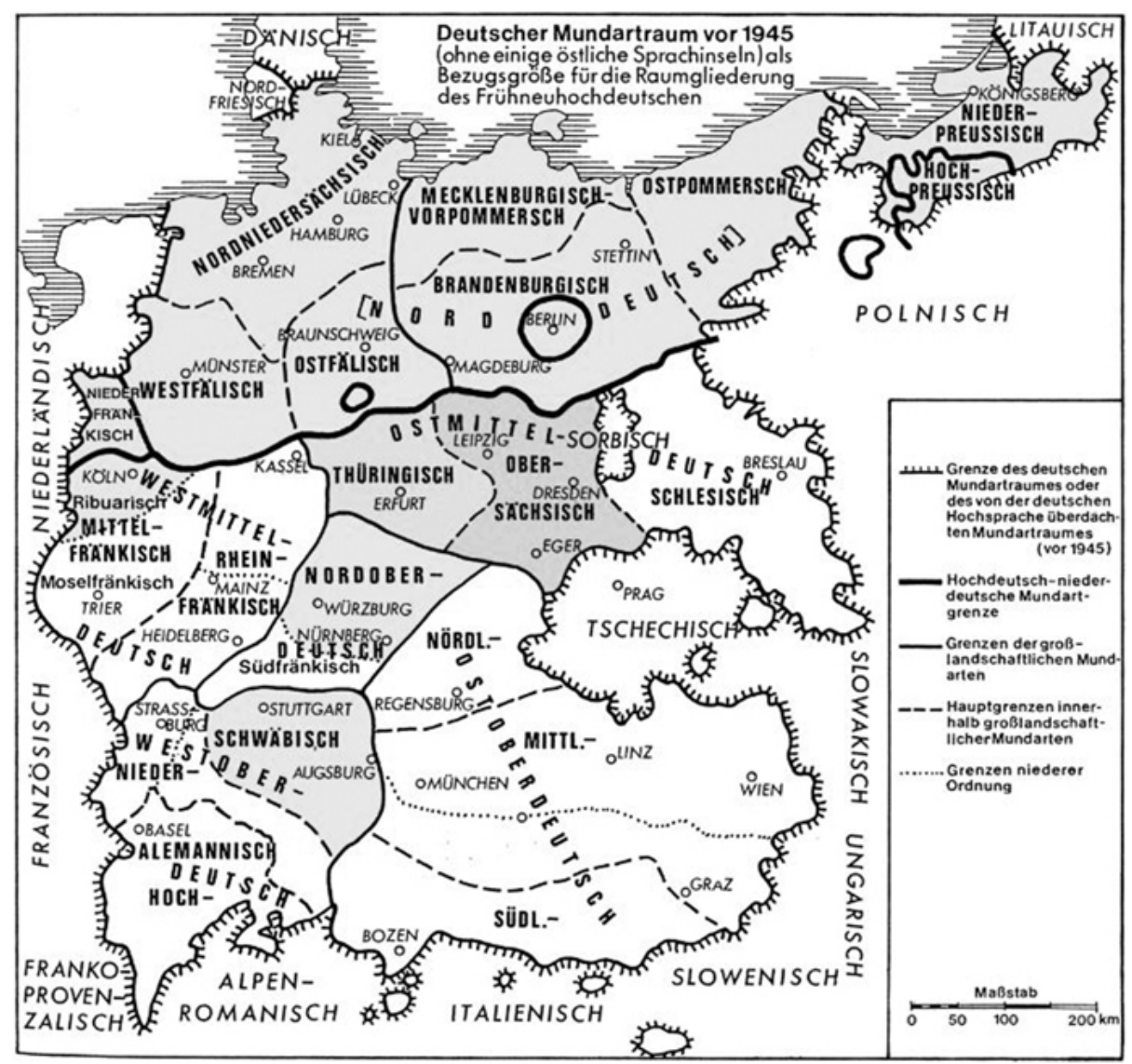

Abb. 9: Das Raumbild der Belegung von got 6 (>Teufel, Beelzebub, Antipode zum christlichen Gott<).

nen Weg der Corpusbildung, -exzerption, und -annotierung als ergänzungsbedürftig offenbart, sollte wahrgenommen werden. In Projekten, die von vorneherein als Akademieprojekte gegründet werden und insofern eine relativ verlässliche Absicherung haben, kann der jeweilige Corpusstand durch Pilotuntersuchungen auf seine Ergiebigkeit geprüft werden. Ich wiederhole dennoch: „Ein Corpus muss bearbeitbar sein“ und verweise ohne weitere Erklärung auf die lexikographische Erkenntniskurve (siehe Abbildung 10). 


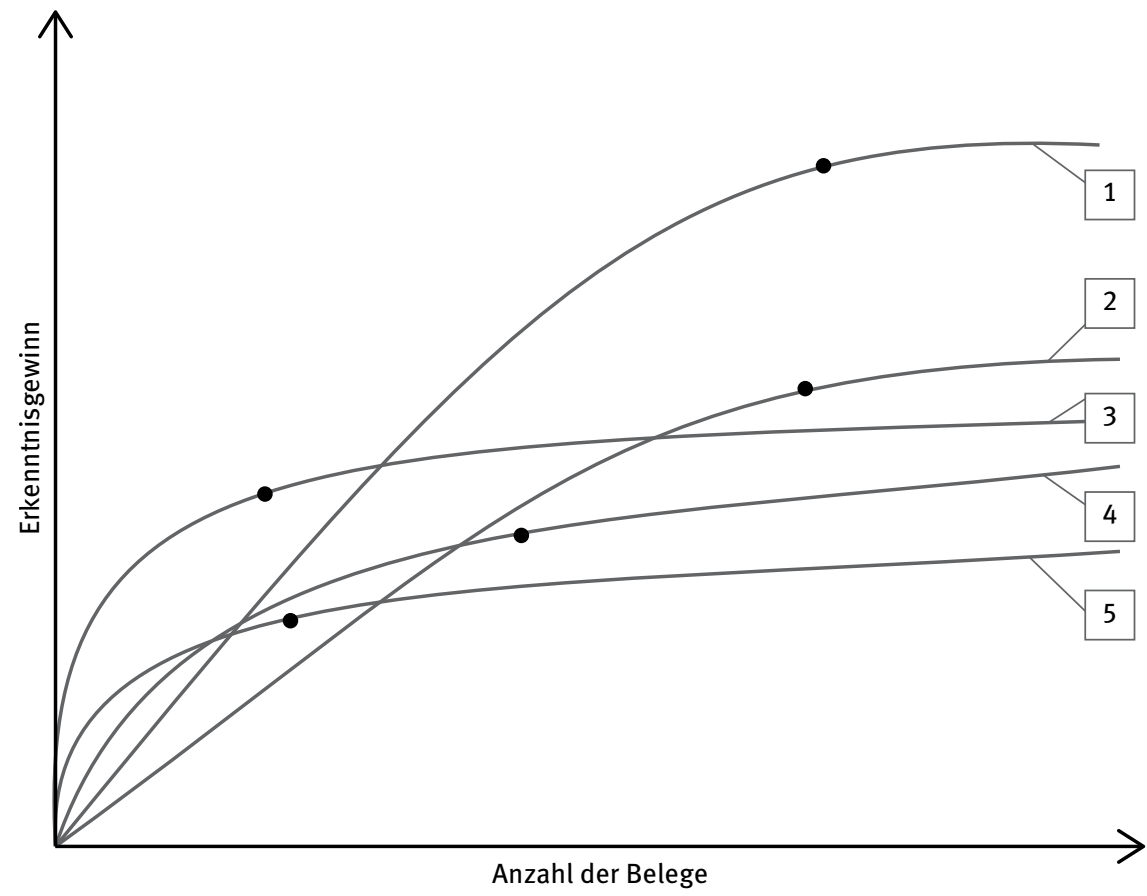

Abb. 10: Die lexikographische Erkenntniskurve (aus: Reichmann 2012, S. 116). Die Zahlen stehen für je eigene Informationstypen: 1 etwa für ,Semantik', 2 für ,Schreibungen', 3 für ,Syntax', 4 für ,Morphologie', 5 für ,Symptomwerte'. • = Saturationspunkt.

\section{Literatur}

Adelung, Johann Christoph (1793-1801). Grammatisch-kritisches Wörterbuch der Hochdeutschen Mundart, mit beständiger Vergleichung der übrigen Mundarten, besonders der Oberdeutschen. 4 Theile. 2., verm. und verb. Aufl. Leipzig, Breitkopf \& Härtel.

Anderson, Robert R./Goebel, Ulrich/Reichmann, Oskar (1977). Projekt eines frühneuhochdeutschen Handwörterbuches. In: Zeitschrift für germanistische Linguistik 5, de Gruyter. 71-94.

Dies. (1983). Ein Vorschlag zur onomasiologischen Aufbereitung semasiologischer Wörterbücher. In: Zeitschrift für deutsche Philologie 102, Erich Schmidt Verlag. 391-428.

Assmann, Jan (2016). Totale Religion. Ursprünge und Formen puritanischer Verschärfung. Wien, Picus Verlag.

Augst, Gerhard (2009). Wortfamilienwörterbuch der deutschen Gegenwartssprache.

Studienausgabe. In Zusammenarbeit mit Karin Müller/Heidemarie Langner/Anja Reichmann. Tübingen, Niemeyer.

$[B M Z=]$ Mittelhochdeutsches Wörterbuch mit Benutzung des Nachlasses v. Georg Friedrich Benecke ausgearb. v. Wilhelm Müller/Friedrich Zarncke. Leipzig 1854-1866. Nachdruck Stuttgart, Hirzel 1990.

Bühler, Karl (1934). Sprachtheorie. Die Darstellungsfunktion der Sprache. Jena, Verlag Gustav Fischer.

[DFWB =] Deutsches Fremdwörterbuch. Von Hans Schulz/Otto Basler [u. a.]; weitergeführt am Institut für deutsche Sprache. 6 Bände. Straßburg [bzw.] Berlin/New York, de Gruyter 
1913-1983. [Photomechanischer Nachdruck Berlin/New York, de Gruyter 1974]. 2. Aufl., völlig neubearb. am Institut für deutsche Sprache. Berlin/New York, de Gruyter $1995 \mathrm{ff}$.

Dittmer, Ernst (1990). Über das Wörterbuch der mittelhochdeutschen Urkundensprache. In: WuN. Marburg. 46-58.

[DRW =] Deutsches Rechtswörterbuch. Wörterbuch der älteren deutschen Rechtssprache. Hrsg. v. d. Preußischen Akademie der Wissenschaften [Bd. 1-3]/Deutschen Akademie der Wissenschaften zu Berlin [Bd. 4; teilweise in Verbindung mit der Akademie der Wissenschaften der DDR]/Heidelberger Akademie der Wissenschaften [ab Bd. 5]. Bearb. v. Richard Schröder [u. a.]. Weimar, Böhlaus $1914 \mathrm{ff}$.

[DWA =] Deutscher Wortatlas. Von Walther Mitzka [ab Bd. 5 von Walther Mitzka/Ludwig Erich Schmitt, Bde. 21 u. 22 hrsg. v. Reiner Hildebrandt]. Gießen, Schmitz 1951-1980.

[DWB =] Deutsches Wörterbuch von Jacob Grimm/Wilhelm Grimm. 16 Bände [in 32]; Quellenverzeichnis. Leipzig, Hirzel 1874-1971.

[DWB, Neubearb. =] Deutsches Wörterbuch von Jacob Grimm und Wilhelm Grimm. Neubearbeitung. Hrsg. v. der Deutschen Akademie der Wissenschaften zu Berlin in Zusammenarbeit mit der Akademie der Wissenschaften zu Göttingen. Leipzig [etc.], Hirzel $1965 \mathrm{ff}$.

Eco, Umberto (1972). Einführung in die Semiotik. München, Fink. (Uni-Taschenbücher 105). [9. Aufl. 2002].

[Findebuch A =] Anderson, Robert R./Goebel, Ulrich/Reichmann, Oskar, Findebuch zu Ausgabenglossaren des Frühneuhochdeutschen. 1981. [Arbeitsstellenintern zum FWB vorliegend].

[Findebuch B =] Dies., Findebuch zum Erläuterungswortschatz frühneuhochdeutscher Glossare und Wörterbücher. 1981. [Arbeitsstellenintern zum FWB vorliegend].

[Frnhd. Gr. =] Reichmann, Oskar/Wegera, Klaus-Peter (Hrsgg.), Frühneuhochdeutsche Grammatik. Von Robert Peter Ebert/Oskar Reichmann/Hans-Joachim Solms/Klaus-Peter Wegera. Tübingen, Niemeyer 1993. (Sammlung kurzer Grammatiken germanischer Dialekte.

A. Hauptreihe, Nr. 12).

[FWB =] Frühneuhochdeutsches Wörterbuch. Hrsg. v. Robert R. Anderson [für Bd. 1]/Ulrich Goebel [für alle Bde.]/Anja Lobenstein-Reichmann [für die Bde. 5; 6, 10-13]/Oskar Reichmann [für alle Bde.; für die Bde. 4 und 7 in Verbindung mit dem Institut für deutsche Sprache]. Bde. 1-3: Bearb. v. Oskar Reichmann; Bd. 4: Bearb. v. Joachim Schildt; Bd. 5: Bearb. v. Markus Dengler/Dagmar Hüpper/Oliver Pfefferkorn/Jürgen Macha/Hans-Joachim Solms; Bd. 6: Bearb. v. Joachim Schildt/Oskar Reichmann, Bd. 7: Bearb. v. Anja LobensteinReichmann/Oliver Pfefferkorn/Oskar Reichmann, Bd. 8: Bearb. v. Vibeke Winge; Bd. 9: Bearb. v. Anja Lobenstein-Reichmann/Oskar Reichmann; Bd. 11: Bearb. v. Oskar Reichmann. [1. Lieferung; Lieferungen 2-6 von der Arbeitsstelle in Göttingen.]

Goebel, Ulrich/Lemberg, Ingrid/Reichmann, Oskar (1995). Versteckte lexikographische Information. Möglichkeiten ihrer Erschließung dargestellt am Beispiel des Frühneuhochdeutschen Wörterbuchs. Tübingen, Niemeyer. (Lexicographica, Series Maior 65).

[Goethe-Wb. =] Goethe-Wörterbuch. Hrsg. von der Akademie der Wissenschaften der DDR, der Akademie der Wissenschaften in Göttingen und der Heidelberger Akademie der Wissenschaften. Stuttgart, Kohlhammer $1978 \mathrm{ff}$.

[GWdS =] Das große Wörterbuch der deutschen Sprache in 10 Bänden. Hrsg. von der Dudenredaktion. Berlin, Bibliographisches Institut 2002.

Hoffmann, Walter/Wetter, Friedrich (1985). Bibliographie frühneuhochdeutscher Quellen. Ein kommentiertes Verzeichnis von Texten des 14.-17. Jahrhunderts. Frankfurt a. M./Bern/ New York, Peter Lang. (Bonner Korpus).

[HTOED = ] Historical Thesaurus of the Oxford English Dictionary with additional material from A Thesaurus of Old English. By Christian Kay [e. a.]. Vol. I: Thesaurus. Vol. II: Index. Oxford, Oxford University Press 2009. 
Kästner, Hannes J./Schütz, Eva/Schwitalla, Johannes (2000). Die Textsorten des Frühneuhochdeutschen. In: Sprachgeschichte 2, de Gruyter. 1605-1623.

Kirkness, Alan (2007). Digitalisierung - Vernetzung - Europäisierung. Zur Zukunft der Historischen Lexikographie des Deutschen. In: Lexicographica 23, de Gruyter. 7-38.

Ders. (2017). Es leben die Riesenschildkröten! Plädoyer für die wissenschaftlich-historische Lexikographie des Deutschen. In: Lexicographica 32, de Gruyter. 17-137.

Konerding, Klaus-Peter (1993). Frames und lexikalisches Bedeutungswissen. Untersuchungen zur linguistischen Grundlegung einer Frametheorie und zu ihrer Anwendung in der Lexikographie. Tübingen, Niemeyer. (Reihe Germanistische Linguistik 142).

[Lexer =] Lexer, Matthias, Mittelhochdeutsches Handwörterbuch. Zugleich als Supplement und alphabetischer Index zum Mittelhochdeutschen Wörterbuch von Benecke-Müller-Zarncke. 3 Bände. Leipzig 1872-1878. Reprografischer Nachdruck Stuttgart, Hirzel 1979.

Lobenstein-Reichmann, Anja (2014): Hört ihr die Kinder weinen. Sprachgeschichte als Beziehungs- und Gesellschaftsgeschichte. In: Paradigmen der historischen Sprachwissenschaft. Jahrbuch für Germanistische Sprachgeschichte. Hrsg. v. Vilmos Ágel/ Andreas Gardt. Berlin/Boston: de Gruyter. 46-62.

Dies. (2018). Mystische Wurzeln in Luthers Sprache. In: Sprache, Reformation, Konfessionalisierung. Jahrbuch für Germanistische Sprachgeschichte. Hrsg. v. Hans Ulrich Schmid/Arne Ziegler. Berlin/Boston: de Gruyter. 27-54.

Dies. (2019). Sprache und Beziehung. In: Handbuch Sprache in der Geschichte. Hrsg. v. Jochen Bär/Anja Lobenstein-Reichmann/Jörg Riecke. Berlin/New York, de Gruyter.

[MWB =] Mittelhochdeutsches Wörterbuch. Erster Band. Hrsg. v. Kurt Gärtner/Klaus Grubmüller/ Karl Stackmann. Erster Band. a-ëbentiure. Bearb. v. [...] Ralf Plate [u. a.]. Stuttgart, Hirzel $2006 \mathrm{ff}$.

Nietzsche, Friedrich (1967-1977). Unzeitgemäße Betrachtungen. Zweites Stück: Vom Nutzen und Nachtheil der Historie für das Leben. [1874]. In: Ders., Sämtliche Werke. Kritische Studienausgabe in 15 Bänden. Bd. 1, 243-334. Berlin/New York, de Gruyter. Neuausgabe München, dtv 1999.

[Peirce, C P =] Peirce, Charles Sanders, Collected Papers of Charles Sanders Peirce. Bd. 8. Ed. by Arthur Burks. Cambridge / Mass., Harvard University Press 1958.

Reichmann, Oskar/Wegera, Klaus-Peter (Hrsgg.). (1991). Zum Urbegriff und seinen Konsequenzen für die Bedeutungserläuterungen Jacob Grimms (auch im Unterschied zur Bedeutungsdefinition bei Daniel Sanders). In: Studien zum Deutschen Wörterbuch I. Tübingen, Niemeyer. 99-345.

Ders. (1996). Der rationalistische Sprachbegriff und Sprache, wo sie am sprachlichsten ist. In: Alte Welten - neue Welten. Akten des IX. Kongresses der Internationalen Vereinigung für germanische Sprach- und Literaturwissenschaft. Bd. 1: Plenarvorträge. Hrsg. v. Michael S. Batts. Tübingen, Niemeyer. 5-31.

Ders. (1990). Sprache ohne Leitvarietät versus Sprache mit Leitvarietät: ein Schlüssel für die nachmittelalterliche Geschichte des Deutschen? In: Deutsche Sprachgeschichte. Grundlagen, Methoden, Perspektiven. Festschrift für Johannes Erben zum 65. Geburtstag. Hrsg. v. Werner Besch. Frankfurt a. M. [etc.], Peter Lang. 141-158. [= 1990d].

Ders. (2001). Das nationale und das europäische Modell in der Sprachgeschichtsschreibung des Deutschen. Freiburg / Schweiz, Universitätsverlag. (Wolfgang Stammler Gastprofessur für Germanische Philologie - Vorträge, H. 8). [= 2001a].

Ders. (2002). Wortbildungsfelder des Frühneuhochdeutschen. Aufbau, Probleme ihrer lexikographischen Behandlung, sprachgeschichtliche Perspektiven. In: Historische Wortbildung des Deutschen. Hrsg. v. Mechthild Habermann/Peter O. Müller/Horst Haider Munske. Tübingen, Niemeyer. 
Ders. (2012). Historische Lexikographie. Ideen, Verwirklichungen, Reflexionen an Beispielen des Deutschen, Niederländischen und Englischen. Berlin, de Gruyter. (Studia Linguistica Germanica 111).

Ders., Frühneuhochdeutsches Lesebuch. Tübingen, Niemeyer 1988.

[Schwäb. Wb. =] Schwäbisches Wörterbuch. [...] Bearb. v. Hermann Fischer, zu Ende geführt v. Wilhelm Pfleiderer. 6 Bände. Tübingen, Laupp 1904-1936.

[Schweiz. Id. =] Schweizerisches Idiotikon. Wörterbuch der schweizerdeutschen Sprache. Gesammelt auf Veranstaltung der Antiquarischen Gesellschaft in Zürich unter Beihülfe aus allen Kreisen des Schweizervolkes. Hrsg. mit Unterstützung des Bundes und der Kantone. Begonnen v. Friedrich Staub/Ludwig Tobler und fortgesetzt unter der Leitung v. Albert Bachmann [u. a.]. Frauenfeld, Huber $1881 \mathrm{ff}$. [Bisher: 15 Bände; a-Walt, 1 Bd. Alphabetisches Wörterverzeichnis zu den Bänden I-XI. Unter Mitarbeit v. Lotti Arter [u. a.] bearb. v. Niklaus Bigler].

Sprachgeschichte. Ein Handbuch zur Geschichte der deutschen Sprache und ihrer Erforschung. Hrsg. v. Werner Besch/Oskar Reichmann/Stefan Sonderegger. 2 Halbbände. Berlin/New York, de Gruyter 1984; 1985. (Handbücher zur Sprach- und Kommunikationswissenschaft 2, 1; 2, 2). 2., vollständig neu bearb. Aufl. Hrsg. v. Werner Besch/Anne Betten/Oskar Reichmann/ Stefan Sonderegger. 4 Teilbände. Berlin/New York, de Gruyter 1998; 2000; $2003 ; 2004$. (Handbücher zur Sprach- und Kommunikationswissenschaft 2, 1-2, 4).

Trier, Jost (1931). Der deutsche Wortschatz im Sinnbezirk des Verstandes. Die Geschichte eines sprachlichen Feldes. Bd. I: Von den Anfängen bis zum Beginn des 13. Jahrhunderts. Heidelberg, Winter. (Germanische Bibliothek, Dritte Reihe).

Wiegand, Herbert Ernst (1998). Wörterbuchforschung. Untersuchungen zur Wörterbuchbenutzung, zur Theorie, Geschichte, Kritik und Automatisierung der Lexikographie. 1. Teilband. Berlin/ New York, de Gruyter. [= 1998a].

[Wörterbücher =] Wörterbücher. Dictionaries. Dictionnaires. Ein internationales Handbuch zur Lexikographie. [...]. Ed. by/Hrsg. v./Ed. par Franz Josef Hausmann/Oskar Reichmann/Herbert Ernst Wiegand/Ladislav Zgusta. 3 Teilbände. Berlin/New York, de Gruyter 1989; 1990; 1991. (Handbücher zur Sprach- und Kommunikationswissenschaft 5, 1; 5, 2; 5, 3). 
